University of Louisville

ThinkIR: The University of Louisville's Institutional Repository

Electronic Theses and Dissertations

8-2009

\title{
Living with Inflammatory Bowel Disease (IBD) : a test of the meaning making model of coping.
}

\author{
Erica Adams \\ University of Louisville
}

Follow this and additional works at: https://ir.library.louisville.edu/etd

Part of the Counseling Psychology Commons, and the Health Psychology Commons

\section{Recommended Citation}

Adams, Erica, "Living with Inflammatory Bowel Disease (IBD) : a test of the meaning making model of coping." (2009). Electronic Theses and Dissertations. Paper 11.

https://doi.org/10.18297/etd/11

This Doctoral Dissertation is brought to you for free and open access by ThinkIR: The University of Louisville's Institutional Repository. It has been accepted for inclusion in Electronic Theses and Dissertations by an authorized administrator of ThinkIR: The University of Louisville's Institutional Repository. This title appears here courtesy of the author, who has retained all other copyrights. For more information, please contact thinkir@louisville.edu. 
LIVING WITH INFLAMMATORY BOWEL DISEASE (IBD):

A TEST OF THE MEANING MAKING MODEL OF COPING

By

Erica Adams

B. A. University of Kentucky, 1999

M. S. Eastern Kentucky University, 2004

\begin{abstract}
A Dissertation
Submitted to the Faculty of the Graduate School of the University of Louisville

In Partial Fulfillment of the Requirements

For the Degree of
\end{abstract}

Doctor of Philosophy

Department of Educational and Counseling Psychology

University of Louisville

Louisville, Kentucky

August 2009 

LIVING WITH INFLAMMATORY BOWEL DISEASE (IBD): A TEST OF THE MEANING MAKING MODEL OF COPING

\author{
By \\ Erica Adams \\ B. A. University of Kentucky, 1999 \\ M. S. Eastern Kentucky University, 2004
}

A Dissertation Approved on

July 10,2009

By the following Dissertation Committee:

Dissertation Co-Chair

Dissertation Co-Chair 


\section{DEDICATION}

This dissertation is dedicated to Chris,

my husband, best friend, and consummate supporter. 


\section{ACKNOWLEDGMENTS}

I would like to thank my husband, Chris, for his boundless love and support. Thank you for always being willing to help...from practice tests and computer assistance to cooking dinner and giving me a shoulder to cry on. You always know just what to say to get me back on track. I could not have accomplished all that I have without you by my side. You have made my dreams and goals your own and for that (and so many other things), I am eternally grateful. I love you.

To my family, through blood and marriage, I am indebted to you for your loving support. You may not totally understand what I'm going through at times, but you are always willing to listen. I especially want to express my sincere appreciation and love to my sister, Sherry. You get me...you always have. You may not always agree with my decisions, like moving further away, but you have never failed to support me. I have always known that you want what's best for me. It means the world to me to know that you always have my back.

To all of my friends, thank you for being my cheerleaders, offering words of encouragement whenever I felt overwhelmed and ready to quit. Thank you for celebrating every major milestone with me....comps, internship, and this dissertation. Thank you for taking me away from psychology every now and then and letting me be a regular person. I want to say a special 'thank you' to Scott and Stacy Pingleton. Not only have you been there for me, but you have been there for Chris when I couldn't be. In many ways, you have followed me and Chris wherever we've gone over the past few 
years. We're glad to know that we'll always have the Pings no matter where we are. As we've said, "Friends are the family of the $21^{\text {st }}$ century", and we're glad to call you family.

Thank you to Dr. Patrick Pössel for taking on an orphan advisee. You have taught me the meaning of mentorship; your guidance and support have gotten me through the toughest part of this journey. You have been a pleasure to work with, and I appreciate the time and effort you've invested into making my dream of graduating a reality. I wish you the best of luck in what I know will be a brilliant career.

To Dr. Sam Stringfield, you have consistently demonstrated remarkable commitment and dedication to the students in ECPY, making it your mission to see us graduate and succeed. Your contribution to my academic and professional development will never be forgotten. I have a tremendous amount of respect for your knowledge and leadership. Thank you for your support and encouragement.

I would like to thank Dr. Crystal Park for her contributions to the field of psychology that ultimately inspired me to develop this study. It was your important and insightful work that led to the development of my research questions all those years ago. Also, it has been an honor working with you throughout this process. I sincerely appreciate your agreeing to be a part of this process... so late in the game.

I also want to thank my remaining committee members, Dr. Lisbeth Selby and Dr. Kathleen Rudasill for their contributions of time and expertise. Both of you have provided me with necessary assistance in completing this project. One last 'thank you' goes to Dr. Kirsten Sundell for her thoughtful instruction and time invested in helping me to become a better writer. 


\begin{abstract}
LIVING WITH INFLAMMATORY BOWEL DISEASE (IBD): A TEST OF THE MEANING MAKING MODEL OF COPING
\end{abstract}

\author{
Erica Adams
}

August 2009

Inflammatory Bowel Disease (IBD) is a chronic illness with the potential to affect many areas of one's life through painful physical symptoms and psychological distress. Despite the debilitating nature and increasing prevalence of IBD, there is little research addressing the coping processes and related psychological adjustment among individuals living with the disease. Moreover, there has been no research conducted investigating how those with IBD make meaning out of their illness experience. Research conducted with other illness populations suggests that meaning making, a specific type of coping may have important implications for psychological adjustment.

This cross-sectional study examines the coping processes and psychological adjustment of individuals diagnosed with IBD, while testing the tenets of the meaning making model of coping proposed by Park and Folkman (1997). This model is based on the assumptions that (a) psychological distress arises from discrepancies between the appraised meaning of a stressful event and one's global beliefs and goals, and (b) people engage in meaning making behaviors (e.g., reappraisals) to reduce the discrepancy and alleviate distress. 
A sample of 229 individuals with IBD, recruited through online support groups/message boards, completed an online survey. The survey contained measures assessing participants' views of their illness, disease-related variables (e.g., length of time since diagnosis), coping efforts, and psychological adjustment, specifically stress-related growth. Data were analyzed through the use of both qualitative and quantitative techniques, including multiple linear regression, Spearman Rho correlation procedures, and structural equation modeling (SEM).

The findings revealed gender differences in meaning making coping efforts. Specifically females report greater use of emotional processing and religious coping, but not positive reframing. Age and level of education were not significantly related to meaning making coping efforts. None of the sociodemographic variables tested (age, gender, education level) were significantly related to reports of stress-related growth. The results provided uneven support for the meaning making model across four hypotheses. Specifically, discrepancies between one's appraised meaning of IBD and his/her global beliefs and goals were significantly related to level of psychological distress. Interestingly, level of psychological distress was not related to meaning making coping efforts. Meaning making coping efforts (i.e., positive reframing, emotional processing, and religious coping) were significantly related to reports of stress-related growth. The meaning making model of coping wasn't fully supported by the data in the present study; however, important implications for this burgeoning area of research are presented. 


\section{TABLE OF CONTENTS}

PAGE

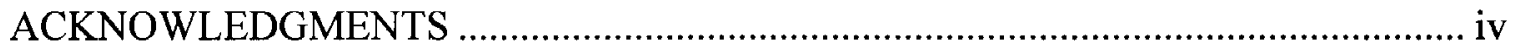

ABSTRACT .

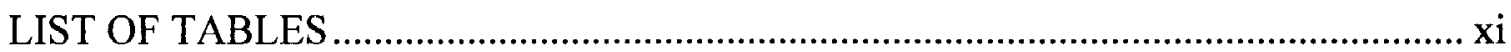

LIST OF FIGURES ……..................................................................................... xii

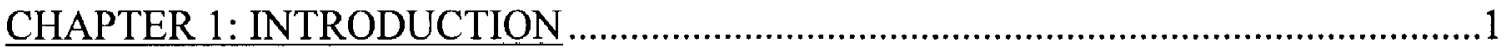

COPING

THE TRANSACTIONAL STRESS AND COPING MODEL …………............................

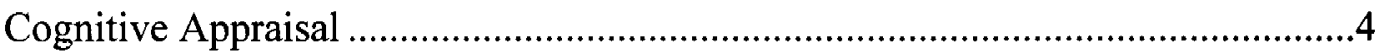

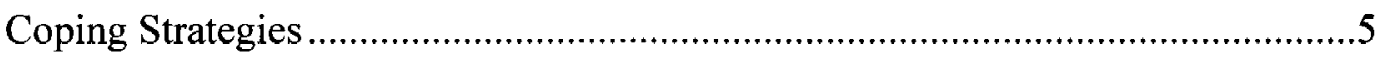

Coping in the Context of Chronic Illness ………….............................................

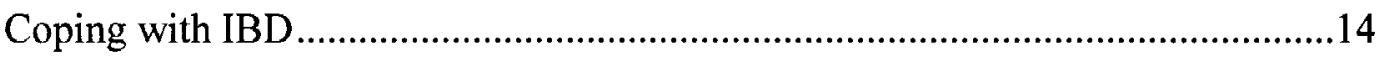

THE MEANING MAKING MODEL OF COPING ....................................................19

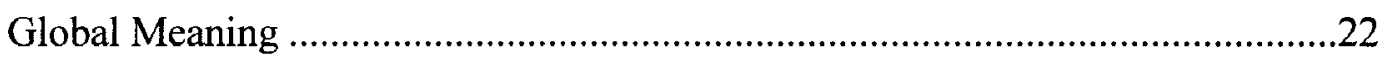

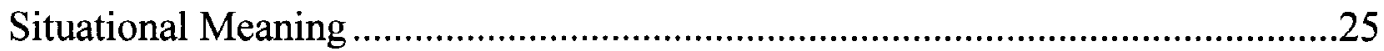

THE MEANING MAKING PROCESS AND OUTCOMES …......................................30

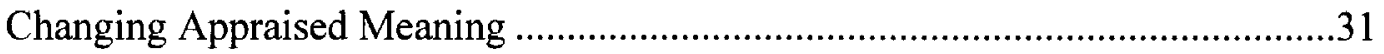

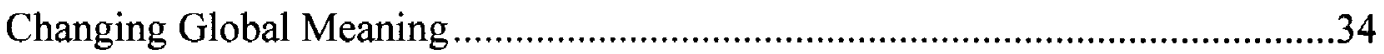

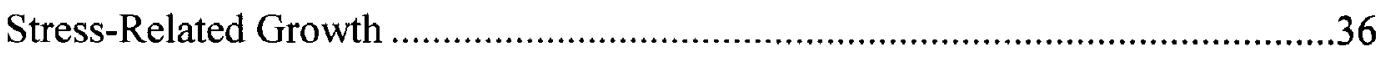

MEANING MAKING COPING IN THE CONTEXT OF IBD .......................................43

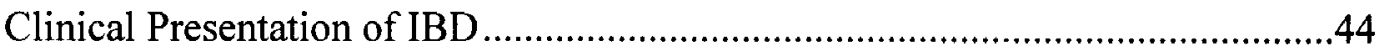


Idiopathic Nature of IBD

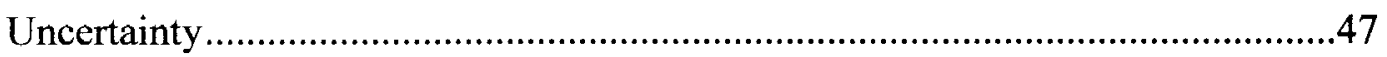

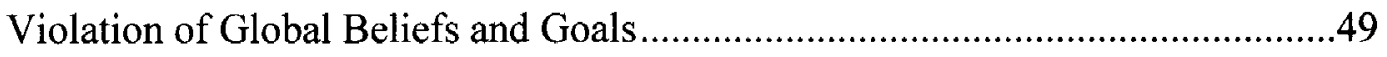

SIGNIFICANCE OF THE PRESENT STUDY ………..............................................53

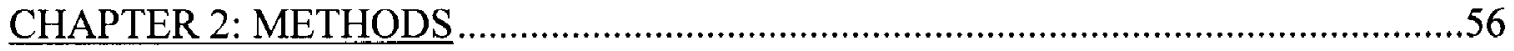

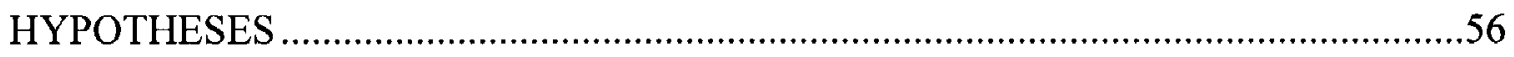

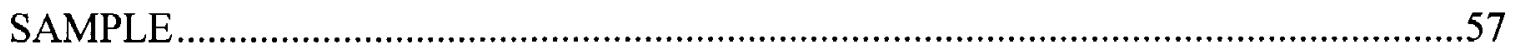

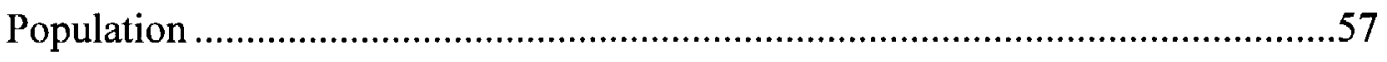

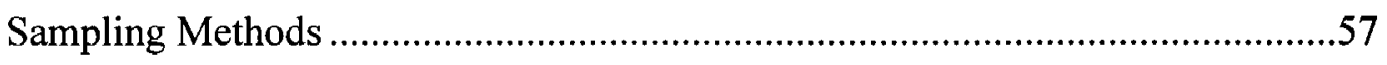

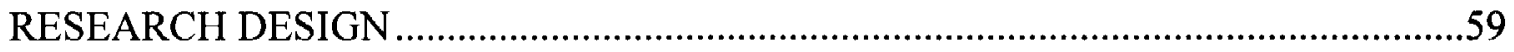

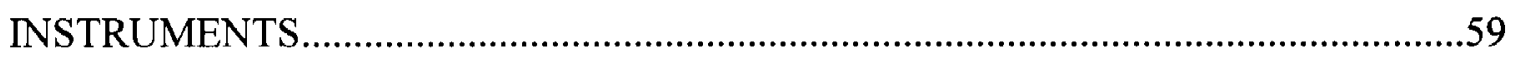

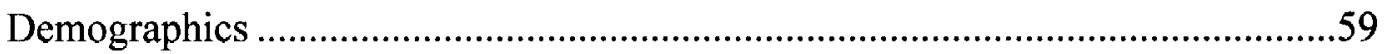

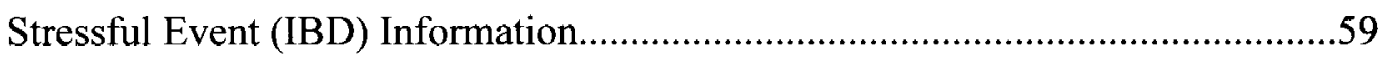

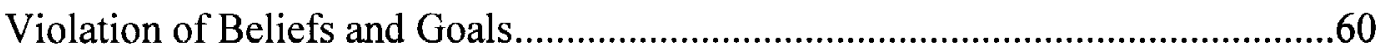

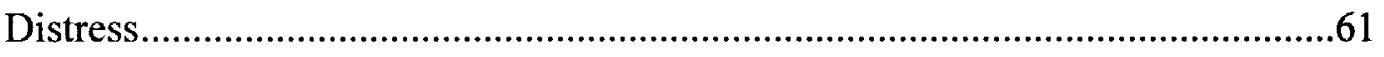

Meaning Making Coping ................................................................................62

Stress-Related Growth ..................................................................................64

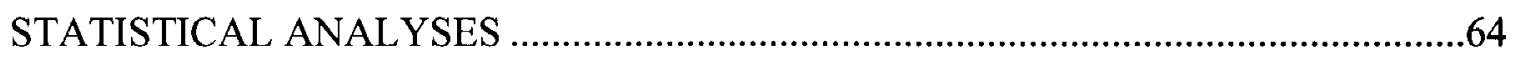

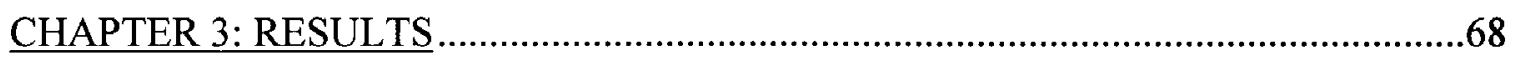

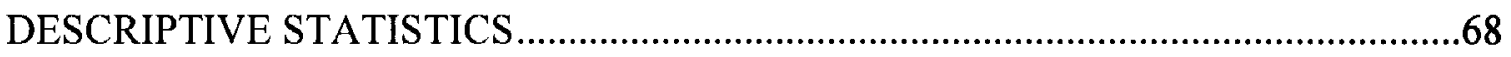

Sociodemographic Variables .........................................................................68

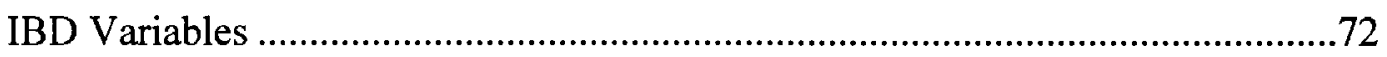

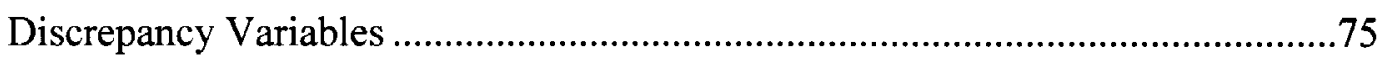

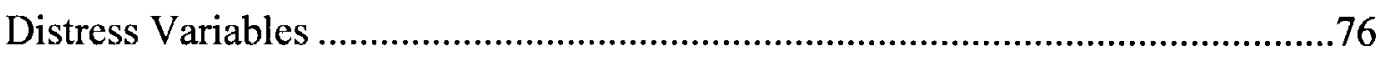




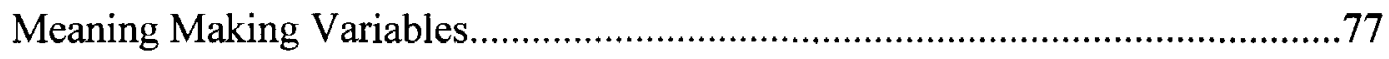

Stress-Related Growth ....................................................................................

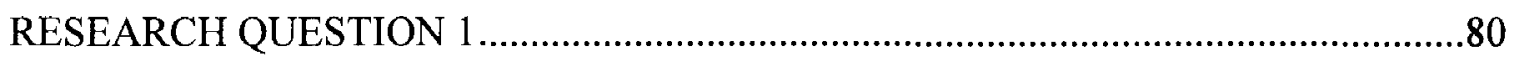

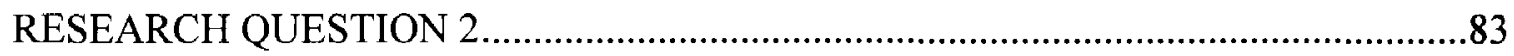

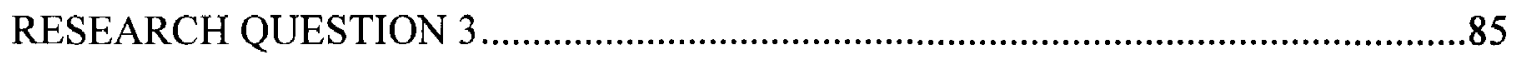

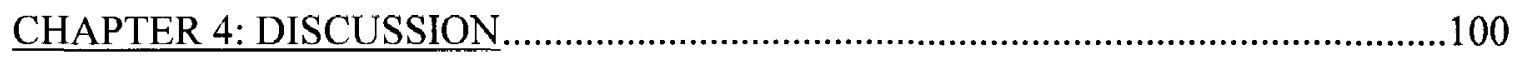

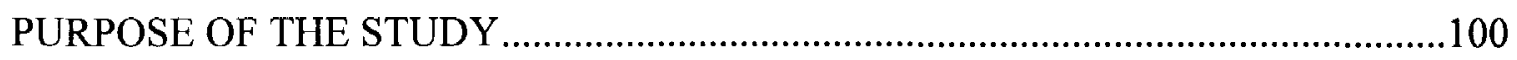

SOCIODEMOGRAPHIC VARIABLES AND MEANING MAKING COPING ...........101

SOCIODEMOGRAPHIC VARIABLES AND GROWTH ……………........................107

THE MEANING MAKING MODEL OF COPING ………………….......................111

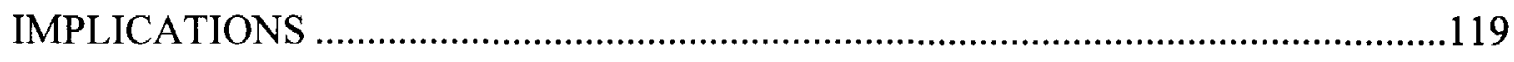

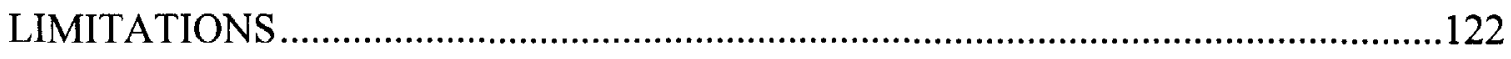

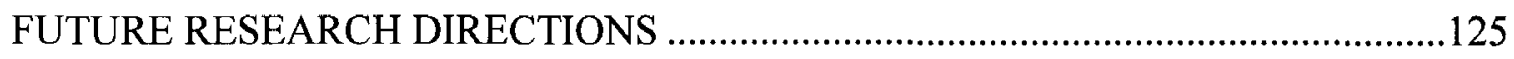

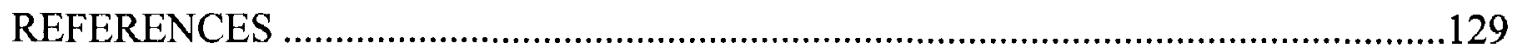

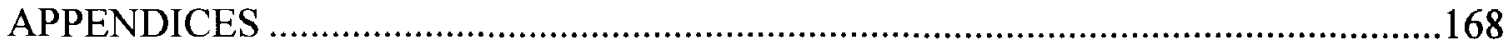

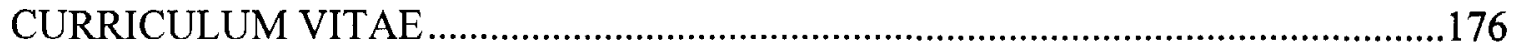


TABLE

\section{LIST OF TABLES}

1. Frequencies and Percentages for Gender and Education ..........................................70

2. Frequencies and Percentages for Race and Ethnicity ..................................................71

3. Frequencies and Percentages for Discrete IBD Variables ..............................................73

4. Means and Standard Deviations for Continuous IBD Variables ....................................74

5. Mean Item Ratings and Standard Deviations for Beliefs Violation ...............................75

6. Mean Item Ratings and Standard Deviations for Goals Violation .................................76

7. Means and Standard Deviations for Meaning Making Coping Variables ......................77

8. Frequencies and Percentages for Coded Meaning Making Efforts ................................78

9. Mean Item Ratings and Standard Deviations for Stress-Related Growth.......................79

10. Means and Standard Deviations for Meaning Making Variables Across Gender .......81

11. Means and Standard Deviations for Meaning Making Variables for all Education

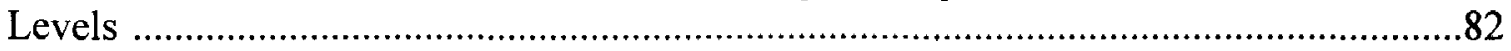

12. Means and Standard Deviations for Stress-Related Growth for all Education Levels 84

13. Intercorrelations Between Indicator Variables in the Proposed Measurement Model 87

14. Chi-Square Statistics and Goodness of Fit Indices for the Proposed Measurement Model

15. Chi-Square Statistics and Goodness of Fit Indices for the Revised Measurement Model

16. Maximum Likelihood Estimates for Indicator Variables in the Revised Measurement Model .93

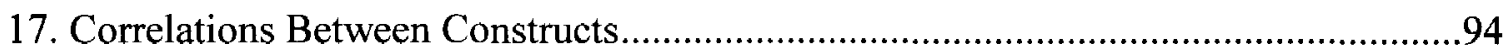

18. Chi-Square Statistics and Goodness of Fit Indices for the Structural Model ..............97

19. Maximum Likelihood Estimates of Hypothesized Paths . .98 


\section{LIST OF FIGURES}

\section{FIGURE}

PAGE

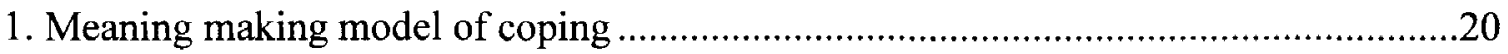

2. Comparison of Ulcerative Colitis and Crohn's Disease …...........................................45

3. Simple schematic of the meaning making model of coping adapted for testing in

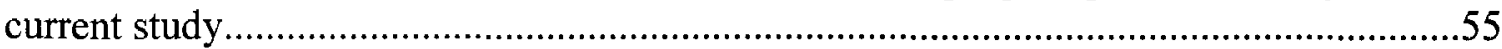

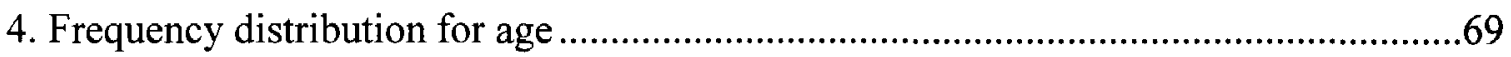

5. Frequency distribution for time since diagnosis ............................................................74

6. Proposed measurement model for relationships between observed variables and latent

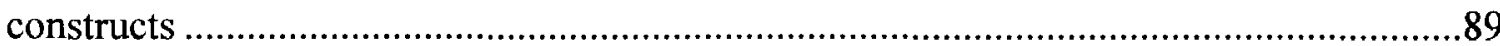

7. Revised measurement model for relationships between observed variables and latent

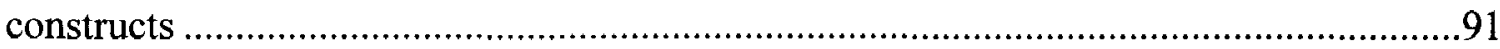

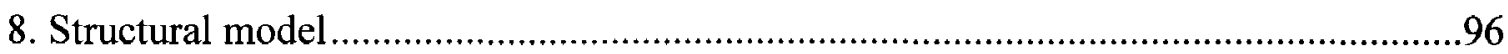

9. Re-iteration of schematic of the meaning making model of coping adapted for testing in current study with corresponding hypotheses.............................................................111 


\section{CHAPTER 1}

\section{INTRODUCTION}

Coping with any chronic illness is a complex process, particularly when the illness requires changes in work habits, social behaviors, desired goals, or fundamental beliefs and values. Inflammatory Bowel Disease (IBD) is a chronic illness with the potential to affect any or all of these areas through painful physical symptoms and psychological distress. IBD is in a category of chronic illnesses that involve inflammation of the digestive system. Crohn's Disease (CD) and Ulcerative Colitis (UC) are two forms of IBD that are similar in their clinical presentation and idiopathic nature. Both disorders are characterized by painful relapse-remitting processes of inflammation and/or ulceration of the gastrointestinal tract. Despite significant advances in research, there is currently no cure for either form of IBD, making the goal of treatment to relieve symptoms and maximize quality of life (Crohn's and Colitis Foundation of America [CCFA], 2009a, "About Crohn's Disease").

Despite the debilitating nature and increasing prevalence of IBD, there is little research addressing the coping processes and related psychological adjustment among individuals living with the disease (Addolorato, Capristo, Stefanini, \& Gasbarrini, 1997; Kinash, Fischer, Luke, \& Carr, 1993; Smolen \& Top, 1998). Moreover, there has been no research conducted investigating how those with IBD make meaning out of their illness experience. Research conducted with other illness populations suggests that meaning making, a specific type of coping (Lazarus \& Launier, 1978; Pearlin \& Schooler, 1978), 
may predict important health-related outcomes, as well as psychological adjustment (Degner, Hack, O'Neil, \& Kristjanson, 2003; Lewis, 1989). Specifically, one's ability to construct positive meaning from a stressful experience has been associated with higher levels of subjective well-being and stress-related growth (McIntosh, Silver, \& Wortman, 1993; Park, Cohen, \& Murch, 1996). It is possible that meaning-related processes may be relevant to people coping with IBD.

There is an obvious need for a model of coping to help us better understand, predict and promote effective adjustment to IBD. One such model is the meaning making model of coping proposed by Park and Folkman (1997). The meaning making model of coping is widely accepted among stress and trauma researchers. It is based on the assumptions that (a) psychological distress arises from discrepancies between the appraised meaning of a stressful event and one's global beliefs and goals, and (b) people engage in meaning making behaviors (e.g., reappraisals) to reduce the discrepancy and alleviate distress. Although the concept of meaning making has been studied among various trauma- and illness-related populations, little research has directly tested the preceding assumptions (Park, 2008).

The overall purpose of this study was to test the assumptions of the meaning making model of coping using a sample of people diagnosed with IBD. Additional research questions will address whether there are specific predictors (i.e., sociodemographic variables) of meaning making behavior and adjustment outcomes, such as stress-related growth. 


\section{Coping}

The complex nature of coping has resulted in the development of numerous models attempting to describe the process. The theory of coping upon which this study is based is the meaning making model of coping as developed by Park and Folkman (1997). The model integrates the work of various meaning and coping theorists (e.g., JanoffBulman, 1991; Taylor, 1983) and extends the transactional stress and coping theory (Lazarus \& Folkman, 1984). What follows is an introduction to the transactional stress and coping model and the research investigating its central constructs in the context of chronic illness. Thereafter, I will present a description of the expanded version of this model, the meaning making model of coping and its relevant research, focusing more explicitly on aspects of meaning as they relate to coping.

\section{Transactional Stress and Coping Model}

Lazarus and his colleagues developed the transactional stress and coping model over a number of years, beginning in the 70's (Folkman \& Lazarus, 1985; Lazarus, 1974; Lazarus \& Launier, 1978). This theory is transactional in that the person and his or her environment are viewed as being in a dynamic, mutually reciprocal, bidirectional relationship. Stress is seen as a relationship between the person and the environment that is appraised as taxing or exceeding one's resources and as significant to one's well-being (Folkman \& Lazarus, 1985). Cognitive appraisal and coping are two processes that are critical mediators of stressful person-environment relationships and their outcomes, both immediate and long-term. 


\section{Cognitive Appraisal}

Cognitive appraisal is a process whereby a person evaluates whether a particular encounter with the environment is relevant to his or her well-being and, if so, in what way. Appraisal is considered to be a two-stage process that consists of primary and secondary appraisals (Folkman \& Lazarus, 1985; Lazarus \& Folkman, 1984). In primary appraisal, a person assesses the meaning of an event or encounter and judges how the situation relates to him or her. In this sense, primary appraisals are the determination of the personal significance of an event and a determination of what is at stake for the person. A situation is evaluated in terms of the harm and/or loss, threat, or challenge it will produce. The appraisal of harm/loss refers to harm or loss that has already occurred. Threat refers to the potential for harm or loss. Challenge refers to the understanding that difficulties may be overcome and there is potential for growth, mastery, or gain; although harm and loss are possible outcomes, they are not inevitable (Folkman \& Lazarus, 1984). Folkman and Lazarus (1985) suggest that challenge and threat appraisals are anticipatory evaluations while an appraisal of harm or loss is an evaluation based on outcome.

Primary appraisals of an encounter are typically defined by a range of personality characteristics including beliefs about oneself and the world, commitments, and goals (Folkman, Lazarus, Gruen, \& DeLongis, 1986; Park \& Folkman, 1997). Being diagnosed with a chronic illness such as IBD could be associated with an appraisal of threat due to the potential to disrupt specific goals that a person has. Conversely, the illness may also been seen as a learning experience that will make an individual stronger, or as a trial that must be overcome. How a person appraises a situation (i.e., what is at stake) plays an important role in his or her decisions regarding coping strategies. Additionally, whether 
or not one thinks anything can be done to affect the harmful or threatening conditions of a stressful encounter influences the choice of coping strategies.

In secondary appraisal a person evaluates what, if anything, can be done to ameliorate the stressful situation. Can something be done to overcome or prevent harm or to increase the possibility of benefit? If coping resources are seen as adequate for dealing with a particular threat, the degree of threat is diminished. Conversely, an event that was initially perceived as non-threatening may become threatening if coping resources turn out to be inadequate for countering the environmental demands (Folkman \& Lazarus, 1985).

It is the combination of these two appraisal processes (the personal significance of the stressor and one's perceived resources for dealing with it) that most heavily influences the type of coping strategies an individual will choose (Lazarus, 1992). In this way, cognitive appraisal and coping are transactional variables as they refer not to the environment or the person alone, but to the integration of both in a given transaction (Folkman et al., 1986). Because of individual variation, appraisals are very personal in nature. Any given event, such as a relapse of disease or surgery, may be perceived as being more or less threatening, harmful, or challenging depending on the individual experiencing it.

\section{Coping Strategies}

Coping can be defined as any cognitive or behavioral attempts to manage, tolerate, and/or minimize difficulties, restrictions, and demands typically associated with stressful situations (Cohen \& Lazarus, 1977; Folkman \& Lazarus, 1985). Coping skills may exist at the moment of diagnosis or be learned during the process of adapting to the 
illness (Samson \& Siam, 2008). Individuals initiate coping processes in response to situations which are perceived as exceeding or placing stress on their personal resources (Lazarus, 1993; Lazarus \& Folkman, 1984; Monat \& Lazarus, 1991).

Folkman and Lazarus (1980) proposed two theory-based categories of copingemotion-focused and problem-focused. Emotion-focused coping strategies are those aimed at regulating internal demands and conflicts, such as psychological distress. These strategies may be behavioral or cognitive, but do not directly alter the actual circumstances of an event or encounter. Rather, emotion-focused coping strategies change either (a) the way the stressful relationship with the environment is attended to (as in vigilance or avoidance); or (b) the relational meaning of what is happening, which mitigates the stress without altering objective circumstance (Lazarus, 1993). Examples of emotion-focused coping skills include escape-avoidance and wishful thinking (Lazarus, 1992). Problem-focused coping strategies are aimed at managing external demands or conflicts between the individual and his/her environment. In other words, these are efforts to change the actual circumstances of the stressful encounter. Examples of problemfocused coping skills include seeking social support and planful problem-solving (Lazarus, 1992).

In addition to emotion-focused and problem-focused coping strategies, investigators have identified another type of coping, meaning-focused coping, in which cognitive strategies are used to manage the meaning of a situation (Folkman \& Moskowitz, 2004). Included in this category is the use of positive reframing, positive comparisons or selective ignoring (Park \& Folkman, 1997; Pearlin \& Schooler, 1978). 
This form of coping will be discussed in greater detail in later sections addressing the meaning making model of coping (Park \& Folkman, 1997).

What determines the form of coping an individual uses? Research suggests that choice of coping strategy is heavily influenced by the perceived controllability of a stressful encounter. When one perceives a situation as changeable or under his or her control, problem-focused coping prevails (Folkman \& Lazarus, 1980; 1985). On the other hand, emotion-focused coping strategies (e.g., avoidance, denial) are used more frequently in encounters that are appraised as unchangeable. Park and Folkman (1997) suggest that meaning making is a form of coping in which a person draws upon values, beliefs, and goals to transform the meaning of a stressful transaction, particularly when there is chronic stress that may not be amenable to problem-focused efforts (Folkman \& Moskowitz, 2004).

Managing the strain and emotional distress associated with a chronic illness such as IBD may require a person to use a variety of coping strategies. Research regarding chronic illness and coping has indicated that the type of strategy a person uses to cope is related to psychological adjustment (Franks \& Roesch, 2006; Livneh, 2000). In general, the coping skills that a person uses can have a positive-adaptive or negative-maladaptive effect on his or her health status (Lazarus, 1993; Moos \& Tsu, 1977). According to Samson and Siam (2008) the former is characterized by a state of psychosocial equilibrium, typically accompanied by a re-established sense of normalcy; however, the latter suggests a degree of psychological deterioration and/or decline.

Despite the findings that some forms of coping are generally functional or dysfunctional, many theorists (e.g., Lazarus, 1992; Lazarus \& Folkman, 1987) discourage 
this type of broad generalization. Any given coping strategy may have positive or negative results depending on who uses it, when it is used, under which circumstances, and with respect to adaptational outcome. A premise of Lazarus and Folkman's conceptual framework is that the functional value of coping processes can seldom if ever be divorced from the context in which it occurs (Lazarus, 1992). This contextual emphasis has been supported by research. For example, residents of Three Mile Island who persisted in problem-focused coping efforts after a nuclear accident exhibited more psychological symptoms than their counterparts who used emotion-focused coping processes (Collins, Baum, \& Singer, 1983). In this context, problem-focused coping was unrealistic as there was little that could be done to change the situation, and persisting in these efforts was unproductive. Emotion-focused coping strategies such as distancing and avoidance were more appropriate. Given the importance of context, investigating the coping processes of individuals with IBD becomes relevant to the study of coping as it may shed some light on how people live with an idiopathic disease that can be unpredictable and debilitating.

Empirical evidence suggests that emotion-focused modes of coping can facilitate problem-focused coping if they are used to manage emotions that would otherwise impede problem-focused activity (Lazarus \& Folkman, 1984). Lazarus and Folkman assessed emotion and coping in 108 college students at three stages of a mid-term examination. They found that problem-focused coping was strongly correlated with emphasizing the positive and seeking social support (emotion-focused strategies) across the three measurement points. This would indicate that these forms of coping may work well together in dealing with the demands of a stressful encounter. Conversely, it is 
possible that some forms of emotion-focused coping, such as self-blame or wishful thinking, will impede problem-focused coping (Aldwin, Folkman, Schaefer, Coyne, \& Lazarus, 1980; Folkman \& Lazarus, 1984).

\section{Coping in the Context of Chronic Illness}

Research addressing appraisal and coping strategies has been conducted with numerous illness populations including those with cancer (Halstead \& Fernsler, 1994; Li, \& Lambert, 2007), rheumatoid arthritis (Treharne, Lyons, Booth, \& Kitas, 2007), systemic sclerosis (Malcarne \& Greenbergs, 1996), various types of chronic pain (Holm, Holroyd, Hursey, \& Penzien, 1986; Snow-Turek, Norris, \& Tan, 1996; Turner, Clancy, \& Vitaliano, 1987) and other chronic illnesses (Bombardier, D'Amico, \& Jordan, 1990; Felton \& Revenson, 1984). For many medical conditions, medical factors alone do not adequately account for the extent of illness-related dysfunction. Functioning may be significantly affected by psychological factors, including how patients appraise and cope with the stress of their illness (Bombardier et al., 1990). Although a comprehensive examination of the literature on coping and chronic illness is beyond the scope of this paper, a sampling of these studies is included to illustrate important adjustment outcomes.

Halstead and Fernsler (1994) examined the coping strategies among long-term survivors of cancer ( $50.8 \%$ breast cancer). The Jalowiec Coping Scale (JCS; Jalowiec, 1991) was used to measure the frequency of use and the degree of effectiveness of coping strategies and coping styles. The JCS contains 60 coping strategies, which are grouped into eight coping styles: optimistic (thinking positively), supportant (using supportive resources), confrontive (facing the situation), self-reliant (relying on onself), palliative (doing things to make one feel better), evasive (avoiding the problem), fatalistic (feeling 
hopeless and pessimistic), and emotive (responding emotionally). Confrontive and supportant coping strategies were classified as problem-focused, whereas the other six were classified as emotion-focused methods, making this instrument more heavily weighted toward the latter. Halstead and Fernsler (1994) found that an optimistic coping style was the most frequently used among these long-term cancer survivors. Participants also reported commonly using confrontive, supportant, and self-reliant coping strategies.

Li and Lambert (2007) examined the coping strategies of 100 Chinese women newly diagnosed with breast cancer. Fourteen different coping strategies were measured using the Brief COPE (Carver, 1997); well-being was assessed with the General Wellbeing Schedule (DuPuy, 1984). The most frequently used coping strategy was a problemfocused coping strategy, planning. Also frequently used were the emotion-focused strategies positive reframing and self-distraction. In other words, the women in the study were likely to (a) think about how to best handle their cancer and make definitive plans accordingly, (b) reframe their cancer in a different light so as to make it more positive, and (c) do something to distract themselves from the stress of their existing health threat (i.e., cancer).

These results (Halstead \& Fernsler, 1994; Li \& Lambert, 2007) support the finding of other researchers (e.g., Folkman \& Lazarus, 1980; Kaptein, et al., 2006) that suggest both functions of coping are typically represented in our response to stressful encounters. These different forms of coping have also been shown to predict specific health-related outcomes in those with chronic illness.

In the aforementioned study of newly diagnosed Chinese women ( $\mathrm{Li} \&$ Lambert, 2007), the coping strategy most strongly correlated (inversely) with general well-being 
was self-blame, explaining a $4.5 \%$ of the variance over and above the $8.1 \%$ accounted for by employment status. The use of self-blame as a coping strategy has been linked to greater psychological distress and is not considered an effective coping strategy (Bennett, Compas, Beckjord, \& Glinder, 2005; Glinder \& Compas, 1999).

In a longitudinal study of 134 people with rheumatoid arthritis (Treharne et al., 2007), engaging in active behavioral coping (i.e., problem-focused coping) was related to lesser depression at baseline, particularly for those with greater perceived stress. Active behavioral coping was also related to increased life satisfaction both at baseline and 6 months later; again, this effect was stronger for those with greater perceived stress. In fact, coping resources accounted for $30 \%$ of the variance in life satisfaction at baseline (largely due to active behavioral coping, social support and perceived stress) and $9 \%$ at 6 months (due to active behavioral coping and pessimism).

Malcarne and Greenbergs (1996) cross-sectionally examined the role of coping strategies in predicting psychological adjustment among 242 individuals with systemic sclerosis. Engaging in wishful thinking as a coping strategy was a significant predictor of psychological distress, accounting for $22 \%$ of the variance. In other words, hoping that one's situation will change and /or improve increased the likelihood of adjustment difficulties. Also significant in the prediction of psychological distress was blaming oneself, which increased psychological distress $(r=.30, p<.0001)$ and accounted for $6 \%$ of the variance, and problem-focused coping, which reduced psychological distress $(r=-$ $.43, p<.0001)$ and accounted for $3 \%$ of the variance. Overall, correlational analyses demonstrated a pattern in which problem-focused strategies (e.g., seeking social support) 
were associated with decreased distress, while emotion-focused strategies (e.g., wishful thinking) were associated to increase distress.

These findings are interesting in light of previous findings regarding effective coping in controllable vs. uncontrollable stressors (Folkman \& Lazarus, 1980; 1985). The nature of systemic sclerosis is such that there is objectively little that patients can do to influence their disease experience; however, it seems that engaging in a more active type of coping, such as problem-focused strategies, was more adaptive than engaging in more passive forms of coping like emotion-focused strategies (Malcarne \& Greenbergs, 1996).

Similar patterns regarding active and passive forms of coping have been found in patients dealing with chronic pain. In a study by Snow-Turek and colleagues (1996) of 76 chronic pain patients, active and passive coping was assessed with the Coping Strategies Questionnaire (CSQ; Rosenstiel \& Keefe, 1983) and the Vanderbilt Pain Management Inventory (VPMI; Brown \& Nicassio, 1987). Active coping was defined as attempting to control pain or functioning in spite of pain, while passive coping was defined as relinquishing control of pain to others or allowing other areas of life to be adversely affected by pain (Brown \& Nicassio, 1987). Active coping was strongly associated with patient activity level and inversely related to psychological distress. Passive coping was positively related to general psychological distress and depression (Snow-Turek et al., 1996).

Esteve, Ramfrez-Maestre, and Lopez-Martinez (2007) conducted a similar study of 117 chronic pain patients. Researchers used Structural Equation Modeling (SEM) to examine relationships between specific coping strategies and adjustment variables. In the final model, there was a statistically significant path coefficient between active coping 
and depression $(\beta=.38, p<.05)$, indicating that higher levels of active coping were associated with lower levels of depression. Passive coping had statistically significant effects (positive) on both depression $(\beta=.30, p<.05)$ and anxiety $(\beta=.30, p<.05)$, as measured by the Hospital Anxiety and Depression Scale (HADS; Zigmond \& Snaith, 1983).

Many measures of coping consider acceptance to be a single coping strategy (e.g., Brief COPE; Carver, 1997). In the aforementioned study by Esteve et al. (2007), however, it was conceptualized as a pattern of cognitive and behavioral responses that involve relating to pain-related experiences without attempts at control or avoidance, engaging in valued activities, and reaching personal goals regardless of these experiences (McCracken \& Eccleston, 2005). Acceptance of pain had a statistically significant effect on functional status $(\beta=.65, p<.05)$ and impairment $(r=-.12, p<.05)$, as measured by the Impairment and Functioning Inventory (IFI; Ramirez-Maestre, \& Valdiva, Y., 2003), a self-report measure designed specifically for patients with chronic pain. These results indicate that persons characterized by higher levels of acceptance reported higher levels of functional status and lower levels of functional impairment (Esteve et al., 2007). Acceptance is not seen as the substitution of control for no-control; rather, it is a change in focus from uncontrollable events (pain) to controllable factors. In this way, it is not surprising that acceptance had strong relationships with both active and passive forms of coping, positive and negative, respectively (Esteve et al., 2007). Active coping and acceptance are seen as having much in common when acceptance is conceptualized in the manner described above (McCracken \& Eccleston, 2005). 
Findings similar to those found by researchers investigating chronic pain (Esteve et al., 2007; Felton \& Revenson, 1984; Snow-Turek et al., 1996; Turner et al., 1987) have also been found in studies investigating heterogeneous chronic illness samples. Bombardier and colleagues (1990) found that the use of emotion-focused coping (i.e., avoidance, wishful thinking, and blaming self) were associated with increased depression scores $(r=.33, p \leq .01)$ and greater psychosocial dysfunction $(r=.37-.53, p \leq .01)$. Together, these three coping styles accounted for $19 \%$ of the variance in depression and $33 \%$ of the variance in psychosocial impairment. Although avoidance coping was associated with greater symptom complaints, none of the other emotion-focused coping strategies were related to disease-related variables (i.e., physical impairment, physicianrated disease severity). On the other hand, in a study of patients with four types of chronic illness, Felton and Revenson (1984) found emotion-focused coping (e.g., wishful thinking) to have a negative impact on adjustment regardless of diagnosis or illness controllability.

\section{Coping with $I B D$}

The increase in literature examining the coping strategies of various medical populations has grown out of evidence suggesting that people who are physiologically and psychologically similar respond very differently to their health condition (Harland \& Georgieff, 2003). This interest is gradually becoming a focus in the IBD research (van der Zaag-Loonen, Grootenhuis, Last, \& Derkx, 2004). Since IBD is a chronic, relapse/remitting disease with the potential to negatively impact several life domains, it presents a special challenge for those who have it. It is important to understand the methods that people with IBD use to cope, as well as how these methods relate to 
adjustment to the disease. Individuals with IBD may be challenged to cope with a number of complex tasks in living with their disease-tasks concerning concepts of normality, lifestyle, the self, social relationships, grief, role changes, physical pain and discomfort, treatment adherence, controllability and predictability (Miller, 1983). Despite this, only a small number of studies have investigated the coping methods of those diagnosed with IBD.

There have been mixed results regarding what form of coping methods are the most commonly used in people living with IBD. Smolen and Top (1998) examined the coping strategies of 46 people with IBD (72.7\% Crohn's Disease; 73.9\% Female). Although the most effective strategies, as rated by IBD patients, were problem-focused (e.g., supportant coping methods), the most frequently used coping strategies were mainly emotion-focused (i.e., optimistic, self-reliant coping methods). Similar results were obtained by Larsson, Lööf, Rönnblom, and Nordin (2008) in their study of 742 IBD patients. Optimistic and self-reliant coping strategies—both emotion-focused—were the most commonly used in dealing with exacerbations of disease.

Conversely, in a study by Kinash et al. (1993) people with IBD $(N=150)$ were more likely to use problem-focused coping strategies (e.g., try to find out more about the situation so as to handle it better) than emotion-focused coping strategies (e.g., take drugs). This was true when comparing males and females, individuals with $\mathrm{CD}$ and UC, and individuals at varying levels of degree severity. In other words, regardless of gender, diagnosis, or disease severity, problem-focused coping processes were more likely to be utilized by those individuals in the sample. These results (Kinash et al., 1993) seem contradictory to the findings of Folkman and Lazarus (1980) that suggest problem- 
focused coping is more likely in situations appraised by people as changeable, while emotion-focused coping is used more frequently in situations appraised by people as not amenable to change. However, the use of a wide range of both problem-focused and emotion-focused coping behavior indicates that patients' coping efforts may be directed towards changing both the situation itself as well as their feelings about it (Larsson et al., 2008).

Generational differences may account for the lack of consistent trends in those with IBD. For example, in their study of 65 adolescents (12-18 years old) with IBD, van der Zaag-Loonen et al. (2004) found an increased use of avoidant coping styles when compared to healthy peers. Avoidant coping included brushing aside the problem, leaving things the way they are, and waiting and seeing what happens. Although the avoidant coping style was more common than the other six types assessed in this study (active problem handling, palliative reaction pattern, social support seeking behavior, depressive reaction pattern, expression of emotion, and comforting cognitions), it was not significantly related to any domains of health related quality of life (HRQoL). HRQoL was defined as "the physical, psychological, and social domains of health that are influenced by a person's experiences, beliefs, expectations, and perceptions" (Testa \& Simonson, 1996). HRQoL was assessed by the Impact-II (NL) (Loonen, Grootenhuis, Last, Haan, Bouquet, \& Derkx, 2002), a disease-specific questionnaire covering six domains - IBD symptoms, systemic symptoms, emotional function, social functioning, body image, and concerns related to treatment/intervention. A depressive reaction pattern of coping (i.e., often worrying about things in the past, not being able to think about anything else but the problem) was positively related to every aforementioned domain 
with the exception of body image. Engaging in depressive reaction coping decreased HRQoL for the adolescents in this sample. Additionally, having an optimistic outlook on the course of one's illness (described as predictive control) was positively related to every HRQoL domain.

Another study investigating quality of life among IBD patients found that escapeavoidance and self-blame were two coping styles related to lower quality of life scores, accounting for up to $10 \%$ of the variance (Maunder \& Esplen, 1999). In addition to HRQoL, the coping strategies utilized by people with IBD have been found to be related to other outcomes. Kinash et al. (1993) found that problem-focused coping styles had significant positive correlation with disease severity, whereas emotion-focused coping correlated positively with depression.

Smolen and Top (1998) examined correlations of coping with perceived health, perceived functioning and well-being in people with IBD. They found that evasive (avoiding the problem), fatalistic (feeling hopeless and pessimistic), and emotive (responding emotionally) coping strategies each had significant negative correlations with perceived health and with well-being. Evasive, fatalistic, and supportive (using support resources) coping strategies each had a significant negative correlation with perceived functioning. A number of emotion-focused coping strategies were inversely related to perceptions of health, functioning, and well-being. In other words, as the use of emotion-focused coping strategies increases, perceptions of health, functioning and wellbeing decrease. The use of emotive coping strategies accounted for $20 \%$ of the variance in health perception while fatalistic coping strategies explained $24 \%$ of perceived functioning. Together, the use of fatalistic coping and the reported degree of effectiveness 
of an optimistic coping style accounted for $51 \%$ of the variability in perceived wellbeing. These findings highlight the importance and influence of emotion-focused coping strategies among individuals with IBD.

Alberts, Lyons, and Anderson (1988) examined correlations between demographic and illness variables (i.e., age, time since diagnosis, disease severity, perceived effectiveness of treatment, perceived control of illness) and coping styles for people with IBD $(\mathrm{N}=38)$. Coping styles were distinguished from coping skills in this study and were measured by the Millon Behavioral Health Inventory (Millon, Green, \& Meagher, 1982). Millon proposed that there are eight distinct styles with which a person deals with physical illness: introversive, inhibited, cooperative, sociable, confident, forceful, respectful, or sensitive. The description of each coping style reads more like a personality description than a collection of coping skills. However, examining patients' coping styles has implications for intervention with people with IBD in an effort to improve quality of life.

Alberts et al. (1988) found that duration and severity of disease did not correlate with any of the coping style variables. Additionally, age of onset correlated positively with the forceful method of coping. People using the forceful style of coping were overly aggressive, hostile and domineering and tended to fight the illness. Effectiveness of medical treatment correlated positively with an introverted style of coping. People using this style of coping minimized distress and were colorless, emotionally flat, reclusive, and aloof (Alberts et al., 1988). As introversion increased, satisfaction with medical treatment increased. Control of the illness correlated negatively with the sociable coping style and correlated positively with the sensitive method of coping. People using the 
sociable style were "outgoing, talkative, and charming, perhaps dramatic and emotional" (p. 73). People using the sensitive style tended to be unpredictable and moody and feel as if they were born to suffer, often "dissatisfied psychologically and physically" (p. 73).

There is obvious within-group variation in coping among individuals with IBD. Since UC and CD differ in their natural history and course, it is understandable that patients may use different coping strategies, depending on the disease involved and the current stage of disease (i.e., exacerbation, remission). A few studies have directly compared the coping strategies of UC and CD patients (Kinash et al., 1993; Larsson et al., 2008) and have found no differences in the coping patterns between the two groups. Only one study, to my knowledge, compared the coping strategies of those in remission to those experiencing active disease (Larsson et al., 2008). Although both UC and CD patients who were experiencing increased disease activity reported more impaired HRQoL and emotional distress, there were no differences in reported coping strategies when compared to UC and CD patients in remission. These results suggest that coping patterns are not solely determined by medical factors (e.g., diagnosis, disease severity), and may be more strongly linked to cognitive and personality factors.

\section{Meaning Making Model of Coping}

Some theorists argue that the transactional stress and coping model (Lazarus \& Folkman, 1984) is of limited usefulness in studying adjustment to major loss and chronic illness (Mikulincer \& Florian, 1996; Park, 2005). In situations where the stressful experience is not amenable to change, the use of problem-solving strategies may prove ineffective. Coping, then, involves a great deal of intrapsychic cognitive processes or "meaning making" through which a person transforms the meaning of a stressful 
experience (Park, 2005). Park and Folkman's (1997) provide a model that describes this dynamic meaning making aspect of coping.

According to this model, shown in Figure 1, there are two broad categories of meaning: global and situational. Global meaning encompasses an individual's enduring beliefs, valued goals, and subjective feelings of purpose in life (Park \& Folkman 1997;

Park \& $\mathrm{Ai}, 2006)$. Situational meaning refers to the meaning ascribed to a particular event (Park \& Folkman, 1997) and includes appraisals of an event as a loss, threat, or challenge, causal attributions explaining why the event occurred (e.g., God's will), and decisions regarding what can be done to cope with the event (Park, 2005).

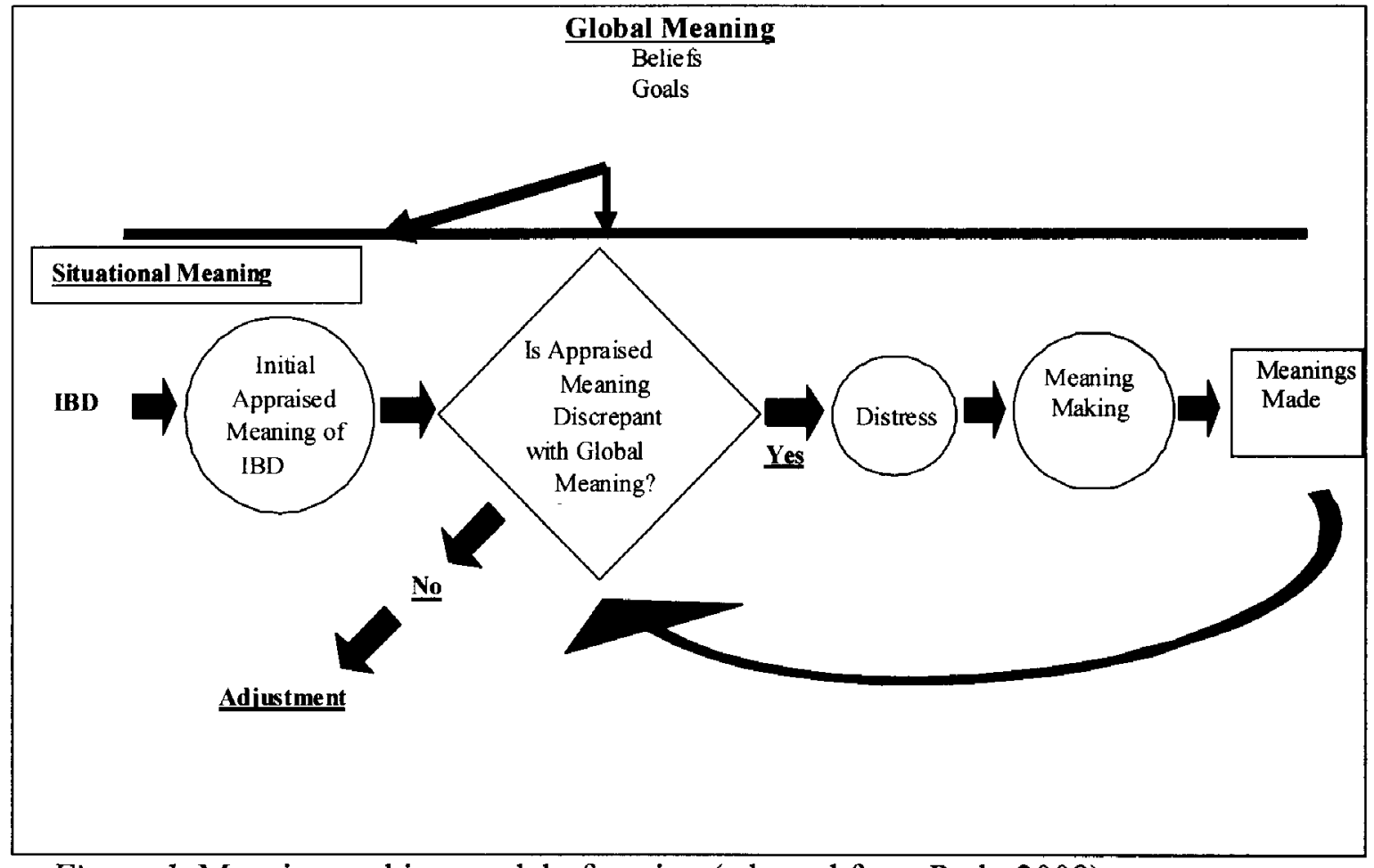

Figure 1. Meaning making model of coping (adapted from Park, 2008) 
Park and Folkman's (1997) model suggests that people experience psychological distress when there is incongruence between these two systems of meaning. More specifically, when a person encounters a potentially stressful event, he or she appraises the meaning of that event and determines the extent to which this appraised meaning threatens his or her global beliefs and goals. For example, people generally maintain adaptive beliefs about personal invulnerability, personal control and meaningfulness in life (Thompson, 1991). With the diagnosis of IBD comes feelings of vulnerability, lack of control and a sense of meaninglessness in their experience. There are often questions concerning why it happened and the personal significance of it. In addition to threatening the assumption of a meaningful world, IBD may threaten a person's overarching goals because of social or vocation limitations incurred by the disease.

To the extent that global beliefs and goals are incongruent with the appraised meaning of IBD, people will experience distress (Park, 2008; Tait \& Silver, 1989). This discrepancy, as well as the resulting distress, is seen as a motivator of change and a crucial part of the meaning making process. In order to "make meaning" people must either change the appraised meaning of IBD to make it fit into their existing beliefs and goals (assimilation), change their beliefs and/or goals to accommodate IBD (accommodation) (Janoff-Bulman \& Frantz, 1997; Joseph \& Linley, 2005), or both. Park and Folkman (1997) suggest that these changes alleviate psychological distress by aligning global and situational meanings. Integrating appraised meaning with global meaning is related to psychological adjustment to the stressful event (Antonovsky, 1987; Davis, Wortman, Lehman, \& Silver, 2000; Greenberg, 1995; Collie \& Long, 2005; Skaggs \& Baron, 2006) as it leads to acceptance and allows the person to move on 
(Horowitz, 1991; Park \& Folkman, 1997). In this way, meaning making is viewed as a type of coping strategy that often results in lower levels of negative affect and depressive symptoms, as well as higher levels of positive affect (Park, 2008).

Meaning making is presumed to occur whenever people experience events that they perceive as being discrepant with their global meaning. However, meaning making may be particularly important when people are dealing with a chronic illness. An illness such as IBD may be viewed as a unique form of harm, which often involves actual as well as symbolic losses (Shuman, 1996). The harm suffered is ongoing, primarily internal in source, and likely to affect all aspects of a person's being-physical, social, psychological, and spiritual (Scioli, McClelland, Weaver, \& Madden, 2000). For this reason, one could argue that a chronic illness that has no known cause or cure is more likely than most acute and non-health-related stressors to bring into question such existential concerns as meaninglessness (Yalom, 1998). For this reason, Park and Folkman's (1997) model of meaning making was chosen as the theoretical framework of the current study investigating the coping processes of individuals with IBD. The following is a more explicit description of the central constructs of the meaning making model, as well as relevant empirical research for each.

\section{Global Meaning}

Global meaning has been described using various terminology, including assumptive worlds (Janoff-Bulman, 1991), meaning structures (Marris, 1986), life schemas (Thompson \& Janigian, 1988), and existential meaning (Richer \& Ezer, 2000). In general, global meaning is made up of one's global beliefs, valued goals, and subjective feelings of meaning, or meaninglessness, in life (Park, 2005; Park \& Ai, 2006; 
Reker \& Wong, 1988). Global beliefs include the fundamental assumptions of a benevolent and meaningful world in which events occur according to what is fair and just (Janoff-Bulman, 1992). These beliefs also encompass broad domains such as control, predictability, coherence, and personal vulnerability (Park, 2008). For example, people tend to believe that the world is fair or that they have some direct control over events that occur (Catlin \& Epstein, 1992; Janoff-Bulman, 1991). Such basic beliefs regarding themselves and the world influence how people perceive events, construct plans, and formulate expectations (Bowlby, 1969; Janoff-Bulman, 1992).Global beliefs represent the dimension of global meaning that pertains primarily to assumptions of order.

Meaning described in terms of purpose refers to the motivational component of global meaning involving goals (Park \& Folkman, 1997). Global goals are the desired outcomes (i.e., ideals, states, or objects) that people seek to obtain, maintain, or avoid in life (Emmons, 1995; Park, 2008). Human beings are goal-directed; the pursuit of goals is basic and central to survival. Not only do people continually pursue goals, both proximal and distal, they also maintain specific beliefs about the likelihood of attaining those goals (Carver \& Scheier, 1991; Thompson, 1985). Many theorists consider people's goals to be a representation of their current identity, as well as their future ideal selves (Clark, Henry, \& Taylor, 1991; Silberman, 2005). As such, Park and Folkman (1997) suggest that global goals constitute a central element of a person's global meaning system. Together, global beliefs and global goals provide an orderly framework for understanding one's past and present experiences and guiding one's expectations for the future (Lee, Cohen, Edgar, Laizner, \& Gagnon, 2004; Park \& Folkman, 1997). 
Feelings of meaning, or meaningfulness, in life have been described as a trait-like variable that allows a person to weather life's stresses (Jim, Richardson, Golden-Kreutz, \& Anderson, 2006). In fact, some aspects of global meaning may be considered protective against psychological distress (Park \& Ai, 2006). Research shows that firm philosophical and spiritual belief systems help people recover from trauma and minimize symptoms of post-traumatic stress disorder (Brune, Haasen, Krausz, Yagdiran, Bustos, \& Eisenman, 2002). Additionally, those who have more positive beliefs before a trauma event are less likely to develop PTSD following the experience of a trauma (Ali, Dunmore, Clark, \& Ehlers, 2002). Results are similar in studies with cancer patients; those who report more meaning in life in the wake of a cancer diagnosis report less distress (Lewis, 1989; Vickberg et al., 2001).

Although little research has been done investigating the development of global meaning, there is general agreement that it is formed through the accumulation of life experiences beginning in childhood (Bowlby, 1969; Catlin \& Epstein, 1992; Klinger, 1977). Culture and socialization play a formative role as well. For example, beliefs about order may be stronger in cultures that emphasize individualism than those who do not. Throughout childhood and adolescence, people's mental structures are refined and embellished by their experiences. However, changes are much less likely to occur in adulthood. For this reason, global meaning is characterized as being largely stable. Although people confront a barrage of stimuli on a daily basis, a fundamental need for stability and coherence results in a tendency to fit new data into their existing beliefs rather than modify those belief systems to fit the stimuli (Janoff-Bulman, 1989; Marris, 1986; Park \& Blumberg, 2002; Park \& Folkman, 1997). This process is known as 
assimilation and is more likely than its counterpart, accommodation (changing global meaning to make it fit with appraised meaning) (Payne, Joseph, \& Tudway, 2007).

In addition to be being stable, global beliefs are generally optimistically biased (Park \& Folkman, 1997) with overly positive self-evaluations and exaggerated perceptions of control (Taylor \& Brown, 1988; 1994). Global beliefs, therefore, are not always accurate representations of a person's past experience (Thompson \& Janigian, 1988). Moreover, people tend to underestimate personal risk for a number of negative occurrences, attributing greater vulnerability and risk to others (Perloff, 1983; Weinstein, 1987). In other words, people believe that bad things happen, but they don't believe that those things will happen to them.

\section{Situational Meaning}

Although global meaning represents the more abstract and generalized level of meaning, it strongly influences many aspects of situational meaning. According to Park and Folkman (1997), situational meaning is the "interaction of a person's global beliefs and goals and the circumstances of a particular person-environment transaction" (p. 121). In other words, when an individual is faced with a diagnosis like IBD, the meaning he or she makes of it - in the short- and long-term - will be influenced by his or her global meaning. Expectations about why and how things happen, perceptions of one's own vulnerability to such events, existing goals that may be threatened, as well as beliefs about the illness itself, influence a person's understanding of their diagnosis.

According to the meaning making model of coping (Park \& Folkman, 1997; Park, 2005), situational meaning has three components - appraisal of meaning, search for meaning, and meaning as an outcome. Appraisal of meaning refers to cognitive appraisal 
as explained earlier, which is the process through which a person evaluates the meaning of a particular event with respect to its personal significance (Lazarus \& Folkman, 1984). Initial appraisals of an event are often made rapidly without much deliberation. Appraisal of meaning is influenced by the relevance of an event to one's beliefs and goals and by perceived options regarding what can be done about one's situation (Lazarus \& Folkman 1984; Thompson \& Janigian, 1988). In effect, appraised meaning is created through the processes of primary and secondary appraisal (Lazarus \& Folkman, 1984). Appraised meaning is additionally influenced by past experiences and the timing of an event. For example, stories of others' success or failure associated with a specific disease impacts a person's emotional and cognitive response to their own diagnosis. Also, the diagnosis of a chronic illness at an early age may be considered an off-time event in that it involves life changes that occur earlier than what might be expected. In other words, the occurrence of such an off-time event doesn't fit with prevailing beliefs about the expected trajectory of life (Richer \& Ezer, 2000; Sorenson, 1995). Ultimately, when a person perceives that the outcome of an unexpected event could be negative, that coping resources are inadequate, or that existing beliefs are threatened, then a search for meaning ensues.

Search for meaning refers to the coping processes through which people attempt to understand unexpected and stressful events (Thompson, 1991; Turnquist, Harvey, \& Anderson, 1988). When the meaning initially ascribed to an event is incompatible or incongruent with the person's global meaning, meaning-based coping techniques are used to work through the process of searching for meaning. Not only does a search for 
meaning help people understand their experience of an illness, it also assists them in finding a sense of meaningfulness in their life (Steeves, 1992).

In a concept analysis conducted by Skaggs and Baron (2006), they discuss four critical attributes of the search for meaning. First, search for meaning is a process. Search for meaning is part of the very nature of being human (Frankl, 1984, Lazarus, 2001). It is a primary and universal human motive and, as such has been reported across all age groups (Frankl, 1984; Reker, Peacock, \& Wong, 1987). Daily events are evaluated on the basis of their "fit" with global meaning (Harvey, Orbuch, \& Fink, 1990; Lazarus \& Folkman, 1984; Lazarus, 2001). The appraisal process in searching for meaning takes place continuously during waking hours, sometimes at an unconscious level (Skaggs \& Baron, 2006). Secondly, search for meaning is temporal. Because evaluation of an event is ongoing, meaning may change as a person receives more information and copes with the experience (Lipowski, 1983). Specific techniques used to find meaning can vary from day-to-day and from one aspect of an event to another (e.g., uncertainty of illness, painful symptoms) (Schwarzer \& Knoll, 2003). Third, the search for meaning is unique for each person (Skaggs \& Baron, 2006). Meaning cannot be received from another person (Frankl, 1988; Park \& Folkman, 1997) as it is situation- and person-specific (Frankl, 1988). The personal nature of meaning helps explain why a particular event may be seen as stressful to one person but not to another (Janoff-Bulman, 1992; Pearlin, 1991). Additionally, an event that is considered to be stressful to a person at one point in life may not be another time (Aldwin, 1994; Park \& Folkman, 1997). Fourth, and last, the search for meaning is a recursive process. Different aspects of the process may overlap and, at any point, a person may revisit the appraised meaning of an event, engage in 
reappraisal, or use a variety of other meaning-based coping strategies (King, 2004; Park \& Folkman, 1997)

Central to the search for meaning are attribution processes (Coward, 1997, Park \& Folkman, 1997). Searching for and finding some reason why an event occurred and who or what is responsible for its occurrence can be helpful in making sense of an unexpected and stressful experience (Baumeister, 1991; Park \& Folkman, 1997; Taylor, 1983). Attributions of causality ("Why did this happen?"), selective incidence ("Why did this happen to me?"), and responsibility ("Who or what is responsible for this happening?") are common among those attempting to cope with a chronic illness (Coward, 1990; Fife, 1994; O'Connor, Wicker, \& Germino, 1990; Steeves, 1992). Research is mixed concerning the extent to which attributions are a necessary part of the coping process. Not everyone includes attribution among their coping efforts (Downey, Silver, \& Wortman, 1990); however, for many people attributions play a major role in coping and adjustment processes. Assigning a cause for one's illness may help a person make sense out of his or her experience. People who believe they understand why it occurred are less likely to have their assumptions of a meaningful world challenged (Thompson, 1991). Additionally, particular attributions can help restore a sense of control and invulnerability (Janoff-Bulman \& Lang-Gunn, 1988; Taylor, 1983). If an identified cause is seen as avoidable or under one's control, a person is provided a potential means for taking action to prevent recurrence (Coward, 1997; Thompson, 1991). Finding answers to attributional questions is not sufficient for providing meaning or for reconciling situational and global meaning (Park \& Folkman, 1997; Taylor, 1983; Thompson \& Janigian, 1988; Skaggs \& Barron, 2006). 
Search for meaning has been characterized as a prevalent thinking process among those newly diagnosed with a major illness, involving attempts to understand the significance of the diagnosis and redefine meaning in life. Studies show that the majority of cancer patients engage in these processes (52\% - 87\%; Dirksen, 1995; O'Connor et al., 1990) in an attempt to understand the significance of the diagnosis, while also redefining meaning in life.

Although search for meaning has received the greatest amount of attention when compared to other aspects of the Park and Folkman (1997) model of meaning making, research diverges on its psychological impact. While some studies show that those who are searching for meaning have poorer mental functioning, less positive affect, and more negative affect than those who are not searching for meaning (Barkwell, 1991; Tomich \& Helgeson, 2002), other studies show the converse (Davis, Nolen-Hoeksema, \& Larson, 1998). One explanation for these contrary results may be related to the hypothesized relationship between the process of meaning making and its outcome (further discussed below). Meaning making as a process may only be considered helpful when it results in some sort of resolution or integration (Park, Edmondson, Fenster, \& Blank, 2008). In other words, meaning making may be helpful only to the extent that it is related to the actual making of meaning. In fact, the ability to find meaning is more consistently related to positive outcomes such as higher self-esteem (Lewis, 1989) and better physical functioning (Thompson \& Pitts, 1993). Conversely, on-going, unsuccessful efforts to make meaning of one's experience may signify a lack of resolution or satisfactory meaning and, therefore, be associated with poorer adjustment (Davis et al., 1998). Adding to the complexity of the issue, it is difficult to determine whether individuals who 
are not searching for meaning are not doing so because they see it as unnecessary or they have already constructed meaning (Lee et al., 2004).

Meaning as an outcome (Park \& Folkman, 1997) is the third, and final, stage of situational meaning and represents the products of the meaning making process. It has been referred to as "found meaning" (Thompson \& Janigian, 1988) or "meanings made" (Park, 2005). In some cases, this reflects a change in the appraised meaning of the event, leaving pre-existing global meaning intact. Other times, meaning as an outcome reflects changes in global meaning (both positive and negative).

Not everyone finds meaning in their illness experience. However, those that do, particularly those that construct positive meaning from their experience, are expected to demonstrate better adjustment (Taylor, 1983; Thompson, 1991). In a study of 1012 women with breast cancer, Degner and colleagues (2003) found that women who constructed positive meaning out of their disease reported significantly less trait anxiety, depression, and better emotional functioning and quality of life compared to those women who found negative meaning. Taylor (1983) suggests that people maintain or improve their sense of quality of life through the construction of new meaning that includes regaining a sense of control and restoring self-esteem.

The Meaning Making Process and Outcomes

According to the Park and Folkman (1997), a person who perceives a discrepancy between the appraised meaning of a situation and his or global beliefs and goals (See Figure 1) will experience psychological distress, including a sense of loss of control, unpredictability, or incomprehensibility of the world. To reduce distress, this discrepancy must be reduced. The meaning making model of coping allows for the reduction of 
discrepancy through changing the appraised meaning of a situation, modifying global beliefs and/or goals, or both. In this way, meaning making is considered to be a specific type of coping that involves coming to see or understand a stressful event in a different way or reviewing and reforming one's beliefs and goals in order to regain consistency among them (Davis et al., 2000).

\section{Changing Appraised Meaning}

One of the central tasks of coping with severe stress is to integrate the occurrence of the stressor with one's beliefs about the world and the self (Folkman \& Moskowitz, 2004; Janoff-Bulman, 1989; Park \& Folkman, 1997). Meaning making coping is a way of linking a person's important values, beliefs, and goals to the illness experience (Folkman, 1997), thereby making it less aversive and distressing. Given the stable nature of global beliefs, people typically make meaning through assimilation, or redefining the appraised meaning of an event rather than changing their global meaning system (Pargament, 1997; Park \& Folkman, 1997; Thompson \& Janigian, 1988). There are a number of means through which people attempt assimilation.

Many researchers operationally define meaning making in terms of attributions. Although people make early, automatic attributions concerning causality and responsibility (Smith, Haynes, Lazarus, \& Pope, 1993), Park and Folkman (1997) propose that initial attributions may be modified throughout the coping process. Revisions of attributions initially made are referred to as reattributions and are thought to develop out of a continued struggle to understand one's experience (Park \& Folkman, 1997). 
The sparse amount of research investigating the association between attributions and adjustment in general has demonstrated mixed results. While some studies have found that asking attributional questions is associated with worse psychological outcomes (van den Bout, van Son-schoones, Schipper, \& Groffen, 1988), others have found it to be related to better adjustment (Tennen, Affleck, Urrows, Higgins, \& Mendola, 1992). These contradictory findings may, in part, be due to the fact that distinctive types of attributions (causal, selective incidence, and responsibility) are often used interchangeably by researchers (Thompson, 1991).

Just as reattributions occur throughout the coping process, coping is continuously mediated by cognitive reappraisals (Lazarus \& Folkman, 1984; Park \& Folkman, 1997). Reappraisal processes transform the appraised meaning of an event making it seem less uncontrollable or threatening than originally (Park \& Blumberg, 2002). Reappraisals can also increase the positive aspects of a specific event or experience. Positive reappraisal, also known as positive reinterpretation or positive reframing (Carver, Scheier, \& Weintraub, 1989), is a type of meaning making coping strategy that involves a reevaluation of an event in terms of benefits to one's values, beliefs, and goals (Folkman \& Moskowitz, 2004). A person may see his or her illness as having been a catalyst for positive growth or for the expression of previously unrecognized strengths (Tennen \& Affleck, 2002).

Positive reappraisal coping is one meaning making coping strategy measured in the current study and has consistently associated with better adjustment to a variety of stressors, including illness (Carver et al., 1993; Mattlin, Wethington, \& Kessler, 1990; Mendola, Tennen, Affleck, McCann, \& Fitzgerald, 1990). In a study of 104 HIV-infected 
men (Kraaij, Van der Veek, Garnefski, Schroevers, Witlox, \& Maes, 2008), positive reappraisal was negatively related to depression $(r=-.37, p<.001)$ and anxiety $(r=-.28$, $p<.01$ ). Similar results were found in a study of people with definitive infertility (Kraaij, Garnefski, \& Vlietstra, 2007). After controlling for sociodemographic characteristics, positive reappraisal was significantly negatively related to depression $(r=-.23, p<.001)$. In addition to depression and anxiety, positive reappraisal has also been associated with decreased levels of psychological distress (Carver et al., 1993) and fatigue (Reuter et al., 2006).

Another coping strategy related to meaning making is emotional processing (Stanton et al., 2000a). Rachman (1980) described emotional processing as a way in which a person processes stressful life events. He defined emotional processing as "a process whereby emotional disturbances are absorbed, and decline to the extent that other experiences and behavior can proceed without disruption" (p. 51). Although emotionfocused coping strategies have been associated with higher levels of distress (Malcarne \& Greenbergs, 1996), Stanton, Kirk, Cameron, and Danoff-Burg (2000b) suggest that this may be due to problems related to the measurement and analysis of this style of coping. In addition to there being distinctly different types of coping included under a general category of emotion-focused coping (i.e., emotion expression, emotion avoidance), these strategies are often confounded with distress (i.e., "I get upset and let my emotions out."). These issues led Stanton et al., 2000b) to develop a scale that more clearly assesses emotional approach types of coping. Similar to cognitive processing, emotional processing is likely an important part of the meaning making process and adaptive in the short-term. However, if it continues on a long-term basis, it may become more ruminative 
in nature and less beneficial in terms of resolution and adjustment (Stanton et al., 2000a). It is not entirely clear, with the current research, at which point these processes become ruminative and maladaptive.

\section{Changing Global Meaning}

In effect, coping strategies such as re-attributions and positive reappraisal (i.e. positive reframing) are attempts at decreasing the incongruence between situational (appraised) and global meaning. However, Park and Folkman (1997) suggest that there are times when the cognitive processes aimed at reinterpreting the situational meaning of an event are not sufficient to achieve congruence between situational and global meaning. This is especially true when pre-existing beliefs are completely shattered or basic goals are thwarted by a particularly stressful experience, such as a chronic illness (Thompson \& Janigian, 1988). In these cases, restoring equilibrium may involve revising one's fundamental beliefs or altering goals.

Religion is considered to be one example of a global meaning system (Park, 2005; Park \& Folkman, 1997). A religious meaning system can provide a framework of meaning that helps the person answer difficult questions related to the event and develop purpose and goals (Paloutzian, Richardson, \& Rambo, 1999; Pargament, 1997). In addition to, or instead of, changing the appraised meaning of an event, people may also change their fundamental philosophical, religious, or existential belief systems or construe drastically altered goal hierarchies (Lehman et al., 1993; Park \& Folkman, 1997). This usually happens when, even after extensive reappraisals, an event is too aversive or extreme to fit into preexisting beliefs and goals (Park \& Folkman, 1997; Park, 2005). For example, following a traumatic or stressful life event, a person may come to 
view God as less powerful (Kushner, 1981) or believe that they are no longer able to understand everything that happens in the world (Pargament, 1997). Religious reappraisal, along with prayer, meditation and finding comfort in spiritual beliefs, is a form of religious coping and one of the meaning making coping strategies measured in the current study.

Living with a chronic illness can produce significant stress, feelings of loss and a changed reality due to the disruption of life goals (Klinger, 1977; Thompson \& Janigian, 1988). Meaning making usually involves a process of evaluating the appraised meaning of a situation in terms of its consequences for one's life, including future goals and priorities (Moos \& Schaefer, 1986). When a goal is thwarted, a person can move on only by revising the old goal, finding an appropriate substitute or abandoning it (Martin \& Tesser, 1989; Park \& Folkman, 1997; Pearlin, 1991). Values may be realigned so that achievable goals have more value and unachievable goals become less important (Sharpe \& Curran, 2006). A person may relinquish goals that are no longer tenable and create new ones that restore a sense of purpose to their lives (Millar, Tesser, \& Millar, 1988; Park \& Folkman, 1997). Essential requirements for a meaningful life may change to include elements that are still achievable within the new context of living with a chronic illness (Sharpe \& Curran, 2006).

Little research has focused on the potential influence of sociodemographic variables on meaning-related constructs. Previous research has found that young and middle-aged adults tend to experience more disruption and threat than do older adults (Bower, Meyerowitz, Desmond, Bernaards, Rowland, \& Ganz, 2005; Park et al., 2008; Vickberg, 2003), suggesting that younger people have a greater need to make meaning 
from off-time experiences (i.e., those life changes that occur earlier or later than expected) (Blank \& Bellizzi, 2006; Park et al., 2008; Tomich \& Helgeson, 2002). However, age has not been consistently associated with meaning-focused styles of coping. Regarding education and income level, a review by Lee et al. (2004) found these two variables to be the least often reported sociodemographic variables in the meaning literature. Although gender, race/ethnicity, and marital status are more commonly reported, samples tend not to be representative, consisting mainly of married, Caucasian females (Lee et al, 2004). Nevertheless, several studies have found that women not only report greater use of meaning making coping strategies, but also report using a greater number of coping strategies in general (Park \& Cohen, 1993; Scioli et al., 2000). The present study aims to further examine the predictive value of specific sociodemographic variables (i.e., age, gender, and education level) on meaning making behaviors.

\section{Stress-Related Growth}

A stressful event or experience such as that associated with a debilitating chronic illness is thought to challenge or violate a person's worldviews (i.e., beliefs about fairness, justice, control, etc.) as well as their goals (Park, 2004; Park \& Folkman, 1997). Through the cognitive processing of information, people engage in meaning making to reduce the violation of their beliefs and goals. Meaning making coping strategies (Folkman \& Moskowitz, 2004) are those aimed at changing their global meaning (beliefs and/or goals), the meaning of the stressful situation, or both (Park, 2005). Meaning making itself is often considered to be of value to people because it provides them with an opportunity to rethink their views, goals, priorities, and situation. As a result of this review, people often identify or produce positive changes in themselves (Park, 2004). 
These positive changes are known as stress-related growth (SRG; Park et al., 1996) and are viewed as one outcome of the meaning making coping process (Park, 2004).

SRG is a relatively new construct within psychological literature that has been studied under various terms, such as posttraumatic growth (Tedeschi, Park, \& Calhoun, 1998) and perceiving benefits (Calhoun \& Tedeschi, 1991). In the current study, the term stress-related growth is preferred over the others for several reasons. First, trauma refers to events or conditions that involve perceived threat to life or bodily integrity, whereas stress encompasses a broader range of life events. Therefore, the use of the term posttraumatic growth is reserved for those who have experienced true trauma (Park, 2004). Secondly, the term perceiving benefits may imply that the positive changes following a stressful experience may not be actual and/or observable changes, but rather perceptions of an individual.

In addition to, or perhaps as a result of, varying terminology, SRG has been conceptualized in different ways. Although it has been characterized by some as a manifestation of defensive denial this view of SRG has been largely refuted (Lerner \& Gignac, 1992; Park \& Cohen, 1993; Park et al., 1996). Several researchers suggest that people can and do alter their emotional reactions by changing their perspective without distorting or denying objectively difficult of deteriorating circumstances (Gilovich \& Medvec, 1995; Lazarus, 1983; Lerner \& Gignac, 1992). For those dealing with stressful life events, reports of growth may not only reflect actual positive changes, but also attempts at reappraising the situation to find the positive (Park, 1998; Park \& Folkman, 1997). In this way, SRG has been viewed as a type of coping strategy not unlike positive reappraisal. In the case of chronic illness, people may be continuously coping; therefore, 
reports of positive change may not only reflect accurate positive changes they have experienced, but also attempts to reappraise the situation positively (Park, 1998).

SRG is also seen as a legitimate adjustment outcome (Park \& Folkman, 1997) and will be operationally defined as such in the current study. A large body of research has established that people do report having experienced growth and positive changes as a result of their coping with stressful life experiences in a variety of life domains (McMillen, Smith, \& Fisher, 1997; Tedeschi \& Calhoun, 1996). Changes include reordering priorities, greater appreciation of life, increases in personal strength or coping resources, desire to help others, learning to take better care of oneself, increased compassion and understanding of others, and increased spirituality and/or faith (Collins, Taylor, \& Skokan, 1990; Park, 2004; Petrie, Buick, Weinman, \& Booth, 1999; Tedeschi \& Calhoun, 1995).

Efforts to better understand the development of SRG have resulted in the proposal of several theoretical models (Park \& Ai, 2006); however, there seems to be general agreement that SRG requires a precipitating "seismic" disruption to one's assumptive world or sense of self (Davis, Wohl, \& Verberg; 2007; Tedeschi \& Calhoun, 2004). To the extent that an event or experience challenges a person's understanding of the world and one's place in it, he or she will be faced with the cognitive task of rebuilding a meaningful and coherent view of the self and the world (Davis et al., 2007; Joseph \& Linley, 2005). The same is true for events that disrupt or threaten major life goals or one's understanding of life's purpose (Taylor, 1983; Thompson \& Janigian, 1988); people must rebuild goal hierarchies and seek out new purpose and meaning in life (Martin \& Tesser, 1989; Park \& Folkman, 1997). Indeed, Tedeschi and Calhoun (1995) 
suggest that if an event is painful and its resolution is challenging and difficult, growth is more likely to be experienced. SRG is contingent on the satisfactory completion of this rebuilding process. In other words, for growth to occur, one must process and reconcile the meaning of the experience for one's life, or "'make sense of it" (Davis et al., 2007). Many people make sense of an event by coming to view it as an opportunity for personal growth.

The role of rebuilding, or meaning making, in the development of SRG has been addressed by several theorists (Janoff-Bulman, 1992; Neimeyer, 2006; Park \& Folkman, 1997; Tedeschi \& Calhoun, 2004). In fact, a close review of the literature suggests that achieving stress-related growth involves many of the key aspects of the meaning making model of coping (Park \& Folkman, 1997). The model highlights the role of cognitive processing. Cycles of cognitive intrusions and avoidance are considered to signify a normative reconstruction of one's assumptive world. The repeated exposures and attempts to work through the stressful encounter help people arrive at a more integrated understanding (Tedeschi \& Calhoun, 2004). Cognitive processing and meaning making processes have been cross-sectionally linked to stress-related growth (Park, 2004; Park et al., 1996). However, those unable to achieve integration or resolution either by changing the appraised meaning of an event to assimilate it into pre-existing global meaning, or by changing their beliefs and goals to accommodate the event, will engage in continued cognitive processing (Park \& Folkman, 1997). Continued cognitive processing becomes maladaptive at greater levels of intensity and longer duration (Park et al., 2008; Harper et al., 2007; Horowitz, 1997; Joseph \& Linley, 2005). These results hark back to those suggesting poor outcomes for those reporting on-going meaning making efforts (Park et 
al., 2008; Tomich \& Helgeson, 2002). On-going meaning making may be considered a ruminative process in which has been associated with depression, poorer mental functioning, less positive affect, and more negative affect (Barkwell, 1991; NolenHoeksema, 1987; Silver, Boon, \& Stones, 1983; Tait \& Silver, 1989; Tomich \& Helgeson, 2002),

Cognitive appraisals (Lazarus \& Folkman, 1984) have also been associated with reports of growth. For example, greater levels of perceived challenge and threat, may facilitate SRG (Armeli, Gunthert, \& Cohen, 2001; Park \& Fenster, 2004). In other words, appraising a situation as a challenge that can be mastered leads a person to cope more actively and, thus, be more apt to grow from the experience (Schaefer \& Moos, 1998). Additionally, Germino, Fife, and Funk (as cited in Schaefer \& Moos, 1998) found that appraisals of threat were associated with increased attempts to find meaning. The influence of cognitive appraisal is highlighted by comparing differences in growth scores across event type. Although research suggests a positive association between severity of a stressful life event and the experienced SRG (Armeli et al., 2001; Kesimci, Göral, \& Gencöz, 2005; Park et al., 1996), level of severity is subjective by nature. Ultimately, it is more likely that the characteristics of the subjective experience of the event (e.g., controllability, threat), rather than the event itself that influences growth processes (Linley \& Joseph, 2004).

In addition to cognitive appraisal and coping strategies (e.g., positive reframing, religious coping), Schaefer and Moos (1992) suggest a number of other factors that may predict whether or not a person experiences growth. Event-related factors, such as duration (or time since onset) and timing, are inconsistently related to growth. Although 
greater length of time since the initiation of a stressor could conceivably provide a person with more opportunity to work through and finding meaning in the experience, this has not been consistently empirically demonstrated (Park et al., 1996).

Sociodemographic variables that have been linked to SRG include age, gender, education, and income (See Linley \& Joseph, 2004, for a review). For example, some studies have found a negative association between age and SRG (Davis et al., 1998; Evers, Kraaimaat, Floris, van Lankveld, Jacobs, \& Bijlsma, 2001, Polatinsky \& Esprey, 2000), while others have found either a positive association (Milam, Ritt-Olson, \& Unger, 2004) or none at all (Kesimci et al., 2005; Siegel, Schrimshaw, \& Pretter, 2005). As stated previously, SRG requires a precipitating "seismic" disruption to one's assumptive world or sense of self (Davis, Wohl, \& Verberg; 2007; Tedeschi \& Calhoun, 2004). Research has found that young and middle-aged adults tend to experience more disruption and threat than do older adults (Bower, Meyerowitz, Desmond, Bernaards, Rowland, \& Ganz, 2005; Park et al., 2008; Vickberg, 2003); therefore, it is feasible to expect a negative association between age and SRG.

Although gender has not always proven to be predictive of SRG (Polatinsky \& Esprey, 2000), many studies suggest that females are more likely to reports SRG (Kesimci et al., 2005; Lehman et al., 1993; Park et al., 1996; Stanton, Bower, \& Low, 2006; Tedeschi \& Calhoun, 1996; Weiss, 2002). Bear and Barnes (as cited in Kesimci et al., 2005) attribute higher levels of SRG in women to the finding that women tend to report higher levels of distress (Bear \& Barnes, 2001). Studies have revealed that women are also more likely to seek social support (Littlewood, Cramer, Hoekstra, \& Humphrey, 1991; Rosario, Shinn, Morch, \& Huckabee, 1988), which seems to facilitate growth 
(Armeli et al., 2001; Park et al., 1996; Weiss, 2004). Furthermore, with gender differences expected in meaning making coping efforts, it follows that gender differences are also expected in SRG.

Only two studies have found higher levels of education to be associated with more SRG (Fontana \& Rosenheck, 1998; Updegraff, Taylor, Kemeny, \& Wyatt, 2002). In the current study, meaning making coping efforts are hypothesized to have a direct causal effect on SRG. Because meaning making is not expected to be contingent on education level, neither is SRG. Although specific hypotheses were formed for the present study, evidence remains mixed in terms of sociodemographic variables' predictive value as related to SRG.

Research has identified reports of stress-related growth following a variety of violent traumas, including military combat (Elder \& Clipp, 1989), child sexual abuse (McMillen, Zuravin, \& Rideout, 1995), a mass killing, plan crash, or tornado (McMillen et al., 1997); and terrorist attacks (Davis \& Macdonald, 2004). In addition to traumatic experiences, stress-related growth is increasingly recognized as an important outcome or end product of meaning making among those living with a serious illness (Danoff-Burg \& Revenson, 2005; Milam, 2004; Schaefer \& Moos, 1992; Siegel et al,, 2005). For example, there has been a proliferation of studies investigating SRG (see Helgeson, Reynolds, \& Tomich, 2006 for a review), many of which focus on illness. Illness populations include cancer (e.g., Sears, Stanton, \& Danoff-Burg, 2003; Thorton \& Perez, 2006), rheumatoid arthritis (Tennen et al., 1992), HIV-AIDS (Siegel \& Schrimshaw, 2000), and multiple sclerosis (Mohr et al., 1999; Pakenham, 2005). Although IBD has characteristics similar to those of the aforementioned illnesses, (i.e., uncertain course, 
debilitating physical symptoms, chronicity), there are no studies investigating SRG among with those living with the disease. The current study was designed to further examine the relationship between specific sociodemographic variables (i.e., age, gender, and education level) and SRG and to determine if SRG occurs among individuals living with IBD.

\section{Meaning Making Coping in the Context of IBD}

Meaning becomes particularly salient when it comes to coping with illness. An extraordinary event such as the diagnosis of a serious illness disrupts the continuity of everyday life, and people are forced to re-define the meanings they have assumed to be true in the routine of living (Fife, 1994). Recognition of the relevance of the meaning making process has led to an increase of research in the past decade (Grossman, Sorsoli, \& Kia-Keating, 2006; Scioli et al., 2000). Much of this research has focused on meaning making as a way for individuals to cope with life threatening illnesses such as cancer and HIV (Lee, Cohen, Edgar, Laizner, \& Gagnon, 2006a; 2006b; Plattner \& Meiring, 2006). Although IBD is not considered to be life-threatening, it was chosen as the stressful experience with which to test Park and Folkman's (1997) meaning making model of coping for several reasons. Living with a disease with no known cause can complicate the meaning making process. IBD is one example of an idiopathic disease with no known cause or cure. Additionally, IBD is characterized by uncertainty in course of illness (unpredictable relapse/remission cycles), as well as day-to-day symptoms. IBD is also an illness capable of shattering basic beliefs and the attainment of valued goals. It affects men and women in a time of life where major changes (i.e., establishing a career, starting a family) often occur. Furthermore, the debilitating symptoms of IBD often 
wreak havoc in several different life domains, including family, work, social activities and one's sex life. Lastly, despite the fact that it affects more than 1 million Americans (Hurd, 1999), no research has been conducted investigating the meaning making process in those living with IBD. To provide adequate rationale for the present study, each of these factors will now be discussed in greater detail.

\section{Clinical Presentation of IBD}

IBD is a category of chronic illnesses that involve inflammation of the digestive system. CD and UC are two forms of IBD that are similar in their clinical presentation but different in terms of histopathology, complications, and ultimate outcomes for the patient (Dudley-Brown, 1996). The major difference between CD and UC is the areas of the digestive track they affect. Specifically, $\mathrm{CD}$ can occur in any portion of the gastrointestinal tract, from the mouth to the anus, whereas $\mathrm{UC}$ is confined to the colon (Cooke, 1991; Dudley-Brown, 1996). Also, CD may involve any layer of the intestinal wall, while UC is restricted to the mucosa.

Because $\mathrm{CD}$ and $\mathrm{UC}$ affect different layers of the intestine, they differ in symptoms and complications. Symptoms of UC typically include periods of both diarrhea (frequently with blood and mucus) and constipation, abdominal pain, and cramping (Rao, Holdsworth, \& Read, 1988). Of course, the severity of symptoms depends on the extent of colon involvement. The same is true for $\mathrm{CD}$ in that a person's symptoms depend on the extent and site(s) of involvement; however, typical symptoms include abdominal pain and diarrhea (Dudley-Brown, 1996). Due to the inflammatory nature of IBD, both CD and UC can involve systemic symptoms of fever and anemia, as well as extraintestinal manifestations such as abscesses and arthritis. In addition to presenting with typical 
symptoms, patients may present with complications-both acute (e.g., obstruction, perforation, cancer) and chronic (e.g., anemia, malnutrition) (Dudley-Brown, 1996; Thompson, 1993). For further comparison of these diseases' clinical features, see Figure

2.

Although the cause of UC and CD are uncertain, evidence suggests that they result from a complex interplay of genetic, immunological, and environmental factors, rather than any one single cause (Hurd, 1999). The general consensus is that symptoms result from an abnormal response of a person's immune system (Ardizzone, \& Bianchi Porro, 2002). Normally, the immune system protects the body from infections caused by

\begin{tabular}{|l|l|l|}
\hline Clinical Feature & Ulcerative Colitis & Crohn's Disease \\
\hline Location in GI tract & Begins in colon, extends proximally & Any \\
\hline Distribution & Continuous & $\begin{array}{l}\text { Discontinuous; Skip } \\
\text { lesions }\end{array}$ \\
\hline $\begin{array}{l}\text { Extent of } \\
\text { inflammation }\end{array}$ & Mucosa (inner lining) & $\begin{array}{l}\text { Transmural (musosa, } \\
\text { muscular layer, serosal } \\
\text { layer) }\end{array}$ \\
\hline Primary symptoms & $\begin{array}{l}\text { Loose, frequent stool; abdominal } \\
\text { pain/cramping; }\end{array}$ & $\begin{array}{l}\text { Depends on location; } \\
\text { nausea, vomiting, } \\
\text { diarrhea, abdominal pain }\end{array}$ \\
\hline $\begin{array}{l}\text { Extraintestinal } \\
\text { Manifestations }\end{array}$ & Yes & Yes \\
\hline Malabsorption & No & Yes \\
\hline $\begin{array}{l}\text { Fistulas, abcesses, \& } \\
\text { Strictures }\end{array}$ & No & Yes \\
\hline
\end{tabular}

Figure 2. Comparison of Ulcerative Colitis and Crohn's Disease (adapted from DudleyBrown, 2002)

viruses or bacteria. Once the infection has cleared up, the immune system "shuts off." In individuals with IBD, the immune system seems to overreact to something in the 
digestive tract, failing to "shut off" once it starts working. This causes the ongoing inflammation, ulcers and other problems associated with IBD. Steroids and immunosuppressant therapies have effectively been used to manage symptoms of the diseases, thereby providing evidence for the overactive immune system hypothesis.

Managing IBD often consists of a combination of drug therapy, lifestyle changes (e.g., diet, smoking cessation), or surgery, depending on diagnosis, location, and severity of the disease (Nightingale, 2006). Though typically not the first therapeutic option, many people with IBD will eventually undergo surgery as part of the management of their illness. As many as one-quarter to one-third of patients with UC and two-thirds to three-quarters of those with $\mathrm{CD}$ will have to have surgery due to complications or unsuccessful medical therapy (CCFA, 2008, "About Ulcerative Colitis and Proctitis; 2009b, "Surgery for Crohn's Disease"). Depending on a number of factors, including the location and extent of the disease and the patient's age and overall health, several surgical approaches are available. A proctocolectomy is the removal of the entire colon and rectum and involves the creation of an ileostomy. In an ileostomy the end of the small intestine (ileum) is brought through a hole (stoma) in the abdominal wall, which allows for the drainage of intestinal waste into an external pouch, or ostomy. A colectomy is the removal of just the colon, or a portion thereof, and does not necessarily require a stoma. Other surgical options include strictureplasty (widening of narrowed portions of the intestine without removal) and resection (removing diseased portions of the intestine and joining two ends of healthy intestine). In UC, although the patient is traditionally considered "cured" once the colon is removed, bowel function is significantly abnormal following post-colectomy reconstructive surgery (typically an ileo-anal pouch 
anastomoses (Delaney et al., 2003). With CD, however, even if the diseased portion of the intestine is removed, the inflammation can reappear in a previously unaffected portion of the intestine. In fact, 50 percent of those adult patients who have surgery will experience a recurrence of symptoms within five years (CCFA, 2008; 2009b).

Idiopathic nature of IBD

Many patients with IBD may experience symptoms long before a correct diagnosis is made. Oftentimes a diagnosis lends meaning to the illness experience by providing an explanation for symptoms and, thus, allowing the individual to impose order upon and regain control over the illness experience (Drauker, 1991; Madden \& Sim, 2006). It is possible that such resolution can occur immediately upon being given a diagnosis; however, for most this occurs over time through repeated processing of illnessrelated information (Adams, Pill, \& Jones, 1997; Madden \& Sim, 2006). When this process is not successful, a maladaptive cycle of rumination can occur (Horowitz, 1991; Martin, Tesser, \& McIntosh, 1993; McIntosh et al., 1993; Park \& Folkman, 1997; Tait \& Silver, 1989); therefore, resolution may not be achieved and the diagnosis, or the illness experience itself, is not accepted by the individual (Adams et al., 1997). This process may be particularly challenging when a diagnosis is confusing or when an illness is largely characterized by uncertainty (Lewis, 1995; Madden \& Sim, 2006).

\section{Uncertainty}

Mishel (1988) defined uncertainty as a cognitive state in which an individual is unable to find meaning in illness-related events; it involves issues of ambiguity, complexity, unpredictability, and lack of information within the illness experience. Specifically, with IBD there is (a) ambiguity regarding the occurrence and pattern of 
symptoms; (b) complexity of disease and symptom management; (c) lack of definitive information regarding etiology, and diagnosis, and treatment; and (d) unpredictability of disease exacerbation (Dudley-Brown, 2002). Therefore, uncertainty is often central to a person's experience of IBD. In fact, research suggests that unpredictability and uncertainty of symptoms is one of the main concerns of individuals living with CD and UC (Carlsson, Bosaeus, \& Nordgren, 2003; Casati, Toner, De Rooy, Drossman, \& Maunder, 2000; de Rooy et al., 2001; Dudley-Brown, 1996).

As explained earlier, most, if not all, people living with IBD will not be able to discover the cause for their illness (Tomich \& Helgeson, 2002). IBD patients may experience uncertainty in trying to manage a condition that may become acute at an uncertain future time (Coward, 1997). The clinical course of IBD is variable both within and among patients (Dudley-Brown, 1996). Both CD and UC are characterized by recurrent attacks, or "flare-ups", interspersed among periods of little to no disease activity (i.e., remissions) (Thompson, 1993). Unfortunately, this cycle of relapse/remission is different for every individual and has been characterized as largely unpredictable.

Patients may also feel uncertain as to how the disease may affect their ability to work or support their family, who they should tell about their disease and when, whether or not they will need surgery, and if they can acquire and afford treatment and health insurance (Irvine, 2004). High levels of uncertainty have been shown to be the cause of stress and anxiety in patients with chronic illness (Warrington \& Gottlieb, 1987), with higher levels of uncertainty related to lower levels of illness adaptation (Wineman, 1990). In studies conducted with individuals with multiple sclerosis, a degenerative neurological disease, researchers found that the greater the uncertainty, the higher the likelihood of 
interpreting the effects of the illness as negatively affecting one's mood states regardless of the level of functional capacity (Wineman, O'Brien, Nealon, \& Kaskel, 1993).

Feelings of helplessness and lack of control associated with uncertainty may contribute to the prevalence of anxiety and depression among those living with IBD (Addolorato et al., 1997; Walker et al., 2008). The task for these people is to live with uncertainty while at the same time doing all that is possible to promote one's health.

Violation of global beliefs and goals

Although both $\mathrm{CD}$ and $\mathrm{UC}$ may occur in people of all ages, $\mathrm{CD}$ affects mainly those aged 15 to 35, while UC most commonly strikes those in their mid-30s (CCFA, 2009a, "About Crohn's Disease"). People at this age tend to have a sense of invulnerability and safety from major illness. In other words, young people generally take their good health for granted; chronic illness does not fit into their realm of possibilities (Fleer, Hoekstra, Sleijfer, Tuinman, Hoekstra-Weebers, 2006).

People with IBD may question previously held beliefs about the benevolence of the world, the extent to which they deserve to have the disease, and the extent to which they are able to control negative events in general (Janoff-Bulman, 1989). The task of the person diagnosed with IBD is to incorporate the diagnosis - and all that comes with itinto existing beliefs and goals (global meaning). He or she may either rework the diagnosis to make it fit global meaning or revise beliefs to better match the illness experience. Revising principles upon which we have interpreted the past is a far more formidable task than conforming present events to existing principles, or beliefs. Therefore, appraised meanings of an event (i.e., chronic illness) are likely to change as a person engages in the coping process and actively struggles to arrive at a meaning that is 
not devastating to his or her self-perception and world view. Arguably, this process can be complicated by the experience of a disease with no known cause or cure and a characteristically unpredictable pattern of relapse and remission.

Moreover, these two diseases tend to strike during the most economically and socially productive years of life. Important decisions are being made concerning relationships, starting a family, and establishing a career (Dudley-Brown, 1996; Fleer et al., 2006). Individuals living with IBD, therefore, often experience disruption of salient goals. The manifestations of IBD are often severe and affect multiple aspects of a person's life, including work, family, and social functioning.

The physical and emotional challenges associated with IBD can greatly impact a person's professional life (Cohen, 2003; Mallett, Lennard-Jones, Bingley, \& Gilon, 1978). In a prospective study conducted by the University of Chicago (as cited in Moyer, $2006)$, nearly two thirds of respondents (65\%) reported their work productivity, work attendance, choice of profession, or location of their profession had been compromised by IBD. The same study found that women had significantly lower quality of life scores than men $(p=.006)$. Additionally, women living with IBD were more likely to be on disability and to require assistance with childcare and basic household activities.

Episodic or chronic disease activity may result in absenteeism from work; many patients report a significant loss of days at work because of the need to be near or in a bathroom most of the day (Dudley-Brown, 1996). The inability to work has been associated with greater interpersonal and body image concerns and greater physical impact concerns, even when controlling for the level of symptom severity (de Rooy et al., 2001). Worries concerning finances and being a burden to others are greater among those 
who are not currently working (de Rooy et al., 2001). Research has shown this to be a more common concern among men than women (Levenstein, Li, \& Drossman, 1998).

Changes in work practices are common, with a number of patients having to cease working completely due to their illness. However, results are mixed concerning unemployment and disability rates among IBD patients. Although some studies report no differences in these rates between IBD patients and the general population (Mayberry, Probert, Srivastava, Rhodes, \& Mayberry, 1992), others report rates significantly higher (Bernklev et al., 2006). Inability to work can lead to a significant reduction or the complete loss of income. One dated study showed $21 \%$ of adult patients reporting reduced earning capacity due solely to their IBD (Mallet et al., 1978). This loss coupled with high medical costs, costly (or no) insurance coverage, and frequent utilization of healthcare can create significant financial strain for those living with IBD, as well as their families. The degree of healthcare resource use among individuals living with IBD tends to be quite high. One study estimated the average annual direct cost of CD to be over $\$ 12,000$ in 1994 (Bodger, 2002). Longobardi and Bernstein (2007) compared 5,485 cases of CD and UC with 45,279 matched controls and found that utilization of outpatient services was twice as high for IBD cases regardless of whether or not the contact was made for IBD-specific reasons. Additionally, their results suggested that within the first 2 years of their diagnosis, IBD patients exhibit a greater amount of surgical visits, outpatient visits with an internist, and overnight hospitalizations than controls at any other time.

Issues such as being close to toilets and feelings of embarrassment may be so pervasive that social functioning is also impaired. Patients may fear incontinence and 
restrict their activities either necessarily or unnecessarily. There have been mixed results concerning the level of functional impairment among patients with IBD. Although some studies have shown social functioning to be impaired in those living with IBD, other studies suggest that social functioning is less commonly affected (Casellas, LópezVivancos, Badia, Vilaseca, \& Malagelada, 2001; Mitchell, Guyatt, Singer, \& Irvine, 1988). The social disability of IBD may be underestimated by researchers and healthcare professionals because it does not always correlate with disease activity or severity (Mallet et al., 1978).

Sexual health is not frequently addressed by researchers or healthcare professionals but is very commonly affected by IBD (Gazzard, Price, Libby, \& Dawson, 1978; Moody, Probert, Jayanthi, \& Mayberry, 1992; Timmer, Bauer, Dignass, \& Rogler, 2007). Sexual health may be impacted by painful symptoms, fatigue, or lowered libido. Individuals often experience lowered libido as a side effect of the medications used to treat IBD. Despite the possibility of lowered libido and fears of incontinence, diarrhea, and abdominal pain, studies have shown there to be no difference in frequency of sexual activity between IBD patients and control subjects (Moody \& Mayberry, 1993). However, research does show that IBD patients frequently experience co-morbid conditions that adversely impact their sex lives. Dyspareunia (i.e., painful intercourse), for example, was reported by $60 \%$ of women with CD (Moody et al., 1992). Depression is also considered to be an important determinant of low sexual functioning (Timmer et al., 2007).

Sexual relationships can also be impacted because of disturbances in body image. Body image is made up of the expectations of how the body should look and function, 
feelings about the body, and perceptions of how others think about or react to the body (McHugh, 1998). Adverse impact on body image has been reported by numerous samples of IBD patients (Casati et al., 2000; Hall, Rubin, Dougall, Hungin, \& Neely, 2005; Joachim \& Milne, 1985). Body image may be altered not only through the effects of the disease itself but also its treatment, which includes surgery and medications. Any surgery that changes the body, either in function or appearance, can have important effects beyond the actual physical changes (McHugh, 1998). A person may have bodily scars or the presence of an ostomy (external pouch) - - both of which can lead to feelings of embarrassment, seeing oneself as "flawed" or otherwise "not normal", and problems with intimacy. In fact, one study found intimacy to be the number one disease-related concern among patients with an ileostomy (Carlsson et al., 2003). People often have difficulty adjusting to the changes in their bodies or are unable to grieve the loss of their ideal or desired body.

\section{Significance of the Present Study}

Prior to the 1960 s, IBD was considered to be one of the seven classic psychosomatic illnesses (Engel, 1955; North, Clouse, Sptznagel, \& Alperes, 1990; Sperling, 1960); therefore, research tended to focus only on the psychodynamics and personality types of those with IBD (Murray, 1984). By the late 1960s, however, advances in research determined that IBD had biological origins. When the view of IBD etiology changed from psychological variables to physiological variables, there was a definitive shift in research investigations (Levenstein, 2004). Grounded in the medical model, research began to focus on physiological and immunological explanations and treatments (Kurina, Goldacre, Yeates, \& Gill, 2001; Murray, 1984; Steiner-Grossman, 
Banks, \& Present, 1992). Unfortunately, as a result of this shift, psychological factors associated with IBD were largely ignored by researchers until the past decade or so (Pollin, 1995).

Research has shown that people living with chronic illness frequently develop problems with depression and anxiety due to the pain, physical changes, loss of personal control, and uncertainty about the future (Addolorato et al., 1997; Pollin, 1995; Roberts, Kiselica, \& Fredrickson, 2002; Steiner-Grossman et al., 1992). IBD is no exception to this finding. In fact, the percentage of individuals with high levels of state anxiety and depression was significantly higher in $\mathrm{CD} / \mathrm{UC}$ groups than in controls $(p<.001)$ (Addolorato et al., 1997). In general, psychological distress (e.g., depression, anxiety, somatization) is a significant issue for many people with IBD. Decades of research support the idea that the relationship between psychological distress and IBD activity is self-perpetuating and mutually reinforcing (Dudley-Brown, 2001; Schwarz \& Blanchard, 1991). That is, stress leads to active disease, or exacerbation, which in turn provokes increased stress within the individual. This provides evidence for the influence of psychological factors in the course of IBD. Although prevention of IBD is not possible, the prevention of psychological distress or stress is both possible and desirable for improving the quality of life for IBD patients. One way this prevention could be accomplished is by addressing meaning-related issues of the illness experience and by helping patients regain a sense of equilibrium in their lives. Despite the relevance of meaning in the coping processes of people with IBD, no studies have been conducted examining this issue. Knowledge regarding meaning and its impact on functioning may 
also help health care providers to identify those patients who might benefit from an intervention based on meaning making processes (Fleer et al., 2006).

Additionally, given the central role that meaning making seems to have in the adjustment to highly stressful events, such as chronic illness, more research is needed to clearly delineate the tenets of a widely-proposed model of meaning making coping (Park \& Folkman, 1997). The current study is a partial test of the meaning making model of coping in that only certain paths were analyzed (See Figure 2). Specifically, the paths being tested are: (a) path between the stressor (IBD) and reported level of discrepancy (beliefs and goals violation); (b) path between discrepancy and distress; (c) path between distress and meaning making coping; and (d) path between meaning making coping and stress-related growth. It is the author's hope that the results of this study will advance the knowledge of meaning making in the context of coping with a chronic, relapse-remitting illness, such as IBD.

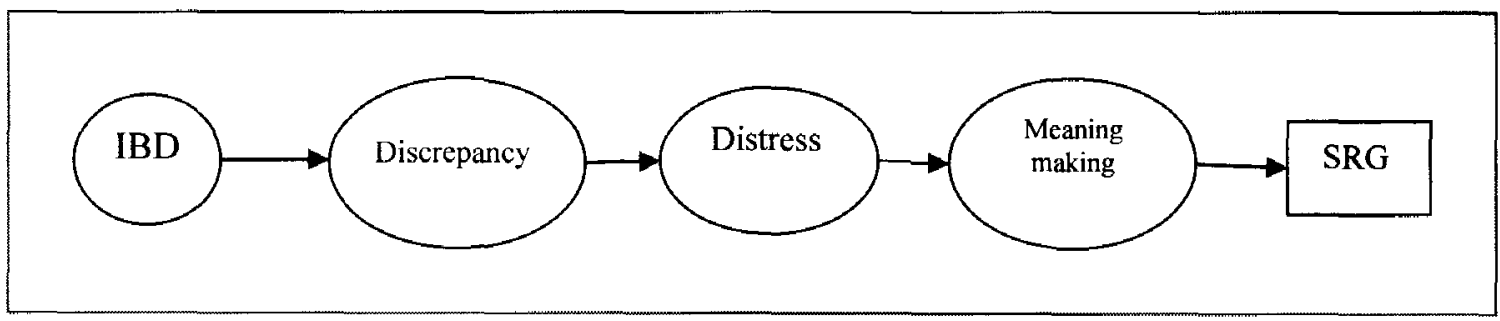

Figure 3. Simple schematic of the meaning making model of coping adapted for testing in current study (adapted from Park, 2008) 


\section{CHAPTER 2}

\section{METHODS}

Hypotheses

Research Question 1: Are there sociodemographic variables that predict meaning making in individuals diagnosed with IBD?

H1a. After controlling for the effects of time since diagnosis, age will be negatively associated with meaning making.

H1b. Females will exhibit greater levels of meaning making than males.

H1c. Level of education will not be associated with meaning making.

Research Question 2: Are there sociodemographic variables that predict stress-related growth (SRG) in individuals diagnosed with IBD?

H2a. After controlling for the effects of time since diagnosis, age will be negatively associated with SRG.

H2b. Females will report greater levels of SRG.

H2c. Level of education will not be related to SRG.

Research Question 3: Does the meaning making model of coping (Park \& Folkman, 1997) apply to individuals with IBD?

H3a. Individuals with IBD will experience a discrepancy in their beliefs and goals.

H3b. When individuals with IBD experience a discrepancy in their beliefs and goals, they will be distressed. 
H3c. Individuals with IBD who are distressed will then engage in meaning making behavior.

H3d. Individuals with IBD who engage in meaning making behavior will experience growth.

$$
\text { Sample }
$$

\section{Population}

All participants in this study were people who have been diagnosed with IBD either Crohn's Disease or Ulcerative Colitis - by a medical physician as determined through self-report. The population of interest was limited to persons who were at least 18-years old.

\section{Sampling Methods}

A purposive sampling method was used for this design as the target population was chosen based on specific variables under consideration-diagnosis of IBD. Purposive sampling is a type of nonprobability sampling in which the selection of the sample is based on the judgment of the researcher as to which subjects best fits the criteria of the study (Trochim, 2006). It is often used when collecting exploratory data from an "unusual", or highly unique, population (Tashakkori \& Teddlie, 1998). Because the experience of both Crohn's Disease and Ulcerative Colitis can vary so much from person to person, the goal was to obtain a heterogeneous sampling of IBD patients. This sampling technique is well-suited based on the current research questions and available resources. Although it restricts the sample to a very specific population, it makes use of all available subjects. 
Due to the self-selective nature by which people will choose to participate, or not participate, in this study, the participants will also represent an overall convenience sample. The diagnosis of IBD was not independently verified. In another study of IBD patients, accuracy of self-report compared with diagnosis using x-ray, pathology, or endoscopy was $98 \%$ (Baird, Narendranathan, \& Sandler, 1990). Participants were recruited through online support groups and message boards for individuals diagnosed with IBD. These forums were found in two ways: (1) through the "Search Groups" function on social networking sites, MySpace.com and Facebook.com, and (2) through a keyword search on Google. On MySpace and Facebook, the terms "Crohn's Disease", "Ulcerative Colitis" and "IBD" were used in the search. On Google, the same terms were used in conjunction with "support group" and "message board". Groups and message boards were not selected for solicitation if it had been more than a month since the date of the board's last post or if its membership was listed as "private."

Based on the aforementioned exclusion/inclusion criteria, messages were posted in online support groups and message boards inviting members to participate in a study about coping with IBD. Due to the anonymous nature of these forums, it was not possible to determine how many people viewed these messages and decided not to participate. Within the message, support group/message board members were provided with a link to the research study hosted on SurveyMonkey.com. Here, they read the consent preamble (Appendix A), containing the purpose of the study, the length of time expected for participants to complete the online survey, and contact information in the case of questions, comments, or concerns. Prospective participants were told of the voluntary nature of the study and reminded that they can discontinue their participation at any time 
without negative consequences. They were also told that, upon completion of the online survey, they will have the option of entering a lottery drawing for the chance of winning one of two cash prizes in the amount of $\$ 50.00$. To enter the lottery drawing, participants had to enter their name, phone number or email address so that they could be contacted in the event that they won.

\section{Research Design}

This cross-sectional mixed-model design (Tashakkori \& Teddlie, 1998) has both qualitative and quantitative components applied throughout its various stages. Statistical and qualitative analysis and inference were utilized. Additionally, the model proposed by Park and Folkman (1997) allows for some tentative a priori hypotheses that are characteristic of a confirmatory investigation.

\section{Instruments}

\section{Demographics}

A sociodemographic information questionnaire was included in the survey packet (Appendix B). Sociodemographic information collected includes age, gender, education level, race/ethnicity, and employment status. Descriptive statistics will be presented for these variables, but only age, gender, and education level are the focus of research questions.

\section{Stressful Event (IBD) Information}

The meaning making model of coping begins with the experience of a potentially stressful event. The current study examines meaning making coping related to a homogenous stressor, IBD. Participants were asked several questions related to their diagnosis of IBD (Appendix B). For example, they were asked to specify which form of 
IBD they have and how long ago they were diagnosed. Additional information was collected on the number of hospitalizations and surgeries related to IBD. To obtain a measure of disease severity, participants were asked to rate various IBD-related symptoms. Three items were modified for use from the Harvey-Bradshaw Index (Harvey \& Bradshaw, 1980)--abdominal pain, general well-being, and number of loose stools. Abdominal pain was rated on a 5-point Likert scale from 1 (not at all severe) to 5 (very severe). General well-being was rated on a 5-point Likert scale from 1 (Very Good) to 5 (Very Poor). Respondents were asked to record the average number of loose stools they had per day in the last week and the number of incontinence episodes they experienced within the last week. In addition, participants were asked to rate their appetite on a 4point Likert scale from 1 (healthy) to 4 (very poor).

Violation of Beliefs and Goals (Discrepancy between appraised and global meaning) According to the meaning making model of coping (Park, 2005) when people encounter a potentially stressful event (e.g., IBD) they appraise the meaning of the event (i.e., "What does this mean? Why did this happen?"). They, then, determine the extent to which this appraised meaning violates, or is discrepant with, their global meaning system. The global meaning system includes one's global beliefs and goals. In order to measure perceived violation of beliefs and goals, items were adapted from the Stressful Event Appraisal Scale (Park \& Folkman, 2005; See Appendix B). Belief violation was assessed with 10 questions with the following stem, "To what extent does having IBD conflict with your..." The scale included items rating the violation of such beliefs as the world is fair and just, life is basically good, and things happen for a reason $(\alpha=.88)$. Participants rated violation of each belief from 1 (not at all) to 4 (very much); scale score ranges from 
10 to 40 . Goal violation was assessed by asking participants to rate how much IBD interferes with their ability to accomplish each of 11 different goals or desired states ( $\alpha=$ $.91)$. These included financial security, inner peace, and intimacy. Participants rated violation of each goal/state from 1 (not at all) to 4 (very much); scale score ranges from 11 to 44 .

Distress

According to Park and Folkman (1997), the extent to which one's beliefs and goals are violated determines the level of distress that an event causes. In other words, the greater the discrepancy between one's appraised meaning of IBD and one's beliefs and goals, the greater psychological distress a person experiences. The Impact of Events Scale (IES; Horowitz, Wilner, \& Alvarez, 1979) is a commonly used measure of distress and was selected for the present study. It consists of 15 items with two subscales. Each item was reworded to ensure that respondents focused on IBD-related thoughts and behaviors. Also, in the original scale, each item is rated in terms of frequency from 0 (not at all) to 4 (extremely). For the present study, the scaling was changed to 1 (not at all) to 5 (extremely) to accommodate the format of the web-based design. The Intrusive Thoughts subscale contains 7 items measuring the extent to which a respondent experiences unbidden thoughts, memories or images $(\alpha=.89)$; subscale scores may range from 7 to 35 . The Avoidance subscale contains 8 items measuring the extent to which a respondent attempts to avoid reminders of the stressful event or to dull their emotions related to it $(\alpha=.82)$; subscale scores may range from 8 to 40 . 


\section{Meaning Making Coping}

Meaning making is considered to be an attempt to alleviate the psychological distress that results from the violation of beliefs and goals. In this way, meaning making is an effort to bring global and situational (appraised) meaning into alignment (Park, 2008). Meaning making is a fairly new construct in psychological research; therefore, no validated instruments currently exist for its measurement. Numerous iterations of the construct also make it difficult to assess. Meaning making has not only been described as an automatic process involving intrusive, ruminative thinking, but also as a more deliberate cognitive process. Regardless, meaning making is understood as a process geared toward creating a more integrated understanding of a particular event or situation. For the purposes of this study, meaning making is conceptualized and measured as a deliberate process.

Deliberate meaning making efforts were assessed with the positive reinterpretation, religious coping, and emotional processing subscales of the Brief COPE (Carver, 1997). These subscales have been used as a measure of meaning making by other researchers (Folkman, 1997; Park, 2005; Park, 2008; Park et al., 2008). Participants were asked to rate the extent to which they used each of these coping activities in response to IBD from 1 (not at all) to 4 (a lot). Each subscale consisted of two items; therefore, the scores may range from 2 to 8 . Positive reinterpretation is a very common, and adaptive, coping response (Aldwin, 2006) that involves construing the situation in a positive way and identifying the benefits that may follow from a stressful encounter (Carver et al., 1989). The positive reinterpretation subscale consists of two items pertaining to attempts to see the stressful situation in a less distressing way (e.g., "I look 
for something good in what is happening") ( $\alpha=$.79). The religious coping subscale consists of two items relating to efforts to deal with one's disease through religion or faith (e.g., "I pray or meditate") $(\alpha=.90)$. The emotional processing subscale consists of two items pertaining to attempting to understand one's emotional reactions to the event (e.g., "I take time to figure out what I'm really feeling) $(\alpha=.81)$.

According to Park and Folkman (1997), meaning making is assumed to lead to changes in situational meaning, changes in global meaning, or both. Information regarding such possible changes was gathered from with the use of the following prompt:

"A stressful life event, such as the experience of IBD, can sometimes conflict with your beliefs about the world and/or goals you have. Take a minute to reflect on any conflicts or contradictions you might have noticed between what your IBD has meant to you and your beliefs about the world, as well as any goals you had. In what ways, if any, have you changed how you see your IBD? Have you changed your goals? Have you changed how you see the world?"

Qualitative coding techniques were used to categorize participants' responses in terms of their meaning making efforts. The qualitative responses were evaluated to determine the ways in which individuals have made meaning from their experience of IBD. Specifically, each open-ended response was reviewed and coded for evidence of no reported change in either situation or global meaning, changes in situational meaning, changes in global meaning (beliefs and/or goals), or changes in both situational and global meaning. All of the participants' responses were evaluated by the lead investigator. Check-coding (Miles \& Huberman, 1994) was used with a random sampling of 10 responses being reviewed by a psychology graduate student. Initially, an intercoder reliability of $70 \%$ was obtained using the formula (Miles \& Huberman):

$$
\text { Reliability }=\frac{\text { number of agreements }}{\text { total number of agreements }+ \text { disagreements }}
$$


Discrepancies were resolved through discussion between the lead investigator and graduate student volunteer. A second round of check-coding was completed using 10 randomly chosen responses and resulted in an intercoder reliability of $80 \%$ was obtained.

\section{Stress-Related Growth}

Stress-related growth was measured with the Stress-Related Growth Scale - short form (SRGS-sf, Park et al., 1996)]. The SRGS-sf was selected as a specific measure of adjustment, and it asks participants to evaluate 15 positive changes that they may have experienced as a result of their IBD (e.g., "I have learned to find more meaning in life", "I have learned to be nicer to others"). In the original scale, each item is rated from 0 (not at all) to 2 (a great deal). For the present study, the scaling was changed to 1 (not at all) to 3 (a great deal) to accommodate the format of the web-based design $(\alpha=.91)$. Scale scores may range from 15 to 45 .

\section{Statistical Analyses}

Descriptive statistics were used to summarize the socio-demographic, diseaserelated and key model variables (i.e., discrepancy, distress, meaning making, stressrelated growth). The hypotheses associated with Research Question 1 (associations between sociodemographic or disease-related variables and meaning making) were tested using multiple linear regression and Spearman Rho correlation procedures. The hypotheses associated with Research Question 2 (the association between sociodemographic variables and stress-related growth) were also tested using multiple linear regression and Spearman Rho correlation procedures. The hypotheses associated 
with Research Question 3 (the meaning making model of coping) were tested using structural equation modeling. Data analysis was conducted with the Statistical Package for the Social Sciences (SPSS) version 17.0 (SPSS, Inc. Chicago, IL) and Analysis of Moment Structures (AMOS) version 17.0 (Arbuckle, 2006).

Structural equation modeling (SEM) is an a priori method, driven by the hypothesized relationships in a given set of data. Simultaneous analysis of the entire model determines the extent of compatibility of the model with the data. It was selected as the statistical methodology for the current study because of its advantages over regression modeling, including its more flexible assumptions (particularly allowing interpretation even in the face of multicollinearity), use of confirmatory factor analysis to reduce measurement error by having multiple indicators per latent variable, better model visualization through its graphical modeling interface, the desirability of testing models overall rather than coefficients individually, the ability to test models with multiple dependent variables, and the desirability of its strategy of comparing alternative models to assess relative model fit (Gordon, 2008).

SEM consists of two main parts: the measurement or confirmatory model, which represents a set of $p$ observed variables as indicators of a smaller set of latent variables, and the path model, which depicts relations of dependency between latent variables (McDonald \& Ho, 2002). Latent variable SEM combines a confirmatory factor analysis (CFA) of the constructs involved in the research study and a path analysis of the relationships among the constructs. This two-step approach has been recommended by Anderson and Gerbing (1988) because it allows the researcher to evaluate the factor loadings and measurement errors of observed variables and distinguish problems of 
imprecise measurement from problems related to misspecification of the theoretical model (Musil, Jones, \& Warner, 1998). A good-fitting confirmatory model should precede specification of the structural model.

In SEM with latent variables, error variances (denoted by ' $\mathrm{e}$ ') represent the measurement error for all observed variables. Disturbances (denoted by ' $D$ ') represent variances due to all other influences on the latent variables other than those shown in the model (Keith, 2005). Because latent variables have no set scale, one of the factor loadings of each latent variable is set to a value of 1.00 . In effect, this sets the scale of the latent variable to match the scale of that particular indicator. Likewise, the scale for each error variance is set to the scale of its corresponding variable by setting the path to a value of 1.00 (Phillips \& Stuifbergen, 2009).

In order to test how well the data from the current study fit the proposed theoretical model for meaning making, analyses with the maximum likelihood method were performed using AMOS 17.0. SEM programs, such as AMOS, derive fit statistics from comparisons between the actual correlation matrix and the implied correlation matrix (which is created by using the solved path model based on the actual correlation matrix). The $\chi^{2}$ goodness-of-fit test statistic determines if the actual and implied matrices are statistically different from one another (Keith, 2005). Therefore, the researcher hopes for a non-significant $\chi^{2}$ as that indicates that the model and the data are consistent with each other. The $\chi^{2}$ statistic is influenced by sample size. Specifically very large samples may result in a statistically significant $\chi^{2}$. Therefore, it has been recommended that additional goodness-of-fit statistics be utilized that are less sensitive to sample size (Boomsma, 2000). In the current study $\chi^{2}$ was complemented by $\chi^{2} /$ degrees of freedom 
ratio. Statistically non-significant values of $\chi^{2}$ and values of $\chi^{2} / \mathrm{df}$ that are close to 1 or smaller indicate a good fit of the model to the data.

The root mean square error of approximation (RMSEA; Steiger \& Lind, 1980) was calculated as a measure of the discrepancy between the empirical data and the implied model (Kline, 2005). A RMSEA value $<.06$ conventionally indicates good model fit (Hu \& Bentler, 1999) with a value of 0 indicating a perfect fit. RMSEA values ranging from .06 to .10 indicate mediocre fit and those greater than .10 indicate poor fit (Byrne, 2001). Additional relative indices were included to compare the fit of the existing model with that of the independence model (null model) which assumes that all variables are uncorrelated (Kline, 2005). Three such indices are the normed fit index (NFI; Bentler \& Bonett, 1980), incremental index of fit (IFI; Bollen, 1989) and comparative fit index (CFI; Bentler, 1990). While a full explanation of these indices and their limitations is beyond the scope of this article, a short description is relevant. NFI, IFI, and CFI values greater than .90 indicate acceptable model fit while values greater than .95 are good/excellent (Hu \& Bentler, 1999).

In addition to evaluating the model as a whole, the fit of the individual parameters was assessed. The magnitude and direction of the standardized path coefficients were checked to see if they were consistent with the hypotheses. The statistical significance ( $p$ $<.05$ ) of each of the parameters was assessed and reported (Byrne, 2001). Reporting SEM results varies widely among researchers, but standard reporting conventions developed by the American Psychological Association (2001) and by McDonald and Ho (2002) have been followed here. 


\section{CHAPTER 3}

\section{RESULTS}

Included in this section are the demographic descriptions of the sample, statistical descriptions of each variable, and statistical analyses for each of the research questions and respective hypotheses.

\section{Descriptive Statistics}

\section{Sociodemographic Variables}

There were a total of 229 participants in the sample. The mean age of the sample was 28.83 years $(\mathrm{SD}=8.65)$. A frequency distribution for age can be viewed in Figure 4 . There was sufficient diversity in age, which ranged from 18 to 60 years of age. Crohn's Disease (CD) typically affects those aged $15-35$, while Ulcerative Colitis (UC) tends to strike those in their mid-30's (Crohn's and Colitis Foundation of America [CCFA], 2009, "How common is IBD?"; 2008, "How common is IBD and Ulcerative Colitis"). In the current sample, however, there was no significant difference in the mean age of each disease group. The mean age of those with Crohn's Disease was $28.76(\mathrm{SD}=8.88)$; the mean age of those with Ulcerative Colitis was 29.13 ( $\mathrm{SD}=7.93$ ), just slightly below the usual age of onset. The current sample was generally younger than those obtained by other IBD studies as well (Casellas et al., 2001; Larsson et al., 2008; Sewitch et al., 2001). This is likely related to the fact that data were collected via the Internet. Studies have confirmed that younger people (18 to 44 year olds) account for the majority (53\%) of the total number of Internet users (Jones \& Fox, 2009). 


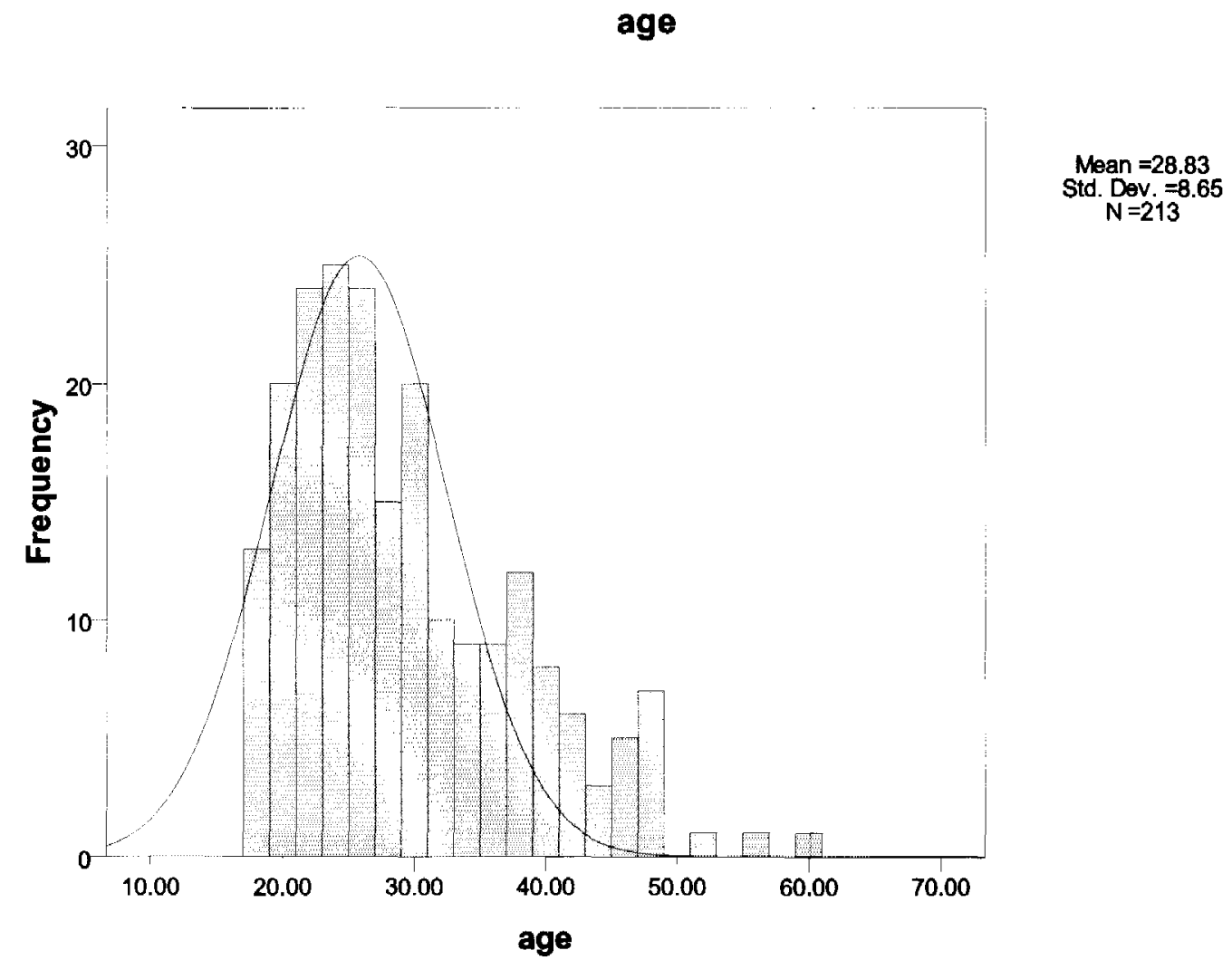

Figure 4. Frequency distribution for age (in years).

Frequencies and percentages for gender and education level are displayed below in Table 1 . The female to male ratio was nearly three to one $(69.4 \%$ and $24.9 \%$, respectively); however, in the general IBD population, males and females are affected equally. Keeping in mind that participants in the current sample were recruited from online support group, obtaining a sample than is primarily female may be due to gender differences in coping. Specifically, research has shown women are more likely to seek social support than are men (Miller \& Kirsch, 1987). Gender differences may also play a role in terms of females being more likely to participate in a research study. Other IBD 
studies report samples that are predominantly female (Sewitch et al., 2001; Smolen \& Topp, 1998).

Table 1

Frequencies and Percentages for Gender and Education Level $(N=229)$

\begin{tabular}{lcc}
\hline \multicolumn{1}{c}{ Variable } & Frequency & Percentage \\
\hline Gender & 161 & 70.3 \\
Female & 61 & 26.6 \\
Male & 11 & \\
Education Level & 25 & 4.8 \\
Some H.S. & 76 & 10.9 \\
H.S. Diploma/GED & 34 & 33.2 \\
Some college & 44 & 13.1 \\
Technical/Associates Degree & 15 & 19.2 \\
Bachelor's Degree & 19 & 6.6 \\
Some Graduate School & 7 & 3.1 \\
Master's Degree & & 8.3 \\
Doctorate & General Education Degree \\
\hline Note. H.S. = High School; GED & &
\end{tabular}

The U.S. Census Bureau (2000) reports that $24.4 \%$ of the population has a bachelor's degree or higher. In the current sample, $37 \%$ of the participants reported at least a bachelor's degree. Again, this is likely reflective of the Internet-based data collection procedure. Research studies have reported greater levels of awareness about the Internet among those with higher educational status (Kommalage, 2009). 
Additionally, a survey conducted by the Pew Internet \& American Life Project (2008) found that $95 \%$ of people who have a college education use the Internet as opposed to $35 \%$ of people with less than a high school education.

Data was also collected on race/ethnicity and employment status. Frequencies and percentages for race/ethnicity are displayed in Table 2.

Table 2

Frequencies and Percentages for Race/Ethnicity

\begin{tabular}{lcc}
\hline \multicolumn{1}{c}{ Variable } & Frequency & Percentage \\
\hline Race/Ethnicity & 199 & 86.9 \\
Caucasian & 13 & 5.7 \\
European & 4 & 1.7 \\
African-American & 1 & .4 \\
South Asian & 2 & .9 \\
Middle Eastern & 2 & .9 \\
Hispanic-American & 1 & .4 \\
Central/South American & 1 & .4 \\
Native American & 3 & 1.3 \\
Other & & \\
\hline
\end{tabular}

The sample was predominantly white $(92.6 \%)$. A large representation of whites is not uncommon in IBD research as IBD has traditionally been seen as a disease mainly affecting this group of individuals (prevalence rate of 149 per 100,000). There has been a steady increase in reported cases for both forms of IBD among African Americans. The prevalence rates among Hispanics and Asians are lower than those for both whites and 
African Americans. Even more striking is the fact that American Jews of European descent are four to five times more likely to develop IBD than the general population (CCFA, 2009c, "Race and Ethnicity"). Participants in the current study self-identified their race/ethnicity and it is not known under which category Jewish individuals placed themselves. Although research suggests that IBD affects certain ethnic groups more than others, this issue was not analyzed in the current study due to the lack of representation from various racial/ethnicity categories. This lack of diversity also prohibited the comparison of key constructs (e.g., meaning making, stress-related growth) across racial/ethnic groups.

A plurality of the sample (41.7\%) was employed full-time; while $53(23.8 \%)$ were employed part-time. Notably, approximately $33 \%$ were unemployed or disabled. These numbers are slightly below those of some other IBD studies (Rhodes, 2006) and comparable to others (Larsson et al., 2008).

\section{IBD Variables}

Frequencies and percentages of the discrete IBD-related variables are displayed in Table 3. The means and standard deviations for the continuous IBD-related variables are displayed in Table 4. Duration of illness (i.e., time since diagnosis) ranged from one month to 312 months (26 years). The mean time since diagnosis for the current sample was 82.03 months, or 6.8 years. This length of time is consistent with those reported by other studies with IBD patients (de Rooy et al., 2001; Moreno-Jiménez, López Blanco, Rodríguez-Muñoz, \& Garrosa Hernández, 2007; Sewitch et al., 2001). A frequency distribution for time since diagnosis is displayed in Figure 5. 
The majority of the sample (71.7\%) was diagnosed with $\mathrm{CD}$, while $22.6 \%$ were diagnosed with UC. The ratio of CD to UC in the current sample is higher than that occurring in the general population; within the estimated 1 million Americans who have $\mathrm{IBD}$, the numbers are generally equally split between $\mathrm{CD}$ and $\mathrm{UC}$. Nevertheless, other studies have reported similar distributions (Smolen \& Top, 1998). The majority of the sample $(57.7 \%)$ reported that their disease was currently active; $38.8 \%$ reported their disease as currently in remission.

Table 3

Frequencies and Percentages for Discrete IBD Variables $(N=229)$

\begin{tabular}{lcc}
\hline \multicolumn{1}{c}{ Variable } & Frequency & Percentage \\
\hline Diagnosis & 172 & 77.5 \\
Crohn's Disease & 50 & 21.8 \\
Ulcerative Colitis & & \\
Disability & 38 & 17.0 \\
Disability income & 183 & 82.1 \\
No disability income & \\
\hline
\end{tabular}


Table 4

Means and Standard Deviations for Continuous IBD Variables

\begin{tabular}{lccc}
\hline \multicolumn{1}{c}{ Variable } & $\mathrm{N}$ & Mean & SD \\
\hline Time since diagnosis $^{\mathrm{a}}$ & 197 & 82.03 & 72.92 \\
Number of hospitalizations & 195 & 2.24 & 2.95 \\
Number of surgeries & 214 & 1.07 & 1.85 \\
Disease severity $^{\mathrm{b}}$ & 224 & 10.86 & 6.62
\end{tabular}

${ }^{\mathrm{a}}$ Time in months. ${ }^{\mathrm{b}}$ Disease severity minimum $=3$; higher numbers indicate worse symptomology.

Time since Diagnosis (mo.)

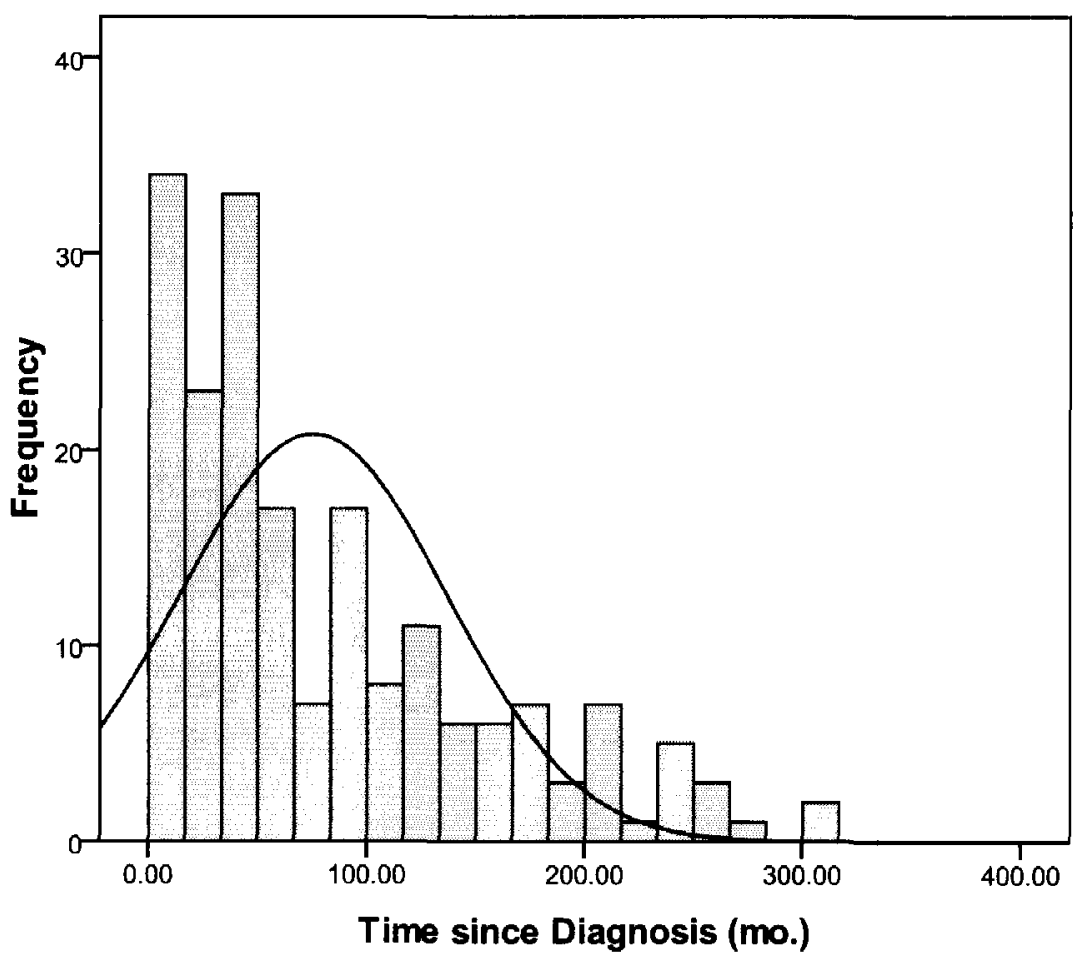

Mean $=82.03$

Std. Dev. $=72.922$

$N=191$

Figure 5. Frequency distribution for time since diagnosis (in months). 


\section{Discrepancy Variables}

Park and Folkman (1997) propose that meaning making occurs whenever people appraise an event in a way that it is discrepant with their global meaning, which includes both beliefs and goals. Discrepancy is a latent variable within the tested model that is made up of beliefs violation and goals violation (observed variables). The mean scale score for beliefs violation in this sample was $19.36(\mathrm{SD}=7.43)$. The mean item ratings

for this scale are displayed in Table 5. The mean scale score for goals violation was 27.55 $(\mathrm{SD}=8.55)$. The mean item ratings for this scale are displayed in Table 6 .

Table 5

Mean Item Ratings and Standard Deviations for Beliefs Violation

\begin{tabular}{lcc}
\hline \multicolumn{1}{c}{ Global Belief } & Mean & SD \\
\hline World as fair/just & 2.12 & .97 \\
Self in control & 2.76 & 1.00 \\
Others in control & 2.20 & .95 \\
God in control & 1.85 & 1.11 \\
Purposeful God & 1.85 & 1.13 \\
Loving/merciful God & 1.83 & 1.12 \\
Angry/vengeful God & 1.48 & .87 \\
Things happen for a reason & 2.05 & 1.09 \\
Understanding life & 2.08 & 1.00 \\
Life is basically good & 2.16 & 1.01 \\
\hline
\end{tabular}

Note. Range is 1 to 4. 
Table 6

Mean Item Ratings and Standard Deviations for Goals Violation

\begin{tabular}{lcc}
\hline \multicolumn{1}{c}{ Global Goal } & Mean & SD \\
\hline Companionship & 2.48 & 1.05 \\
Social Support and Community & 2.26 & 1.07 \\
Spirituality & 1.69 & .95 \\
Self-acceptance & 2.43 & 1.09 \\
Physical Health & 3.26 & .86 \\
Inner Peace & 2.57 & 1.07 \\
Financial Security & 2.70 & 1.18 \\
Career Achievement & 2.75 & 1.14 \\
Creative/Artistic Accomplishment & 2.12 & 1.15 \\
Athletic Accomplishment/Fitness & 2.94 & .96 \\
Intimacy & 2.62 & 1.09 \\
\hline Note. Rangeisin 4. & & \\
\hline
\end{tabular}

Note. Range is 1 to 4 .

Distress Variables

To the extent that beliefs and goals are discrepant with the appraised meaning of IBD, people will experience distress (Park, 2008; Tait \& Silver, 1989). This distress is seen as a motivator of change and a crucial part of the meaning making process. In the tested model, distress is a latent variable that consists of the observed variables of avoidance and intrusive thoughts. The mean subscale score for avoidance was 17.43 (SD 
$=6.53)$; range is 7 to 35 . The mean subscale score for intrusive thoughts was 17.21 ( $\mathrm{SD}=$ $7.20)$; range is 8 to 40 .

\section{Meaning Making Variables}

Meaning making in the tested model is a latent variable consisting of three measures of coping--positive reframing, religious coping, and emotional processing. The means and standard deviations of these meaning making subscales from the Brief COPE (Carver, 1997) are displayed in Table 7. Meaning making was also measured via qualitative data. Participants' responses to open-ended questions were reviewed for evidence of no change in either situational or global meaning (coded as ' 0 '), changes in situational meaning (' 1 '), changes in global meaning (either beliefs and/or goals; ' 2 '), or changes in both situational and global meaning (' 3 '). The frequencies and percentages for these reports of meaning making are displayed in Table 8.

Table 7

Mean and Standard Deviations for Meaning Making Coping Variables

\begin{tabular}{lccc}
\hline \multicolumn{1}{c}{ Variable } & $\mathrm{N}$ & Mean & $\mathrm{SD}$ \\
\hline Positive Reframing & 195 & 5.00 & 1.71 \\
Religious Coping & 193 & 4.41 & 2.17 \\
Emotional Processing & 193 & 5.05 & 1.38 \\
\hline
\end{tabular}

Note. Range is 2 to 8 . 
Table 8

Frequencies and Percentages for Coded Meaning Making Efforts $(N=134)$

\begin{tabular}{lcc}
\hline \multicolumn{1}{c}{ Reported Meaning Making } & Frequency & Percentage \\
\hline No change & 45 & 20.2 \\
Changed Situational Meaning & 21 & 9.4 \\
Changed Global Meaning & 57 & 25.6 \\
Changed Both & 11 & 4.9 \\
\hline
\end{tabular}

Stress-Related Growth

Self-reported levels of stress-related growth were measured by the Stress-Related Growth Scale--short form (SRGS-sf, Park et al., 1996). The mean score for the present sample was $33.26(\mathrm{SD}=7.74)$. The mean-item ratings for 15 -item SRGS-sf are presented in Table 9. 
Table 9

Mean Item Ratings and Standard Deviations for Stress-Related Growth (SRG)

\begin{tabular}{|c|c|c|}
\hline Area of SRG & Mean & $\mathrm{SD}$ \\
\hline Being nicer to others & 2.23 & .64 \\
\hline Being freer to make my own decisions & 1.99 & .79 \\
\hline Learning something of value & 2.32 & .73 \\
\hline Being myself & 2.34 & .73 \\
\hline Working through problems & 2.38 & .64 \\
\hline Finding more meaning in life & 2.32 & .74 \\
\hline Learning to reach out/help others & 2.25 & .75 \\
\hline Being a more confident person & 1.95 & .80 \\
\hline Listening more carefully to others & 2.17 & .71 \\
\hline Being open to new information/ideas & 2.32 & .70 \\
\hline Communicating more honestly & 2.26 & .70 \\
\hline Wanting to have an impact on the world & 2.21 & .78 \\
\hline Learning it's ok to ask for help & 2.22 & .67 \\
\hline Standing up for my personal rights & 2.35 & .73 \\
\hline Finding out that people care for me & 2.30 & .76 \\
\hline
\end{tabular}

Note. Range is 1 to 3 . 


\section{Research Question 1}

Are there sociodemographic variables that predict meaning making in individuals diagnosed with IBD?

Hypothesis la: After controlling for the effects of time since diagnosis, age will be negatively associated with meaning making.

Time since diagnosis was controlled for in order to isolate the relationship between age and meaning making coping. Theoretically, the longer a person lives with IBD the more likely he or she is to have made meaning, thereby reducing the use of meaning making coping. Additionally, it has been suggested that younger adults may have a greater need to make meaning out of their illness experience as a result of greater disruption (i.e., the violation of beliefs and goals)(Bower et al., 2005; Park et al., 2008; Vickberg, 2003). Controlling for time since diagnosis allows for a more clear examination of this suggestion. Multiple linear regression procedures were used to determine whether age was associated with meaning making, after controlling for the effects of time since diagnosis. Results of these procedures indicate that age was not significantly associated with positive reframing $(\beta=-.10, p=.29)$, religious coping $(\beta=$ $.15, p=.11)$, or emotional processing $(\beta=-.00, p=.99)$.

Hypothesis $1 b$ : Females will exhibit greater levels of meaning making than males.

The means and standard deviations for meaning making variables across gender groups are displayed in Table 10. Spearman Rho correlation procedures were conducted to assess the relationship between gender and the three indicators of meaning making. The findings suggest that gender was significantly related to emotional processing $(r=-$ $.18, p=.01)$ and religious coping $(r=-.21, p<.001)$. Females were coded as ' 1 ', and 
males were coded as ' 2 '; therefore negative coefficients represent the tendency for females to report higher levels of both emotional processing and religious coping. Gender was not significantly related to the use of positive reframing $(r=-.04, p=.43)$.

Table 10

Means and Standard Deviations for Meaning Making Variables across Genders

\begin{tabular}{ccccc}
\hline \multicolumn{1}{c}{ Variable } & \multicolumn{2}{c}{ Females } & Males \\
& Mean & SD & Mean & SD \\
\hline Positive Reframing & 5.04 & 1.66 & 4.88 & 1.54 \\
Religious Coping $^{* * *}$ & 4.69 & 2.16 & 3.72 & 2.06 \\
Emotional Processing $^{* *}$ & 5.21 & 1.29 & 4.67 & 1.54 \\
\hline
\end{tabular}

Note. Range is 2 to 8 .

${ }^{*} \mathrm{p}<.05 .{ }^{* *} \mathrm{p}<.01 .{ }^{* * *} \mathrm{p}<.001$

Hypothesis 1c: Level of education will not be associated with meaning making.

The means and standard deviations for meaning making variables for all education levels are displayed in Table 11. Spearman Rho procedures were conducted to assess the relationship between level of education and the three indicators of meaning making. The findings suggest that education was not significantly related to positive reframing $(r=-.02, p=.18)$, religious coping $(r=.07, p=.37)$, or emotional processing $(r=.10, p=.80)$. 
Table 11

Means and Standard Deviations of Meaning Making Coping Variables for All Education Levels $(N=188)$

\begin{tabular}{lcccccc}
\hline & \multicolumn{2}{c}{ Positive Reframing } & \multicolumn{2}{c}{ Religious Coping } & \multicolumn{2}{c}{ Emotional Processing } \\
\multicolumn{1}{c}{ Education Level } & Mean & SD & Mean & SD & Mean & SD \\
\hline Some H.S. & 4.38 & 1.19 & 3.25 & 1.83 & 4.63 & .92 \\
H.S. Diploma/GED & 5.11 & 1.59 & 4.42 & 2.29 & 5.16 & 1.12 \\
Some College & 4.93 & 1.83 & 4.35 & 2.19 & 5.19 & 1.33 \\
Associate's Degree & 5.04 & 1.45 & 5.22 & 2.26 & 5.00 & 1.36 \\
Bachelor's Degree & 4.85 & 1.68 & 4.06 & 1.98 & 5.00 & 1.41 \\
Some Graduate School & 5.67 & 1.78 & 3.92 & 1.93 & 4.58 & 1.31 \\
Master's Degree & 5.07 & 2.22 & 4.67 & 2.41 & 5.07 & 1.75 \\
Doctorate & 6.00 & 1.58 & 5.8 & 1.64 & 5.60 & 1.52 \\
\hline Note. H.S. = High School; GED = General Educational Development. Range is 2 to 8.
\end{tabular}

\section{Summary}

The preceding results provide only minimal support for the study's first set of hypotheses. Neither age nor education level were significant predictors of meaning making coping behaviors. Gender was the only sociodemographic variable that significantly predicted meaning making coping behavior. Specifically, females exhibited higher levels of both emotional processing and religious coping. 


\section{Research Question 2}

Are there sociodemographic variables that predict stress-related growth in individuals diagnosed with IBD?

Hypothesis 2a: After controlling for the effects of time since diagnosis, age will be negatively associated with SRG.

The effects of time since diagnosis were controlled for here for reasons similar to those related to meaning making. Specifically, younger adults may experience greater disruption (of beliefs and goals) as a result of their illness (Bower et al., 2005; Park et al., 2008; Vickberg, 2003) which increases the likelihood of their experiencing growth. Controlling for time since diagnosis allows for a clearer examination of the relationship between age and growth. Multiple linear regression procedures were conducted to determine whether age was correlated with stress-related growth, after controlling for the effects of time since diagnosis. The findings indicate that age was not significantly related to stress-related growth $(\beta=-.13, p=.18)$.

Hypothesis 2b: Females will report greater levels of SRG.

The mean level of SRG reported by females was $33.73(\mathrm{SD}=7.37)$; males reported a mean $\mathrm{SRG}$ level of $31.88(\mathrm{SD}=8.65)$. Spearman Rho correlation procedures were conducted to assess the relationship between gender and SRG. The findings suggest that gender was not significantly related to $\operatorname{SRG}(r=-.09, p=.25)$.

Hypothesis 2c: Level of education will not be related to SRG.

The means and standard deviations for stress-related growth across educational levels are presented in Table 12. A Spearman Rho correlation procedure was performed 
to assess the relationship between level of education and SRG. The findings suggest that level of education was not significantly related to stress-related growth $(r=.03, p=.76)$.

Table 12

Means and Standard Deviations of Stress-Related Growth for All Education Levels $(N=172)$

\begin{tabular}{lcc}
\hline \multicolumn{1}{c}{ Education Level } & Mean & SD \\
\hline Some H.S. & 31.57 & 8.02 \\
H.S. Diploma/GED & 30.81 & 9.99 \\
Some College & 33.67 & 7.73 \\
Associate's Degree & 35.17 & 7.34 \\
Bachelor's Degree & 32.16 & 5.44 \\
Some Graduate School & 33.75 & 7.16 \\
Master's Degree & 32.08 & 8.75 \\
Doctorate & 36.40 & 11.39 \\
\hline
\end{tabular}

Note. H.S. $=$ High School; GED $=$ General Educational

Development. Range is 15 to 45 .

Summary

The preceding results show no support for the study's second set of hypotheses. None of the sociodemographic variables (age, gender, education level) were predictive of perceived stress-related growth. 


\section{Research Question 3}

Does the meaning making model of coping apply to individuals with IBD?

Hypothesis $3 a$ : Individuals with IBD will experience a discrepancy in their beliefs and goals.

Hypothesis $3 b$ : When individuals with IBD experience a discrepancy in their beliefs and goals, they will be distressed.

Hypothesis $3 c$ : Individuals with IBD who are distressed will then engage in meaning making behavior.

Hypothesis 4c: Individuals with IBD who engage in meaning making behavior will experience growth.

Intercorrelations Between Indicator Variables

Bivariate correlations were calculated to examine intercorrelations among the indicator variables specified in the proposed measurement model; these values are presented in Table 13. Overall, there was a good deal of intercorrelations among the indicator variables for IBD (i.e., time since diagnosis, number of hospitalizations and surgeries, and disease severity). For example, time since diagnosis was significantly correlated with both number of hospitalizations $(r=.47, p<.01)$ and surgeries $(r=.39, p$ $<.01)$. This relationship is not surprising as the longer a person lives with IBD, the more likely he or she is to have been hospitalized or require surgery.

Also, disease severity had significant positive relationships with both measures of discrepancy (beliefs violation, $r=.18, p<.01$; goals violation, $r=.40, p<.01$ ), as well as both measures of distress (intrusive thoughts, $r=.30, p<.01$; avoidance, $r=.26, p<$ $.01)$. 
There were significant positive relationships between the discrepancy measures (beliefs and goals violations) and distress measures (intrusive thoughts and avoidance), a finding consistent with the assumptions of the meaning making model of coping (Park \& Folkman, 1997, Park, 2005). In contrast to the tenets of the meaning making model of coping, however, distress measures were not significantly correlated with any of the measured meaning making efforts. The two measures of distress (intrusive thoughts and avoidance) were significantly correlated with each other $(r=.50, p>.01)$.

The measured meaning making coping efforts were inconsistently related to one another. Positive reframing was significantly positively correlated with each of the meaning making coping (religious coping, $r=.34, p<.01$; emotional processing, $r=.29$, $p<.01$; coded meaning making, $r=.18, p<.05$ ). Religious coping was significantly correlated with emotional processing $(r=.15, p<.05)$ but not coded meaning making $(r$ $=-.03, p=.70$ ). Emotional processing was significantly correlated with coded meaning making $(r=.24, p<.01)$. Notably, all of the scaled meaning making coping efforts were significantly positively associated with stress-related growth (positive reframing, $r=.39$, $p<.01$; religious coping, $r=.30, p<.01$; emotional processing, $r=.28, p<.01$ ). 
Table 13

Intercorrelations Between Indicator Variables in the Proposed Measurement Model

\begin{tabular}{|c|c|c|c|c|c|c|c|c|c|c|c|c|c|}
\hline Variable & 1 & 2 & 3 & 4 & 5 & 6 & 7 & 8 & 9 & 10 & 11 & 12 & 13 \\
\hline $\begin{array}{l}\text { 1. Time since } \\
\text { Diagnosis }\end{array}$ & -- & $47^{k-k}$ & $39^{* * k}$ & .09 & -.02 & -.02 & -.11 & -.05 & 0.10 & 0.04 & -.09 & -.04 & 14 \\
\hline 2. No.hosp. & & -- & $.57 * *$ & $.15^{*}$ & -.01 & .08 & .03 & .02 & .02 & -.06 & .01 & -.18 & -.00 \\
\hline 3. No/surg. & & &.- & .08 & -.03 & -.03 & .02 & -.00 & -.02 & -.14 & -.04 & .07 & .00 \\
\hline $\begin{array}{l}\text { 4. Disease } \\
\text { Severity }\end{array}$ & & & & - & $.18^{* * *}$ & $40^{* * *}$ & $30 * *$ & $26^{* * *}$ & .03 & -.04 & .02 & .09 & .04 \\
\hline $\begin{array}{l}\text { 5. Belief } \\
\text { Violation }\end{array}$ & & & & & -- & $43^{* * *}$ & $28^{* * *}$ & $30^{* * *}$ & .04 & 12 & $.17^{*}$ & .14 & .07 \\
\hline $\begin{array}{l}\text { 6. Goal } \\
\text { Violation }\end{array}$ & & & & & & -- & $.60^{* * *}$ & $33^{* k}$ & -.13 & -.08 & .02 & .15 & -.05 \\
\hline $\begin{array}{l}\text { 7. Intrusive } \\
\text { Thoughts }\end{array}$ & & & & & & & -- & $.50^{* * *}$ & -.07 & .06 & .08 & .11 & -.00 \\
\hline 8. Avoidance & & & & & & & & -- & .10 & .02 & -.00 & -.06 & .02 \\
\hline $\begin{array}{l}\text { 9. Positive } \\
\text { Reframing }\end{array}$ & & & & & & & & & -- & $.34 * *$ & $29 * *$ & $.18^{*}$ & $39 * *$ \\
\hline $\begin{array}{l}\text { 10. Religious } \\
\text { Coping }\end{array}$ & & & & & & & & & & -- & $15^{*}$ & -.03 & $.30^{* *}$ \\
\hline $\begin{array}{l}\text { 11. Emotional } \\
\text { Processing }\end{array}$ & & & & & & & & & & & - & $24^{* *}$ & $28^{* * k}$ \\
\hline $\begin{array}{l}\text { 12. Meaning- } \\
\text { Making }\end{array}$ & & & & & & & & & & & & -- & .15 \\
\hline $\begin{array}{l}\text { 13. Stress- } \\
\text { related } \\
\text { growth }\end{array}$ & & & & & & & & & & & & & -- \\
\hline
\end{tabular}




\section{Confirmatory Factor Analysis}

The proposed measurement model and its parameters are shown in Figure 6. The model fit statistics and indices are summarized in Table 14. Results of the confirmatory factor analysis indicate that the model did not fit the data well. The ratio between $\chi^{2}$ (122.52) and the degrees of freedom (56) is $2.19(p=.000)$, suggesting that the hypothesis bearing on meaning making coping, as summarized in the model, represents an unlikely event and should be rejected.

Additionally, the values of the other goodness-of-fit indices did not reach acceptable levels (See Table 14). The NFI, IFI, and CFI values were all below .90. Further, the RMSEA was only mediocre.

Table 14

Chi-square Statistic and Goodness of Fit Indices for the Proposed Measurement Model

\begin{tabular}{lc}
\hline \multicolumn{1}{c}{ Index } & Proposed Model \\
\hline Chi-square $(\chi 2)$ & $122.52^{* *}$ \\
Degrees of Freedom (df) & 56 \\
Chi-square/df & 2.19 \\
Normative Fit Index (NFI) & 0.76 \\
Incremental Fit Index (IFI) & 0.86 \\
Comparative Fit Index (CFI) & 0.84 \\
Root Mean Squared Error (RMSEA) & 0.07 \\
\hline$* * \mathrm{p}<.001$.
\end{tabular}


Not all of the indicator variables loaded significantly onto their respective latent constructs. As in Kline (2005), a revised measurement model was tested and excluded the statistically non-significant indicator variables, Disease Severity and Meaning. Even after the deletion of these variables, their respective latent constructs had three indicator variables. The revised measurement model and its parameters are shown in Figure 7. The model fit statistics and indices are summarized in Table 15. Results of the confirmatory factor analysis indicate that the model did fit the data well. 


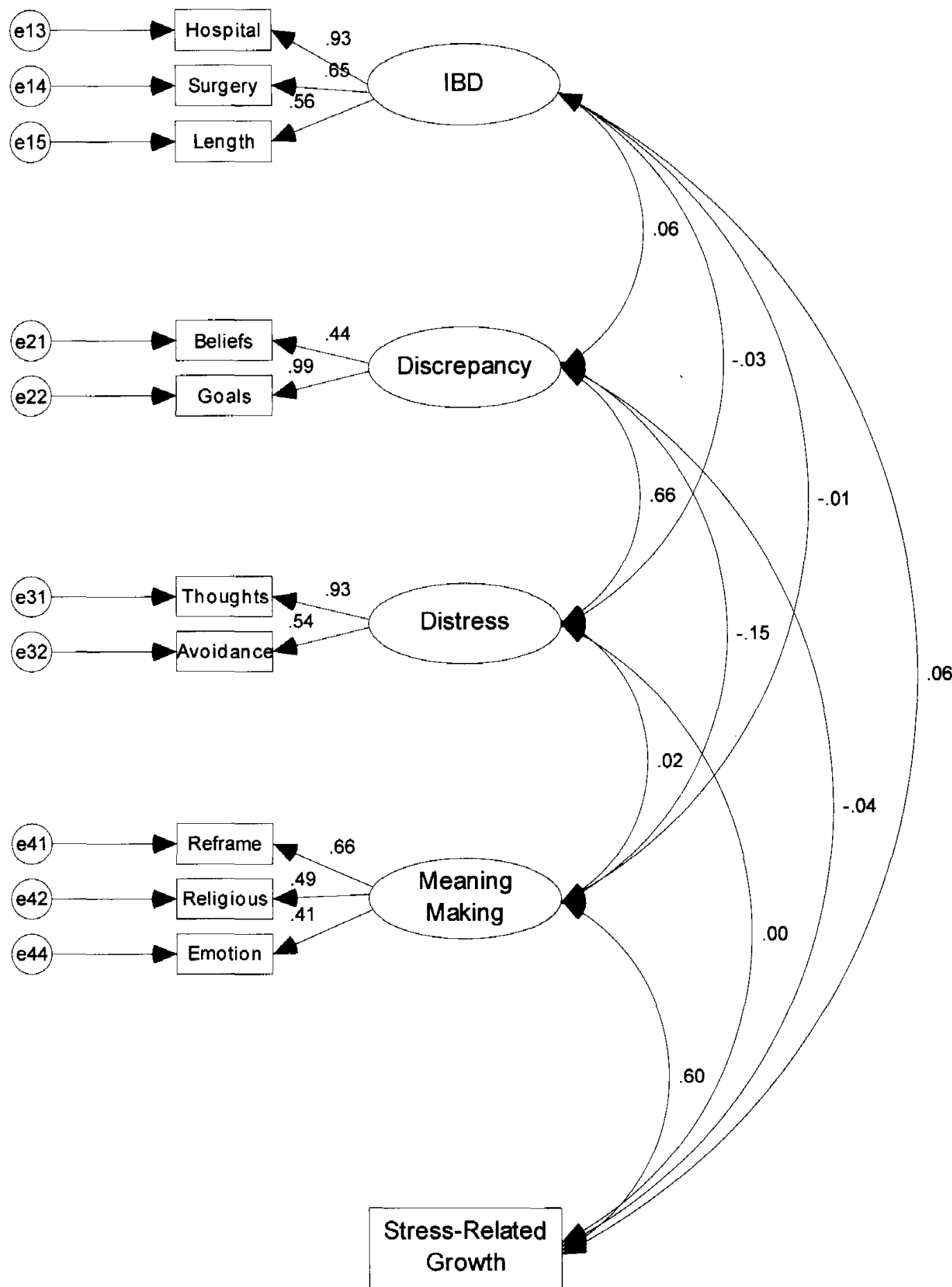

Figure 7. Revised measurement model for relationships between observed variables and latent constructs. 
Table 15

Chi-square Statistic and Goodness of Fit Indices for Revised Measurement Model

Index

Revised Model

Chi-square $\left(\chi^{2}\right)$

$56.31^{*}$

Degrees of Freedom (df)

Chi-square/df

Normative Fit Index (NFI)

0.87

Incremental Fit Index (IFI)

0.95

Comparative Fit Index (CFI)

0.95

Root Mean Squared Error (RMSEA)

0.05

$$
{ }^{*} \mathrm{p}<.05 \text {. }
$$

The values of the goodness-of-fit indices were acceptable. The ratio of the chisquare to the degrees of freedom was below 3 and the IFI and CFI values were above .90 . Only the IFI value was below .90. Further, the RMSEA was acceptable. As shown in Table 16, all the indicator variables significantly loaded onto their respective latent constructs.

The final model consisted of only significant paths and was, therefore, a more parsimonious model. Additionally, a chi-square difference test was conducted to compare the fit of the revised (final) model with the proposed (hypothesized) model. The change in chi-square was 66.21 (122.52 - 56.31); the change in df was 20 (56 - 36), indicating that the proposed model fits the data significantly worse than the revised model. 
Table 16

Maximum Likelihood Estimates for Indicator Variables in the Revised Measurement Model

Path

B

S.E.

Beta

C.R.

Sig.

IBD to:

Number of Hospitalizations

$1.00 \quad$ Fixed $\quad .93 \quad$ Fixed Fixed

Number of Surgeries

.07

.65

6.30

.00

Time Since Diagnosis

14.40

2.46

.56

5.85

.00

Discrepancy to:

Beliefs

Goals
.39

$1.00 \quad$ Fixed
.44

.99
6.86

.00

Fixed Fixed

Distress to:

Thoughts

Avoidance

Meaning Making to:

Positive Reframing

Religious Coping

Emotional Processing
$1.00 \quad$ Fixed .52
.93

.54

Fixed

.66

Fixed Fixed

.94

.21

.49

4.41

.000

.50

.13

.41

3.96

.00

Note. Paths of the indicator variable with the higher standardized loading were fixed at 1.00

As can be gleaned from Figure 7 and the findings in Table 17, not all of the correlations between constructs were statistically significant. IBD was not significantly correlated with any other latent constructs in the model (all $p$ 's $>.46$ ). Discrepancy was significantly positively correlated with Distress $(\mathrm{r}=.66, p<.01)$. Distress was not 
significantly correlated with any of the other latent constructs. Meaning making was significantly positively correlated with only Stress-Related Growth $(\mathrm{r}=.60, p<.01)$.

Table 17

Correlations between Constructs

$\begin{array}{llll}\text { Relationship } & \text { R } & \text { C.R. } & \text { Sig. }\end{array}$

IBD and:

Discrepancy

.06

.71

.48

Distress

$-.03$

$-.32$

.75

Meaning Making

$-.01$

$-.08$

.94

Stress-Related Growth

.06

.74

.46

Discrepancy and:

Distress

$.66^{* *}$

7.14

.00

Meaning Making

$-.15$

$-1.56$

.12

Stress-Related Growth

.02

$-.53$

.59

Distress and:

Meaning Making

.02

.22

.83

Stress-Related Growth

$-.00$

$-.02$

.99

Meaning Making and:

Stress-Related Growth

$.60^{* *}$

6.02

.00 
Structural Model

The proposed structural model and its parameters are shown in Figure 9. The model fit statistics and indices are summarized in Table 18. The findings indicate that the data fit the model well. The ratio of the chi-square to the degrees of freedom was below 3 and the IFI and CFI values were above .90 . Only the NFI value was below .90 . The RMSEA was acceptable at .05 . 


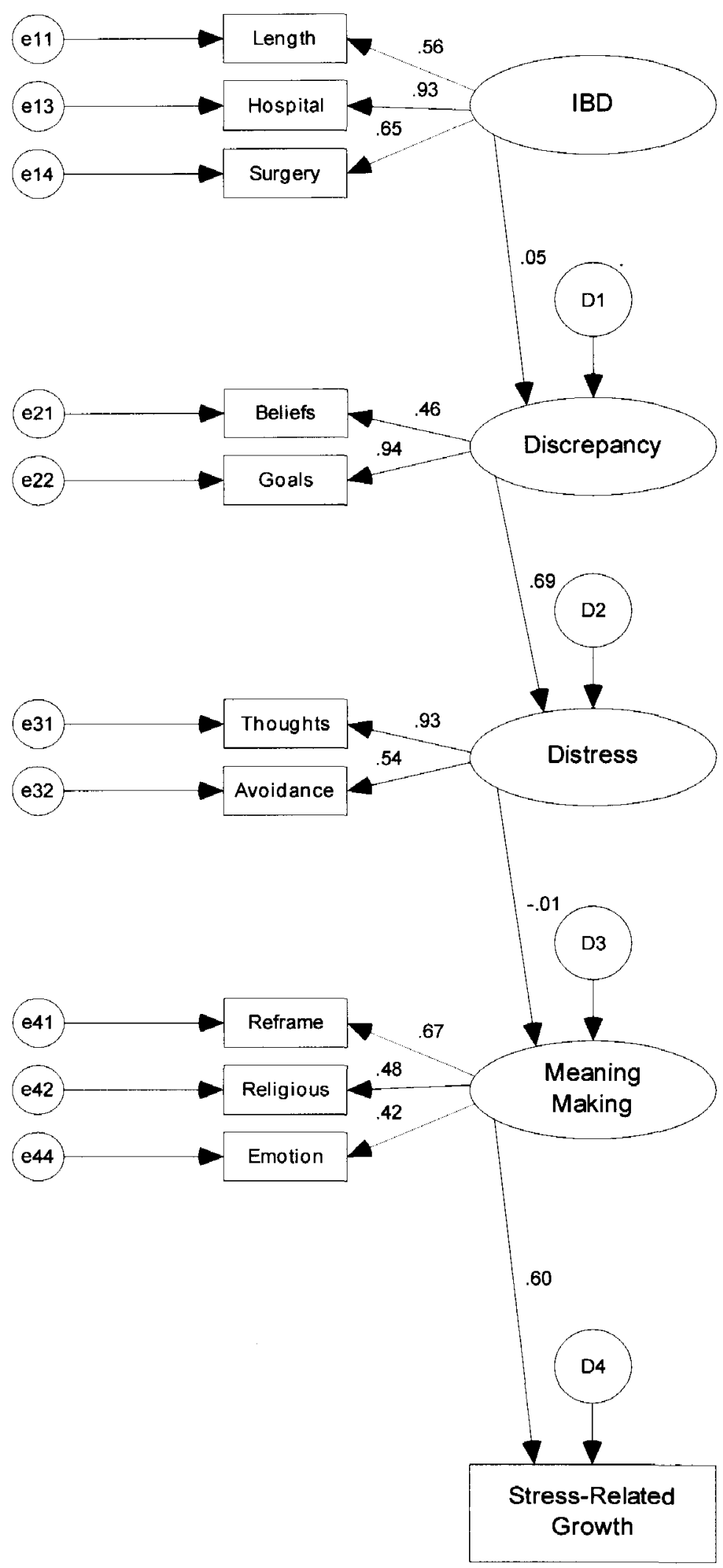

Figure 8. Structural Model 
Table 18

Chi-square Statistic and Goodness of Fit Indices for the Structural Model

\begin{tabular}{lc}
\hline \multicolumn{1}{c}{ Index } & Proposed Model \\
\hline Chi-square $(\chi 2)$ & $61.88^{*}$ \\
Degrees of Freedom (df) & 41 \\
Chi-square/df & 1.51 \\
Normative Fit Index (NFI) & 0.86 \\
Incremental Fit Index (IFI) & 0.95 \\
Comparative Fit Index (CFI) & 0.94 \\
Root Mean Squared Error (RMSEA) & 0.05 \\
\hline * $\mathrm{p}<.05$.
\end{tabular}

Not all the path coefficients were statistically significant, however, providing only partial support for the hypotheses generated from Research Question 3. The path coefficient between IBD and Discrepancy (Beta $=.052, p=.518$ ) was not statistically significant. Accordingly, Hypothesis 3a was not supported by the data. The path coefficient between Discrepancy and Distress $($ Beta $=.688, p<.001)$ was statistically significant. Thus, Hypothesis $3 b$ was supported by the data; the greater the discrepancy between global meaning (global beliefs and goals) and one's appraised meaning of IBD, the higher the distress. The path coefficient between Distress and Meaning Making, however, was also not statistically significant $($ Beta $=-.012, p=.904)$. Therefore, Hypothesis $3 \mathrm{c}$ was not supported by the data. The path coefficient between Meaning Making and Stress-Related Growth $($ Beta $=.598, p<.001)$ was statistically significant. 
Thus, Hypothesis $3 \mathrm{~d}$ was supported by the data; greater meaning making efforts from individuals with IBD predict higher levels of stress-related growth.

Table 19

Maximum Likelihood Estimates for Hypothesized Paths

\begin{tabular}{lccccc}
\hline \multicolumn{1}{c}{ Path } & B & S.E. & Beta & C.R. & Sig. \\
\hline IBD to Discrepancy & .15 & .23 & .05 & .65 & .52 \\
Discrepancy to Distress & -.58 & .12 & $.69 * *$ & 4.94 & .00 \\
Distress to Meaning Making & -.00 & .02 & -.01 & -.12 & .90 \\
Meaning Making to Stress-Related Growth & 4.00 & .90 & $.60 * *$ & 4.46 & .00 \\
\hline${ }^{*} \mathrm{p}<.05 .{ }^{*} \mathrm{p}<.01$. & & & & &
\end{tabular}

Summary

Confirmatory factor analysis was conducted to examine a proposed model of meaning making coping. All but two indicator variables (disease severity and coded meaning making) loaded significantly onto their respective latent constructs; however, the goodness of fit indices revealed that the proposed measurement model did not fit the data well. Models with fewer parameters are generally preferred in structural equation modeling; therefore, non-significant paths were trimmed to form a revised measurement model. Confirmatory factor analysis of the revised measurement model resulted in a good fit, with all of the indicator variables loading significantly onto their respective latent constructs.

A test of the structural model revealed that the data fit the model well. However, there was only partial support for the hypotheses formed from the meaning making model 
of coping (Park \& Folkman, 1997). The first hypothesis, that individuals with IBD will experience a discrepancy in their beliefs and goals, was not supported. The second hypothesis predicted that individuals who experience discrepancy (i.e., violation of global beliefs and goals) will report higher levels of distress. This hypothesis was supported by the data. The third hypothesis predicted that distressed individuals will engage in meaning making behavior; this hypothesis was not supported by the data. Finally, the last hypothesis stated that individuals who engage in meaning making behavior will experience stress-related growth. Although stress-related growth has not been an explicit outcome associated with previous iterations of the meaning making model of coping (see Park, 2005; 2008; Park \& Folkman, 1997), it is assumed to be a potential adaptive outcome of the search for meaning (i.e., meaning made; Park et al., 2008). This assumption was upheld by the current data. 


\section{CHAPTER 4}

\section{DISCUSSION}

\section{Purpose of the Study}

The overall purpose of this study was to test the assumptions of the meaning making model of coping using a sample of people diagnosed with IBD. Additional research questions addressed whether there are specific predictors (i.e., sociodemographic variables) of meaning making behavior and adjustment outcomes, such as stress-related growth. This study is an extension of previously conducted basic, descriptive research (Park, 2008). Although not all of the model's assumptions were upheld by the present data, they do provide support for the meaning making model. This study's results may serve as a springboard for future rigorous research on meaning making.

This study examined 10 hypotheses related to meaning making and stress-related growth among individuals living with an often debilitating chronic illness, IBD. The first set of hypotheses under Research Question 1 made predictions about whether specific sociodemographic variables are related to meaning making behavior. The second set of hypotheses under Research Question 2 made predictions about whether specific sociodemographic variable would be related to stress-related growth (SRG) in individuals diagnosed with IBD. The final four hypotheses, under Research Question 3, were derived specifically from the meaning making model of coping (Park \& Folkman, 1997). Each of these research questions will be discussed in turn. 


\section{Sociodemographic Variables and Meaning Making Coping}

Participants in the current sample engaged in modest amounts of meaning making coping. Although scores on the meaning making coping subscales of the Brief COPE (Carver, 1997) range from 2.00 to 8.00 , actual reported levels ranged from only 4.41 to 5.05. It is difficult to compare these reported levels of meaning making to other samples due to the lack of standardized measurement. The few studies that have examined meaning making through the use of these subscales have used different Likert scaling, included a different number of items to make up the subscale, or have not reported the means of the coping subscales (Park, 2005; 2008; Park \& Cohen, 1993).

According to the meaning making model of coping (Park \& Folkman, 1997), individuals reduce discrepancies between global meaning and situation meaning by changing the appraised meaning of a situation, modifying global beliefs and/or goals, or both. In the current study, participants' qualitative responses were coded for these meaning making efforts. The largest percentage of the sample $(25.6 \%)$ reported having changed aspects of their global meaning (either beliefs and/or goals) in order to reconcile discrepancies. Although consistent with the model, this is contrary to other research that characterizes global meaning as largely stable. Several researchers have suggested that people are more likely to fit new data into their existing beliefs rather than modify those belief systems to fit the stimuli (Janoff-Bulman, 1989; Marris, 1986; Park \& Blumberg, 2002; Park \& Folkman, 1997). In the present sample, only $9.4 \%$ of the participants reported having changed their situational meaning. Therefore, these results indicate that individuals with IBD are more likely to engage in accommodation than assimilation. 
In line with the previously mentioned use of meaning making coping efforts, a large percentage of participants $(20.2 \%)$ reported no change in either global or situational meaning. Other studies have reported variable percentages of people $(29 \%$, O'Dougherty Wright, Crawford, \& Sebastian, 2007; 50\%, Silver et al., 1983) who have not found meaning in their stressful experience. What is generally not known about these individuals is whether or not "no meaning" is indicative of unsuccessful attempts at meaning making or the absence of meaning making efforts.

Age

Hypothesis la stated that after controlling for the effects of time since diagnosis, age would be negatively associated with meaning making. Although it is generally accepted that coping changes with age, this has been inconsistently shown in the literature. Additionally, there is considerable debate as to the reason behind such changes. Several theorists have proposed developmentally-based changes in coping (e.g., Aldwin \& Levenson, 2001) with coping strategies becoming more mature, adequate and comprehensive as one ages, concurring with general developmental trends (Alumran $\&$ Punamäki, 2008). However, other researchers propose a contextual basis for age-related differences in coping. In other words, coping depends on the types of stressors experienced by the individual (McCrae, 1982). For example, Folkman and colleagues (1987) found that younger adults (approximately 41 years old) were more likely to report stress related to work and child-rearing than were older adults (approximately 68 years old). Older adults were more likely to report stress related to health problems. There was also evidence that older adults perceived their stressors as more refractory. Further 
research is needed to determine if age-related differences in coping are more closely tied to the type of stressor experienced or its appraisal.

Few studies have directly examined the relationship between coping style and age (Richaud de Minzi \& Sacchi, 2005; Schnoll, Harlow, Stolbach, \& Brandt, 1998) and even fewer have examined the relationship between meaning making processes and age (Park et al., 2008; Scioli et al., 2000). Correlational analyses in the current study revealed no relationship between age and meaning making coping behavior; therefore, Hypothesis 1a was not supported. Specifically, there were no differences in the reported use of positive reframing, religious coping, or emotional processing across various age groups. The finding that there were no age-related differences in meaning making coping suggests that coping is not driven by developmental changes. Instead, it is more likely that changes in coping strategies across age groups found in other studies are related to the types of stressors experienced. In the current study, there was a homogeneous stressor, and participants reported on their use of coping strategies specific to their IBD. If coping is more closely tied to the type of stressor, then it is understandable that no differences were found across age groups in the current sample.

Rowland (1989) proposed that the timing of a stressful event in one's life span, specifically the diagnosis of a serious illness, can influence coping responses. Although illness causes some common disruptions throughout various stages of life (independence, physical ability, interpersonal relationships, etc.), some disruptions may be particularly salient for certain age groups. For example, young and middle-aged patients may experience disruptions more in terms of altered relationships, educational and career achievement, and physical disability, whereas older patients may feel disruptions more in 
terms of existential issues (Bower et al., 2005; Rowland, 1989; Vickberg, 2003). If the preceding is true, one would expect differences in the use of meaning making coping strategies across age groups. Despite its intuitive appeal, however, this assumption has not been fully tested or consistently demonstrated in the literature. In the current study, there was no relationship between participants' age and the violation of beliefs and/or goals (i.e., disruption, discrepancy).

Gender

The second hypothesis (H1b) predicted that females would exhibit greater levels of meaning making than males; this hypothesis was partially supported. Females within the current sample reported greater levels of religious coping and emotional processing in their efforts to cope with IBD; however, there were no significant gender differences related to the use of positive reframing as a coping strategy.

The current results replicate those of other studies in which women report greater use of emotion-focused coping strategies (Ninot et al., 2006). One possible explanation for this difference relates to gender-specific socialization processes. Females tend to be socialized to be more emotionally sensitive and to connect with and express their emotions (Ptacek, Smith, \& Zanas, 1992). Additionally, processing and sharing emotions may be more socially acceptable for women than men (Stanton, Danoff-Berg, Cameron, \& Ellis, 1994). The social support literature suggests that women have multifaceted social networks that provide more emotional and health-related support. Therefore, women are more likely to mobilize their supports and cope through emotional expression when dealing with a stressful situation. Men, on the other hand, tend to have more extensive but 
less intense networks (Shumaker \& Hill, 1991). This may explain the predominantly female sample in the current study.

The finding that women reported greater use of religious coping strategies is also consistent with the results of other coping studies. Park and Cohen (1993) found that women exhibited higher levels of various religious coping strategies than did men in their attempts to cope with the death of a friend. Given previously mentioned results suggesting that women report using a greater number of coping strategies (Scioli et al., 2000), higher levels of religious coping may reflect a more complete and diverse coping style on the part of women. These findings lend support to studies in which spirituality is considered to be a valuable tool for coping with stress related to chronic illness (see Rowe \& Allen, 2004).

Among other populations, researchers have found gender differences in coping, such as women being more likely to seek social support (Stanton, Tennen, Affleck, \& Mendola, 1992) and men being more likely to utilize problem-focused coping strategies (Miller \& Kirsch, 1987). However, these differences have recently been questioned with regard to IBD. Kinash et al. (1993) found that both men and women were more likely to use problem-focused, rather than emotion-focused coping strategies in dealing with their disease. This was true regardless of participants' form of IBD (CD vs. UC) or disease severity. There is research to suggest, however, that choice of coping strategy may be more related to the types of stressful event encountered by men and women rather than genuine gender differences (Porter \& Stone, 1995).

Although Scioli et al. (2000) found that females use a greater number of coping strategies they found no gender differences in integrative meaning (i.e., meaning related 
to values, life lessons, transcendent experiences, and relationships). Relatedly, Dirksen (1995) found no significant correlation between search for meaning and gender. In contrast to the current study's results, small, but significant, gender differences have been found in the use of positive reframing as a coping strategy (Park et al., 2008).

Gender differences in coping may also be due to inconsistencies in the types of coping strategies assessed. Coping efforts have been traditionally categorized into two types: problem focused coping, which are efforts aimed at altering the situation or environment (e.g., direct problem solving); and emotion-focused coping, which involves efforts to manage or reduce emotional distress (e.g., avoidance; Lazarus \& Folkman, 1984). However, findings related to these categories may be misleading because these broad categories of coping efforts often combine diverse strategies that may actually operate differently. For example, emotion-focused coping typically has included coping strategies such as acceptance, which may be an adaptive strategy, as well as denial and avoidance, which may be maladaptive strategies (Glyshaw, Cohen, \& Towbes, 1989). These strategies may differ not only in their function but also in their association with outcomes (Armistead, McCombs, Forehand, Wierson, Long, \& Fauber, 1990; Glyshaw et al., 1989). Thus, it is essential to distinguish both the focus of the strategy (problem- or emotion-focused) and whether the strategy may be expected to be adaptive or maladaptive. Observed gender differences in coping may be clarified by separating functionally distinct dimensions of coping (Lengua \& Stormshak, 2000). 


\section{Education Level}

The third hypothesis (H1c) predicting that education level would not be associated with meaning making was supported. Level of education is rarely examined in relation to meaning making (Lee et al., 2004). Meaning making may be considered a cognitive coping strategy; therefore, its use could theoretically be connected to one's level of education. However, meaning making in the present study was conceptualized as

a universal phenomenon. This conceptualization is consistent with the current results that suggest one's level of education is not a significant predictor of meaning making coping behavior.

\section{Summary}

The only sociodemographic variable significantly related to meaning making coping behavior was gender. This effect was only found for religious coping and emotional processing with women reporting higher levels of both of these coping strategies. Men and women did not differ significantly in their use of positive reframing as a way of coping with IBD. There were no significant relationships observed between participants' age or education level and meaning making behaviors.

Sociodemographic Variables and Stress-Related Growth (SRG)

A life crisis, such as a serious illness, can serve as a catalyst for personal growth.

In fact, many researchers view growth as a frequent outcome of the process of struggling with a severe life event (Armeli et al., 2001; Cordova, Cunningham, Carlson, \& Andrykowski, 2001; Park et al., 1996; Tedeschi \& Calhoun, 1995). As shown in the current study, individuals living with IBD do experience a moderate level of psychological distress related to their disease. Although no other study has examined 
SRG in this population, a large body of research examining other physical illness suggests that such growth is not uncommon (e.g., Cordova et al., 2001; Fromm, Andrykowski, \& Hunt, 1996; Schaefer, \& Moos, 1998).

Stress-related growth was measured by the Stress-Related Growth Scale—short form (SRGS-sf; Park et al., 1996), a measure directly influenced by Schaefer and Moos (1992). Through their review of the growth literature, Schaefer and Moos grouped stressrelated growth outcomes into three distinct, but interrelated, categories: (a) enhanced social resources (b) enhanced personal resources, and (c) new or improved coping skills. An examination of the SRGS-sf (Park et al., 1996) mean-item ratings from the current sample suggests that individuals living with IBD do, in fact, experience moderate levels of stress-related growth in all of these areas. However, participants were most likely to report growth in the areas of personal resources (e.g., standing up for my personal rights, learning to be myself) and new/improved coping skills (e.g., learning to work through problems, learning to find more meaning in life). Stress-related growth in the area of social resources was also reported by participants, but to a lesser extent. Of note, the sample consisted entirely of individuals recruited through online support groups. It is possible that these individuals learned to develop their social resources as a result of IBD and this was manifest by their participation in online social support forums. Because this was the area of least reported growth, it is also possible that these individuals already possessed adequate social resources and perceived there to be little change as a result of IBD.

Schaefer and Moos (1992) also developed a conceptual model to explain the determinants of SRG. In their model, certain characteristics of the stressor are likely to be 
associated with SRG. Bivariate correlations revealed that none of the assessed diseaserelated variables (i.e., time since diagnosis, number of hospitalizations and surgeries, disease severity) were significantly related to $\mathrm{SRG}$. This is consistent with the findings of a meta-analysis by Helgeson and colleagues (2006). Eighty-seven studies of growth following a variety of traumatic stressors (e.g., illness, loss of a loved one, natural disasters) were reviewed, and time since event was not a significant predictor of stressrelated growth.

Schaefer and Moos (1992) also suggested that certain personal factors are predictive of SRG. In the present study, personal factors consisted of key sociodemographic variables--age, gender, and education level.

Age

The first hypothesis (H2a) stated that, after controlling for the effects of time since diagnosis, age will be negatively associated with SRG. The results of this study do not support this hypothesis, and the current literature related to age and SRG is inconsistent. While some studies have found a negative association between age and SRG (for a meta-analysis see Helgeson et al., 2006; for a review see Linley \& Joseph, 2004), others have found either a positive association (e.g., Milam, Ritt-Olson, \& Unger, 2004) or none at all (e.g., Kesimci et al., 2005; Siegel et al., 2005).

Gender

Hypothesis 2b states that females will report greater levels of SRG than males. There is an absence of reliable gender differences in terms of SRG within the literature (Tedeschi et al., 1998). Many studies are unable to examine gender differences due to single sex samples (e.g., McIntosh et al., 1993) or samples too small to make meaningful 
comparisons (Borden \& Berlin, 1990). Other studies, however, have found that women report higher levels of SRG than men (Park et al., 1996); while others have found similar gender differences in terms of positive adjustment outcomes (e.g., Lehman et al., 1993). There were no significant gender differences in reported SRG in the current study. This finding may be due to the similar levels of distress reported by men and women. Consistently, previous research has found positive relationships between level of distress (or impact of the event) and stress-related growth (Fromm et al., 1996; McMillen \& Fisher, 1998; Tedeschi \& Calhoun, 1995)

Education Level

As expected in Hypothesis 3c, level of education was not related to greater SRG. Although this finding is consistent with that of other studies examining SRG (Siegel et al., 2005), the relationship between education and SRG has been infrequently examined in the research.

\section{Summary}

Research Question 2 directly addressed category two of Schaefer and Moos's model (1992), personal factors. In a failure to support Schaefer and Moos's model, none of the measured socio-demographic variables (personal factors) were predictive of SRG. Based on these results, it is possible that previously found associations between SRG and various sociodemographic variables were due to spurious correlations, confounded by other psychosocial variables (e.g., cultural norms, level of social support) that possess a clearer theoretical relation to SRG. Unfortunately, these variables were not measured or controlled for in the present study. 
The Meaning Making Model of Coping

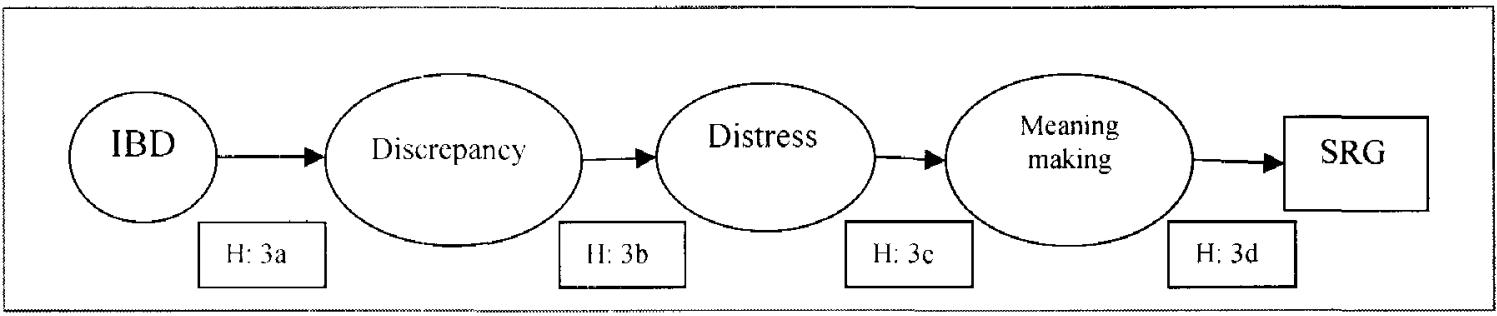

Figure 9. Re-iteration of schematic of the meaning making model of coping adapted for testing in current study (adapted from Park, 2008), with corresponding hypotheses.

Research Question 3 includes hypotheses that test the assumptions associated with the meaning making model of coping (Park \& Folkman, 1997; Park, 2005). Specifically, it asks, "Does the meaning making model of coping apply to individuals with IBD?" The model was tested as a whole using structural equation modeling (SEM). Four hypotheses were derived to test the specific hypothesized paths of the model.

Hypothesis $3 a$

This hypothesis stated that individuals with IBD will experience a discrepancy in their beliefs and goals. Despite the fact that much has been written about the violation of one's fundamental assumptions in response to a trauma or loss (Janoff-Bulman \& Schwartzberg, 1997), few studies have directly measured participants' violation of global beliefs and goals (Park, 2008). Additionally, no study has utilized a standardized measure of such violation. Therefore, it is difficult to compare the total level of violation across samples. However, mean-item ratings are consistent with those obtained by a similar study examining violation/discrepancy (Park, 2008). In the present study, although the path between IBD and Discrepancy in the structural model was not statistically 
significant, mean-item ratings of perceived discrepancy between the appraised meaning of IBD and global meaning (both beliefs and goals) suggest that participants did experience a moderate amount of discrepancy. The mean scale score for beliefs violation was $19.36(\mathrm{SD}=7.43)$; range was 10 to 40 . Further, mean item ratings reveal that there were several beliefs likely to be challenged by one's experience with IBD.

Global beliefs related to control and one's understanding of the world were among those most discrepant from participants' appraised meaning of IBD. Participants in the current study were most likely to agree strongly with the following: "Having IBD conflicts with my feelings of being in control of my life", "Having IBD conflicts with my sense that 'the people who are supposed to be in charge' have control", "Having IBD conflicts with my sense that the world is fair and just", "Having IBD conflicts with my understanding of what life is all about", "Having IBD conflicts with my belief that things happen for a reason", and "Having IBD conflicts with my belief of life being basically good". Experiencing these discrepancies makes sense in light of the nature of IBD. Specifically, uncertainty is often central to living with IBD given the complexity of the disease and symptom management and lack of definitive information regarding etiology, diagnosis, and treatment. The idiopathic nature and unpredictable course of the disease (de Rooy et al., 2001; Dudley-Brown, 1996; 2002) can lead to feelings of helplessness and challenge beliefs about the extent to which one is able to control negative events in general (Janoff-Bulman, 1989).

Additionally, the mean age of participants was $28.83(\mathrm{SD}=8.65)$. Being diagnosed with a chronic illness at this age could be considered an "off-time" experience in terms of expected age norms (Fleer et al., 2006) and may understandably challenge 
one's fundamental assumptions about the order of the world. Beliefs about the benevolence of the world and the extent to which one deserves to have such a disease can be called into question as well.

Those beliefs least likely to be challenged by the experience were those related to God or a higher power. The mean-item ratings for these items were all under 2.0 (range was 1 to 4). Participants did not feel that having IBD conflicted with their views of God being in control. Nor did they feel that having IBD conflicted with their views of God being purposeful, loving/merciful, or angry/vengeful. These results could be reflective of the religious beliefs of the sample (religious coping was used the least of all three meaning making coping strategies) or poor wording of these belief violation items. As previously mentioned, given the lack of standardized instruments geared toward the assessment of meaning making processes, items were created for use in the present study.

In addition to the violation of global beliefs, participants experienced moderate violation of global goals. The mean scale score for goals violation was $27.55(\mathrm{SD}=$ 8.55); range was 11 to 44 . Examining the mean-item ratings of the 11 desired states/outcomes reveals that the most commonly violated goal was that of physical health. This finding is expected given that the individuals in the present sample are living with a major chronic illness. A related goal likely to be violated was related to athletic/fitness achievement. IBD has a number of debilitating symptoms that could limit one's physical activity, such as diarrhea, abdominal pain, and fatigue. These manifestations of IBD are often severe and may also affect various other aspects of a person's life, including work, family, and social functioning. IBD tends to strike during the most economically and socially productive years of life; therefore, salient goals related to career and family may 
be threatened or thwarted altogether (Dudley-Brown, 1996; Fleer et al., 2006). In fact, career achievement, financial security, and intimacy were also among the top goals interrupted by IBD.

Although there are contrary results when it comes to unemployment and disability as a result of $\mathrm{IBD}$, the research is clear that changes in work practices are common among those living with IBD (Bernkley et al., 2006; Mallet et al., 1978; Mayberry et al., 1992). In addition to career disruption, including loss of employment, reduced productivity, and lost time due to illness, patients can experience financial strain related to medical costs. Obtaining health insurance coverage may prove difficult for some given the chronicity of the disease. IBD patient's utilization of healthcare services is often higher than that of the general population (Grace \& Priest, 1982), and the costs associated with medical procedures and treatment (e.g., surgery, medications) can be astronomical. Therefore, it is not surprising that participants rated financial security highly in terms of goal violation.

Participants' reports of disrupted intimacy are likely related to body image issues as well as variable physical symptoms like fatigue, diarrhea and abdominal pain. Other barriers to a healthy, pleasurable sex life may be IBD-related medications. For example, steroids, a commonly used medicinal treatment for IBD, are known to frequently affect sexual drive and function (Silberman, n.d.).

In sum, although the hypothesized path between IBD and Discrepancy in the structural model was not significant, individuals living with IBD do report moderate amounts of discrepancy (i.e., belief and goal violation) as a result of the disease. The nonsignificance of this path may most likely be attributed to the nature of the indicator 
variables used for IBD as a latent construct. Although time since diagnosis and number of surgeries and hospitalizations are appropriate quantifiable characteristics of IBD, it is difficult to say what variables would best capture the experience of IBD.

Hypothesis $3 b$

This hypothesis stated that when individuals with IBD experience a discrepancy in their beliefs and goals. they will be distressed. The meaning making model of coping posits that the extent of such discrepancies determines one's level of distress (JanoffBulman, 1989; Park \& Folkman, 1997). In the current study, the path coefficient between Discrepancy and Distress was statistically significant; therefore, the aforementioned hypothesis was supported. The greater the discrepancy between global meaning (global beliefs and goals) and one's appraised meaning of IBD, the higher the distress.

In the current study, distress was measured by the Impact of Events Scale (IES; Horowitz et al., 1979). The IES includes items that assess both intrusive thoughts and avoidant behavior. It is commonly used to assess distress associated with trauma, including life-threatening illness such as cancer. It is possible that this measure is not appropriate for use with a population dealing with IBD, an often debilitating, but not lifethreatening illness. However, the current results suggest that individuals living with IBD do experience moderate levels of distress related to their disease. The mean reported levels of intrusive thoughts and avoidance are consistent with those reported by other studies (e.g., Cordova et al., 2001). 


\section{Hypothesis $3 c$}

This hypothesis stated that individuals with IBD who are distressed will engage in meaning making behavior. The meaning making model of coping (Park \& Folkman, 1997) posits that to the extent that global beliefs and goals are incongruent with the appraised meaning of a situation, people will experience distress and attempt to alleviate this distress through coping. The findings from the present study do not replicate previous findings supporting this pathway of the meaning making model of coping. Structural equation modeling revealed a non-significant path coefficient between Distress and Meaning Making. Additionally, bivariate correlations reveal that neither avoidant behavior nor intrusive thoughts were significantly associated with meaning making coping behaviors (i.e., positive reframing, religious coping, or emotional processing). Although the participants in the current study did engage in meaning making coping, the results suggest that such coping was not directly related to their level of distress.

In addition to being used as a measure of psychological distress, the IES (Horowitz et al., 1979) has been used as a measure of cognitive processing. Cognitive processing is often described as a way of mentally reworking appraised and global meaning in attempts to change or reframe them and make them consistent (Davis et al., 2000; Greenberg, 1995; Park \& Folkman, 1997; Park, 2008). In this way, the repeated exposures (i.e., intrusive thoughts) in cognitive processing can be thought of as unconscious and automatic efforts to make meaning (Horowitz, 1997; McIntosh et al., 1993). Using this conceptualization of the measure, the results may suggest that automatic meaning making efforts are not related to more deliberate efforts as measured by the Brief COPE (Carver, 1997). 
It could be that the coping behaviors of those living with IBD are more closely tied to illness appraisal (e.g., threat, challenge, harm/loss; Folkman \& Lazarus, 1985) than subjective distress. Other research suggests that choice of coping strategy is heavily influenced by the perceived controllability of a stressful encounter (Folkman \& Lazarus, 1980; 1985). Emotion-focused coping strategies (e.g., avoidance, denial) are used more frequently in encounters that are perceived to be unchangeable. Although meaning making coping is also thought to be a more likely choice for those dealing with a chronic stressor that is not amenable to problem-focused efforts (Folkman \& Moskowitz, 2004), it is possible that the current sample relied on other emotion-focused coping strategies. Results across studies have found the use of avoidant coping strategies, such as denial, distancing, and disengagement, to be associated with more psychological distress (Bal, Van Oost, De Bourdeaudhuij, \& Crombez, 2003; Futa, Nash, Hansen, \& Garbin, 2003). The current results may be more indicative of this dynamic than a lack of support for the meaning making model of coping.

Previous research has found that emotion-focused coping strategies tend to be more stable than problem-focused coping strategies. In this way, problem-focused forms of coping may be more responsive to contextual factors (e.g., characteristic of stressor), whereas emotion-focused forms are influenced mainly by person factors (Lazarus, 1992). Keeping in mind that the current sample consisted entirely of individuals recruited from online support groups, one must consider whether or not there are personality variables unique to this population that influence the choice of coping strategies. 


\section{Hypothesis $3 d$}

This hypothesis stated that individuals with IBD who engage in meaning making behavior will experience stress-related growth (SRG). Meaning making itself is often considered to be of value to people because it provides them with an opportunity to rethink their views, goals, priorities, and situation. As a result of this review, people often identify or produce positive changes in themselves (Park, 2004). These positive changes are known as stress-related growth (SRG; Park et al., 1996) and are viewed as one outcome of the meaning making coping process (Park, 2004).

In the current study, the hypothesized path between Meaning Making and StressRelated Growth was statistically significant. This finding is consistent with the ideas of Schaefer and Moos (1992) who propose that style of coping can be an important predictor of SRG. Many studies have found positive relationships between cognitive coping strategies, particularly positive reframing, and SRG (Park et al., 1996; Sears et al., 2003;

Siegel et al., 2005). In fact, many researchers would consider these forms of coping fundamental to the growth process (Schaefer \& Moos, 1992; Taylor, 1983). In addition to SRG, positive reframing has been associated with other positive outcomes in the adjustment to illness, including lower levels of depression, anxiety, general distress, and fatigue (Carver et al., 1993; Kraaij et al., 2007; 2008; Reuter et al., 2006).

For many people, religion serves as a global meaning system through which they make sense of the world (Park, 2005; 2006; Park \& Folkman, 1997) and is, therefore, often implicated in meaning making efforts (Park, 2006). Additionally, religiousness has been consistently linked to positive outcomes following highly stressful life events (Park \& Cohen, 1993; Tomich \& Helgeson, 2004). Many religions promote the idea that 
suffering brings about positive changes or transformation (Aldwin, 2006; Exline, 2002;

Park, 2006). In addition to enhancement of character and ability to cope, many people report feeling closer to God, more sure in their faith, and more religious (Emmons, Colby, \& Kaiser, 1998; Pargament, 1997).

Religious reappraisal, along with prayer, meditation and finding comfort in spiritual beliefs, is a form of religious coping, one of the meaning making coping strategies measured in the current study. The current findings are similar to those of other studies whose results show that religious coping is positively associated with stressrelated growth (Pargament, Smith, \& Koenig, 1996; Park et al., 1996). Higher levels of religiousness have been linked to greater growth following stressors (Pargament, Koenig, \& Perez, 2000); other studies have found this relationship to be mediated by meaning making coping (Park, 2005).

\section{Implications}

Few studies have explicitly tested hypotheses associated with the meaning making model of coping (Park, 2008; Park et al., 2008). The results of the current study are consistent with those of similar studies in that they generated mixed but generally positive support for the assumptions of the meaning making model of coping (Park \& Folkman, 1997). Although participants reported experiencing violations of global beliefs and goals as a result of living with their IBD, statistical analyses showed no significant causal path between the identified stressor (IBD) and level of discrepancy (violation of beliefs and goals). Despite the fact that this type of path has not been empirically tested before, the results were unexpected. Shortcomings in measurement likely hindered the ability to detect true relationships between the experience of IBD and violations of beliefs 
and goals. That is, the measure utilized in the current study to assess the violation of beliefs and goals was not a standardized instrument. Many of its items were developed specifically for use in this study; therefore, its validity has not been established.

Furthermore, the variables used to quantify IBD (i.e., time since diagnosis, number of surgeries and hospitalizations) likely do not truly capture the experience of IBD.

As hypothesized, discrepancies between one's appraised meaning of IBD and his/her global beliefs and goals were significantly related to level of psychological distress. This is an affirming result that advances the knowledge of meaning as it relates to adjustment to a disruptive, chronic illness. Interestingly, level of psychological distress was not related to meaning making coping efforts. This finding may be one that is unique to individuals living with a multifaceted disease like IBD. Their choice of coping efforts may be more closely tied to particular aspects of this multifaceted disease-a supposition that may be explored more clearly with greater specificity in coping measures.

As hypothesized, meaning making coping efforts (e.g., positive reframing) were significantly related to stress-related growth, a result that has been reported elsewhere (Park, 2004; Park et al., 1996). This finding provides meaningful support for the meaning making model of coping and its hypotheses delineating the role of meaning making in the psychological adjustment to a major life stressor.

Although the fit of the structural model was good, there is the possibility of the existence of a better model. There may be other equivalent models that would fit the data equally well; there may also be non-equivalent alternative models that fit the data better than the present model. Future researchers should endeavor to test and rule out likely alternative models. 
A biopsychosocial view of IBD necessitates paying attention to the combination of biological, psychological, and social factors that influence one's experience of the disease. Findings related to participants' perceived levels of belief and goal violation and the psychological impact of IBD demonstrate that individuals living with IBD experience a moderate amount of distress. The link between psychological distress and IBD symptoms is well established. However, despite its prevalence, patients don't always mention their psychological concerns to physicians. Therefore, it is imperative that physicians initiate conversations with their patients about such things as the disease's impact on various life domains and feelings of uncertainty related to an unpredictable disease course. It might also be helpful for physicians to have materials on-hand about coping with IBD and other available resources (e.g., local support groups). Such information may serve to normalize patients' experiences and enhance their coping abilities; ideally, this information would be distributed as soon as possible after the diagnosis is given. Doctors also need to have a counseling referral list available for their patients who voice social and psychological concerns as there are a variety of psychotherapeutic interventions relevant in facilitating healthy psychological adjustment to IBD.

The present findings suggest that IBD patients experience moderate violation of important goals/states, including physical health, career achievement, financial security, and intimacy. For example, social activities may be eliminated or significantly reduced due to debilitating symptoms or the need to be near a restroom. Family/home obligations can be upset by changes in work status. Sexual intimacy may be reduced due to painful physical symptoms, fatigue, or body image issues. Rather than abandoning certain goals 
that are important, individuals with IBD may benefit from therapeutic interventions that broaden their awareness of alternative ways of achieving these goals/desired states. Family or couples counseling may help to open the lines of communication, improve awareness of personal needs for all parties involved, and help people with IBD and their family members navigate the life changes they are experiencing.

Career disruption is prevalent among individuals living with IBD. Although it is not clear if participants were unemployed by choice or as a result of their disease, these numbers may reflect a need for vocational counseling among individuals living with IBD. IBD-related support groups may also address issues related to control, uncertainty and goal-disruption.

In the present study, all forms of meaning making coping were significantly related to stress-related growth. Notably, these coping strategies are all cognitive in nature; therefore, patients can be trained in their use. Teaching patients to use coping strategies, such as positive reframing and emotional processing will facilitate growth. The same is true for religious coping. There is a growing body of literature that addresses the integration of spirituality and religion into psychotherapy and its positive effects of patient well-being (Plante \& Sherman, 2001).

\section{Limitations}

The sample for the present study consists entirely of individuals recruited via Internet-based support groups. For people living with certain chronic conditions, the Internet serves as both a resource and a community (Ziebland, Chapple, Dumelow, Evans, Prinjha, \& Rozmovits, 2004). Internet-based support groups tend to arise for conditions that are chronic, disabling or poorly understood. These Internet-based support 
groups represent a concentration of individuals with a specific condition and such groups are a potentially fertile sampling ground for research recruitment. While recruitment through Internet-based support groups offers easy, low cost access to large study populations, concerns exist regarding the essential anonymity of subjects and potential sampling bias particularly related to gender, ethnicity and socioeconomic status.

Patients who have sufficient interest and the technological capability to access online surveys are likely to be different from the general patient population (Treadwell, Soetikno, \& Lenert, 1999); however, few studies have directly compared Internet-based populations with patients recruited from a clinical setting. In a study by Soetikno, Mrad, Pao, and Lenert (1997), UC patients recruited through the Internet were younger, wealthier, and better educated than those recruited through a surgical clinic. Similar results were found by van Uden-Kraan and colleagues (2009) in their study examining non-IBD patients' usage of health-related Internet applications (e.g., online support groups). Specifically, they found that being younger, better educated, and employed predicted patients' health-related internet use.

Research suggests that many patients' initial contact with Internet-based groups tends to occur during an active phase of their disease (Treadwell et al., 1999). In other words, patients' health-related Internet usage may be predicted by their current level of disease severity. At the peak of symptoms, patients engage in information-seeking behavior in an attempt to manage, or cope with, their disease. In fact, van Uden-Kraan et al. (2009) found that patients' health-related Internet usage consisted mainly of seeking information about their illness. This may partially explain why Internet-recruited participants often display levels of disease severity that are beyond those observed among 
comparison clinical groups. In particular, studies have shown that Internet-recruited IBD patients report significantly poorer quality of life (Jones, Bratten, \& Keefer, 2007; Soetikno et al., 1997). Symptom severity and other health-related characteristics do not consistently differentiate online samples from community samples, however. (Treadwell et al., 1999; van Uden-Kraan et al., 2009). Ultimately, future research should compare Internet-based populations with patients recruited from clinical settings in order to ascertain what differences exist.

Another limitation of the current study is the self-selected sample. It is very possible that there are differences between people who would chose to participate and those who would not. For example, choice of coping strategies may be influenced by certain person factors (e.g., personality; Lazarus, 1992). The results of this research can only be generalized to people with IBD who would choose to respond to an IBD research survey online. Another restriction in terms of generalizability relates to the demographics of the present sample. Although there was diversity in age, disability status, and education level, the sample was predominantly comprised of Caucasian females. Further research should involve samples with greater diversity, particularly in terms of ethnicity and gender.

All data collected in the current study were of a self-report nature. Having participants' diagnoses, as well as disease severity, confirmed by a physician would lend credibility and validity to participants' reporting. Additionally, one must consider the potential bias of self-presentation. Participants may be reluctant to admit to using coping strategies traditionally considered to be maladaptive (e.g., substance use). They may also feel pressured to report growth or to present as well-adjusted. 
As for reports of coping, the current study utilized a coping measure that asked participants to report how they cope with their IBD "in general". This approach, however, is vulnerable to response bias in that participants may be reporting vague impressions about how they prefer to cope that are influenced by what they believe to be socially desirable or ideal coping responses rather than what they actually have done (Lazarus, 1993).

Just as with previous research examining various coping strategies and SRG, there is a potential confound between reports of positive reframing coping and reports of SRG on the SRGS-sf (Park et al., 1996). Given the overlap between the item content of the scales used to measure these constructs, it is no surprise that the two were strongly correlated. Although, conceptually, positive reframing and SRG are distinctly different phenomena (coping vs. outcome), one must consider the possibility that participants' responses to the SRG-sf may reflect attempts at positive reframing rather than actual positive outcomes related to their experience with IBD (Park et al., 1996).

Future Research Directions

The current study examined previous efforts to make meaning out of the illness experience. Longitudinal research would better capture the complex process of meaning making. Appraisals of one's illness change over time, as does one's level of perceived stress. According to the transactional stress and coping model, both of these factors are critical mediators of the person-environment relationship and influence the type of coping strategies an individual will choose (Folkman \& Lazarus, 1985; Lazarus, 1992). In other words, what a person does to cope depends on the context in which the disease occurs, and this will change over time because of what is attended to. For example, whether or 
not a person is fearing the recurrence or exacerbation of symptoms, facing a surgical procedure, or confronting the possibility of becoming disabled will influence the process of coping.

According to Livneh (2000), "When confronted with traumatic life events, individuals normally resort to a wide range of coping strategies to alleviate resultant stress (p.40)". Due to the complexity of coping processes, people tend to combine different types of coping at various times in their interactions with a stressful encounter. Due to inadequate measurement and the predominance of cross-sectional designs, it is difficult to determine to what extent coping strategies are linked either to particular aspects of the encounter (e.g., painful symptoms) or temporal factors (e.g., switching to another coping strategy based on the perceived effectiveness of another) (Lazarus, 1993). The issue of coping being based on particular threat contents or trial and error has not been unequivocally demonstrated with the current research. Therefore, future studies should not only include repeated observations, but should consider using measures that specify the particular aspects of a person's illness that is of immediate concern and to treat them separately rather than broadening the focus of attention to the illness in general (Lazarus, 1993).

Longitudinal designs would allow researchers to more fully examine the influence of important disease-related factors (e.g., active disease vs. inactive disease). It is likely that whether one's disease is currently active will influence not only the appraisal of their illness, but reports of belief and goal violation, perceived distress, coping efforts, and perceived growth. Future studies might include disease status as a covariate when 
examining relationships among the aforementioned variables. This is particularly relevant for a relapse-remitting disease such as IBD.

Longitudinal studies are also critical to the understanding of stress-related growth. Growth occurs as a result of a developmental process that follows the experience of psychological distress and disorganization (Schaefer \& Moos, 1992). Although some people report stress-related growth as soon as 3 months after the onset of a stressor (e.g., cancer; Urcuyo, Boyers, Carver, \& Antoni, 2005), it may take many months or years of struggle and effort for a person to find meaning in their experience and to grow from it. Although some research has demonstrated a link between time since diagnosis/onset and stress-related growth, this relationship is not likely to be linear. Multiple assessment points across an individual's experience with a disease would be invaluable in providing insight into the dynamic process of growth-related changes subsequent to chronic illness.

To date, this is the only study examining the meaning making efforts of individuals living with IBD. Few others have examined meaning making as a viable form of coping with a medical illness. Given that the empirical study of meaning making is still in its early stages, there is a paucity of assessment methods related to its various constructs. Researchers should continue to refine these operational definitions and work toward the development of standardized measures for global meaning (including beliefs and goals), situational meaning (including appraised meaning, search for meaning, and meanings-made), and discrepancies between the two.

The current study did not address the possibility of negative meanings-made from the experience of IBD. There is evidence to suggest that some individuals' efforts to reconcile their global and appraised meaning may result in changes for the worse, such as 
increased vulnerability and mistrust (Bower et al., 2005; O’Dougherty Wright et al., 2007). Although having made meaning is generally considered to be a successful conclusion of meaning making efforts, the content of the meaning influences subsequent adjustment (Pargament, Koenig, Tarakeshwar, \& Hahn, 2001; Thompson \& Janigian, 1988).

Now that it has been shown that individuals living with IBD do engage in meaning making coping efforts and experience stress-related growth, future research should examine specific correlates of these phenomena. For example, are there particular personality features that determine to the extent to which individuals with this disease engage in meaning making? Are there other forms of coping, disease-related factors, or personality variables that determine the level and type of stress-related growth? 


\section{REFERENCES}

Adams, S., Pill, R., \& Jones, A. (1997). Medication, chronic illness, and identity: the perspective on people with asthma. Social Sciences and Medicine, 45(2), 189-201.

Addolorato, G., Capristo, E., Stefanini, G. F., \& Gasbarrini, G. (1997). Inflammatory bowel disease: a study of the association between anxiety and depression, physical morbidity, and nutritional status. Scandinavian Journal of Gastroenterology, 32, 1013-1021.

Alberts, M. S., Lyons, J. S., \& Anderson, R. H. (1988). Relations of coping style and illness variables in ulcerative colitis. Psychological Reports, 62, 71-79.

Aldwin, C. M. (2006). Stress, coping, and development: An integrative perspective $\left(2^{\text {nd }}\right.$ Ed.), New York: Guilford.

Aldwin, C. M. (1994). Stress, coping, and development: An integrative perspective. New York: Guilford.

Aldwin, C. M., \& Levenson, M. R. (2001). Stress, coping, and health at mid-life: a developmental perspective. In M. E. Lachman (Ed.), The handbook of midlife development (pp. 188-214). New York: Wiley.

Aldwin, C., Folkman, S., Schaefer, C., Coyne, J. C., \& Lazarus, R. S. (1980, September). Ways of Coping: a process measure. Paper presented at meetings of American Psychological Association, Montreal. 
Ali, T., Dunmore, E., Clark, D., \& Ehlers, A. (2002). The role of negative beliefs in posttraumatic stress disorder: a comparison of assault victims and non-victims. Behavioral and Cognitive Psychotherapy, 30, 249-257.

Alumran, J. I. A., \& Punamäki, R. (2008). Relationship between gender, age, academic achievement, emotional intelligence, and coping styles in Bahraini adolescents. Individual Differences Research, 6, 104-119.

American Psychological Association (2001). Publication manual of the American Psychological Association (5 $5^{\text {th }}$ ed.). Washington, DC: American Psychological Association.

Anderson, J. C., \& Gerbing, D. W. (1988). Structural equation modeling in practice: A review and recommended two-step approach. Psychological Bulletin, 103, 411423.

Antonovsky, A. (1987). Unraveling the mystery of health. San Francisco: Jossey-Bass. Arbuckle, J. L. (2006). Amos (Version 17.0) [Computer Program]. Chicago: SPSS.

Ardizzone, S., \& Bianchi Porro, G. (2002). Inflammatory bowel disease: new insights into pathogenesis and treatments. Journal of Internal Medicine, 252, 475-496.

Armeli, S., Gunthert, K. C., \& Cohen, L. H. (2001). Stressor appraisals, coping, and postevent outcomes: the dimensionality and antecedents of stress-related growth. Journal of Social and Clinical Psychology, 20, 366-395.

Armistead, L., McCombs, A., Forehand, R., Wierson, M., Long, N., \& Fauber, R. (1990). Coping with divorce: a study of young adolescents. Journal of Clinical Child Psychology, 19, 79-84. 
Baird, D. D., Narendranathan, M., \& Sandler, R. S. (1990). Increased risk of pre-term birth for women with inflammatory bowel disease. Gastroenterology, 99, 987994.

Bal, S., Van Oost, P., De Bourdeaudhuij, I., \& Crombez, G. (2003). Avoidant coping as a mediator between self-reported sexual abuse and stress-related symptoms in adolescents. Child Abuse \& Neglect, 27, 883-897.

Barkwell, D. P. (1991). Ascribed meaning: a critical factor in coping and pain attenuation in patients with cancer-related pain. Journal of Palliative Care, 7, 5-14.

Baumeister, R. F. (1991). Meanings in life. New York: Guilford.

Bennett, J., Compas, B., Beckjord, E., \& Glinder, J. (2005). Self-blame and distress among women with newly diagnosed breast cancer. Journal of Behavioral Medicine, 28, 313-323.

Bentler, P. M. (1990). Comparative fit indexes in structural models. Psychological Bulletin, 107, 238-246.

Bentler, P. M., \& Bonett, D. G. (1980). Significance tests and goodness of fit in the analysis of covariance structures. Psychological Bulletin, 88, 588-606.

Bernklev, T., Jahnsen, J., Henriksen, M., Lygren, I., Aadland, E., Sauar, J. et al., (2006). Relationship between sick leave, unemployment, disability, and health-related quality of life in patients with inflammatory bowel disease. Inflammatory bowel diseases, $12,402-412$.

Blank, T. O., \& Bellizzi, K. M. (2006). After prostate cancer: predictors of well-being among long-term prostate cancer survivors. Cancer, 106, 2128-2135.

Bodger, K. (2002). Cost of illness of Crohn's disease. Pharmacoeconomics, 20, 639. 
Bollen, K. A. (1989). A new incremental fit index for general structural models. Sociological Methods \& Research, 17, 303-316.

Bombardier, C. H., D’Amico, C., \& Jordan, J. S. (1990). The relationship of appraisal and coping to chronic illness adjustment. Behavior Research and Therapy, 28(4), 297-304.

Boomsma, A. (2000). Reporting analyses of covariance structures. Structural Equation Modeling, 7, 461-483.

Borden, W., \& Berlin, S. (1990). Gender, coping, and psychosocial well-being in spouses of older adults with chronic dementia. American Journal of Orthopsychiatry, 60 , 603-610.

Bower, J. E., Meyerowitz, B. E., Desmond, K. A., Bernaards, C. A., Rowland, J. H., \& Ganz, P. A. (2005). Perceptions of positive meaning and vulnerability following breast cancer: predictors and outcomes among long-term breast cancer survivors. Annals of Behavioral Medicine, 29, 226-238.

Bowlby, J. (1969). Attachment. New York: Basic Books.

Brown, G. K., \& Nicassio, P. M. (1987). The development of a questionnaire for the assessment of active and passive coping strategies in chronic pain patients. Pain, 3, 53-65.

Brune, M., Haasen, C., Krausz, M., Yagdiran, O., Bustos, E., \& Eisenman, D. (2002). Belief systems as coping factors for traumatized refugees: a pilot study. European Psychiatry, 17, 451-458.

Byrne, B.M. (2001). Structural equation modeling with AMOS: Basic concepts, applications, and programming. New Jersey: Lawrence Erlbaum Associates. 
Calhoun, L. G., \& Tedeschi, R. G. (1991). Positive aspects of critical life problems: recollections of grief. Omega, 20, 265-272.

Carlsson, E., Bosaeus, I., \& Nordgren, S. (2003). What concerns subjects with inflammatory bowel disease and an ileostomy? Scandinavian Journal of Gastroenterology, 9, 978-984.

Carver, C. S., Pozo, C., Harris, S., Noriega, V., Scheier, M. F., Robinson, D. S. et al. (1993). How coping mediates the effect of optimism on distress: a study of women with early stage breast cancer. Journal of Personality and Social Psychology, 65, 375-390.

Carver, C. S., \& Scheier, M. F. (1991). Unresolved issues regarding the meaning and measurement of explanatory style. Psychological Inquiry, 2, 21-24.

Carver, C. S., Scheier, M. G., \& Weintraub, J. G. (1989). Assessing coping strategies: A theoretically-based approach. Journal of Personality and Social Psychology, 56, 267-283.

Carver, C. S. (1997). You want to measure coping but your protocol's too long: Consider the brief COPE. International Journal of Behavioral Medicine, 4, 92-100.

Casati, J. M., Toner, B. B., De Rooy, E. C., Drossman, D. A., \& Maunder, R. G. (2000). Concerns of patients with inflammatory bowel disease: a review of emerging themes. Digestive Diseases and Sciences, 45, 26-31.

Casellas, F., López-Vivancos, J., Badia, X., Vilaseca, J., \& Malagelada, J. R. (2001). Influence of inflammatory bowel disease on different dimensions of quality of life. European Journal of Gastroenterology \& Hepatology, 13, 567-572. 
Catlin, G., \& Epstein, S. (1992). Unforgettable experiences: the relation of life events to basic beliefs about self and world. Social Cognition, 10, 189-209.

Clark, L. F., Henry, S. M., \& Taylor, D. M. (1991). Cognitive examination of motivation for childbearing as a factor in adjustment to infertility. In A. L. Stanton \& C. Dunkel-Schetter (Eds.). Infertility: Perspectives from stress and coping research (pp. 157-180). New York: Plenum.

Cohan, N. (1997). AIDS and the family narrative: reconstructing a story to encompass an illness. In J. Atwood (Ed.), Challenging family therapy situations (pp. 71-97). New York: Springer.

Cohen, F., \& Lazarus, R. S. (1977). Coping with the stress of illness. In: Stone, C. G., Cohen, F., \& Adler, N. E. (Eds.), Health psychology: A handbook (217-254). San Francisco, CA: Jossey-Bass.

Cohen, R. D. (2003). IBD: the drugs work but do the patients? American Journal of Gastroenterology, 98, 722-723.

Collie, K. K., \& Long, B. C. (2005). Considering 'meaning' in the context of breast cancer. Journal of Health Psychology, 10, 843-853.

Collins, D. L., Baum, A., \& Singer, J. E. (1983). Coping with chronic stress at Three Mile Island: Psychological and biochemical evidence. Health Psychology, 1, 149166.

Collins, R. L., Taylor, S. E., \& Skokan, L. A. (1990). A better world or a shattered vision? Changes in life perspectives following victimization. Social Cognition, 8 , 263-285. 
Cooke, D. M. (1991). Inflammatory bowel disease: primary health care management of ulcerative colitis and Crohn's disease. Nurse Practitioner, 16(8), 27-36.

Cordova, M. J., Cunningham, L. L. C., Carlson, C. R., \& Andrykowski, M. A. (2001). Posttraumatic growth following breast cancer: a controlled comparison study. Health Psychology, 20, 176-185.

Coward, D. D. (1990). The lived experience of self-transcendence in women with advanced breast cancer. Nursing Science Quarterly, 3, 162-169.

Coward, D. D. (1997). Constructing meaning from the experience of cancer. Seminars in Oncology Nursing, 13, 248-251.

Crohn's and Colitis Foundation of American (2008). About Ulcerative Colitis and Proctitis. Retrieved from http://www.ccfa.org/info/about/ucp

Crohn's and Colitis Foundation of America (2009a). About Crohn's Disease? Retrieved from http://www.ccfa.org/info/about/crohns

Crohn's and Colitis Foundation of America (2009b). Surgery for Crohn's Disease.

Retrieved from http://www.ccfa.org/info/surgery/surgerycd

Crohn's and Colitis Foundation of American (2009c) Race and ethnicity. Retreived from http://www.ccfa.org/about/press/epidemiologyfacts

Danoff-Burg, S., \& Revenson, T. (2005). Benefit finding among patients with rheumatoid arthritis: positive effects on interpersonal relationships. Journal of Behavioral Medicine, 28, 91-103.

Davis, C. G., \& Macdonald, S. L. (2004). Threat appraisals, distress, and the development of positive life changes after September $11^{\text {th }}$ in a Canadian sample. Cognitive Behaviour Therapy, 33, 68-78. 
Davis, C. G., Nolen-Hoeksema, S., \& Larson, J. (1998). Making sense of loss and benefiting from the experience: two construals of meaning. Journal of Personality and Social Psychology, 75, 561-574.

Davis, C. G., Wohl, M. J. A., \& Verberg, N. (2007). Profiles of posttraumatic growth following an unjust loss. Death Studies, 31, 693-712.

Davis, C. G., Wortman, C. B., Lehman, D. R., \& Silver, R. C. (2000). Searching for meaning in loss: are clinical assumptions correct? Death Studies, 24, 497-540.

Degner, L. F., Hack, T., O'Neil, J. \& Kristjanson, L. J. (2003). A new approach to eliciting meaning in the context of breast cancer. Cancer Nursing, 26, 169.

Delaney, C. P., Fazio, V. W., Remzi, F. H., Hammel, J., Church, J. M., Hull, T. L. et al. (2003). Prospective, age-related analysis of surgical results, functional outcome, and quality of life after ileal pouch-anal anastomosis. Annals of Surgery, 238, $221-228$.

de Rooy, E. C., Toner, B. B., Maunder, R. G., Greenberg, G. R., Baron, D., Steinhart, A. H. et al. (2001). Concerns of patients with inflammatory bowel disease: results from a clinical population. The American Journal of Gastroenterology, 96, 18161821.

Dirksen, S. R. (1995). Search for meaning in long-term cancer survivors. Journal of Advanced Nursing, 21, 628-633.

Downey, G., Silver, R. C., \& Wortman, C. B. (1990). Reconsidering the attributionadjustment relation following a major negative event: coping with the loss of a child. Journal of Personality and Social Psychology, 59, 925-940. 
Drauker, C. B. (1991). Coping with a difficult-to-diagnose illness: the example of interstitial cystitis. Health Care for Women International, 12(2), 191-198.

Dudley-Brown, S. (1996). Living with Ulcerative Colitis. Gastroenterology Nursing, 19, 60-64.

Dudley-Brown, S. (2001). Psychosocial issues in IBD. Nurse-Patient Link, 2, 1-13.

Dudley-Brown, S. (2002). Prevention of psychological distress in persons with inflammatory bowel disease. Issues in Mental Health Nursing, 23, 403-422.

DuPuy, H. (1984). The Psychological General Well-being (PGWB Index). In: N.Wenger, M. Mattson, C. Furberg, \& J. Ellison (Eds.), Assessment of quality of life in clinical trials of cardiovascular therapies (pp. 170-183). New York: Le Jacq.

Elder, G. H., \& Clipp, C. L. (1989). Combat experience and emotional health: impairment and resilience in later life. Journal of Personality, 57, 311-341.

Emmons, R. A. (1995). Striving and feeling: personal goals and subjective well-being. In Gollitzer, P. M. \& Bargh, J. A. (Eds.), The psychology of action: Linking cognition and motivation to behavior (pp.313-337). New York: Guilford.

Emmons, R. A., Colby, P. M., \& Kaiser, H. A. (1998). When losses lead to gains: personal goals and the recovery of meaning. In P. T. P. Wong \& P. S. Fry (Eds.), The human quest for meaning (pp. 163-178). Mahwah, NJ: Erlbaum.

Engel, G. L. (1955). Studies of ulcerative colitis III: The nature of the psychological process. American Journal of Medicine, 17, 231-256.

Esteve, R., Ramirez-Maestre, C., Lopez-Martinez, A. E. (2007). Adjustment to chronic pain: the role of pain acceptance, coping strategies, and pain-related cognitions. Annals of Behavioral Medicine, 33(2), 179-188. 
Evers, A. W. M., Kraaimaat, F. W., Floris, W., van Lankveld, W., Jacobs, J. W. G., \& Bijlsma, J. W. J. (2001). Beyond unfavorable thinking: the illness cognition questionnaire for chronic diseases. Journal of Consulting and Clinical Psychology, 69, 1036-1036.

Exline, J. J. (2002). Stumbling blocks on the religious road: fractured relationships, nagging vices, and the inner struggle to believe. Psychological Inquiry, 13, 182189.

Felton, B. J., \& Revenson, T. A. (1984). Coping with chronic illness: a study of illness controllability and the influence of coping strategies on psychological adjustment. Journal of Consulting and Clinical Psychology, 52, 343-353.

Fife, B. L. (1994). The conceptualization of meaning in illness. Social Science \& Medicine, 38, 309-316.

Fleer, J., Hoekstra, H. J., Sleijfer, D. Th., Tuinman, M. A., \& Hoekstra-Weebers, J. E. H. M. (2006). The role of meaning in the prediction of psychosocial well-being of testicular cancer survivors. Quality of Life Research, 15, 705-717.

Folkman, S. (1997). Positive psychological states and coping with severe stress. Social Science \& Medicine, 45, 1207-1221.

Folkman, S., \& Lazarus, R. S. (1980). An analysis of coping in a middle-aged community sample. Journal of Health and Social Behavior, 21, 219-239.

Folkman, S., \& Lazarus, R. S. (1985). If it changes it must be a process: Study of emotion and coping during three stages of a college examination. Journal of Personality and Social Psychology, 48, 150-170. 
Folkman, S., Lazarus, R. S., Pinley, S., \& Novacek, J. (1987). Age differences in stress and coping processes. Psychology and Aging, 2, 171-184.

Folkman, S., \& Moskowitz, J. T. (2004). Coping: pitfalls and promise. Annual Review of Psychology, 55, 745-774.

Folkman, S., Lazarus, R. S., Gruen, R. J., \& DeLongis, A. (1986). Appraisal, coping, health status, and psychological symptoms. Journal of Personality and Social Psychology, 50, 571-579.

Fontana, A., \& Rosenheck, R. (1998). Psychological benefits and liabilities of traumatic exposure in the war zone. Journal of Traumatic Stress, 11, 485-505.

Franks, H. M., \& Roesch, S. C. (2006). Appraisals and coping in people with cancer: a meta-analysis. Psycho-Oncology, 15, 1027-1037.

Frankl, V. E. (1984). Man's search for meaning. New York: Washington Square.

Frankl, V. E. (1988). The will to meaning. New York: Meridian.

Fromm, K., Andrykowski, M. A., \& Hunt, J. (1996). Positive and negative psychosocial sequelae of bone marrow transplantation: implications for quality of life assessment. Journal of Behavioral Medicine, 19, 221-240.

Futa, K. T., Nash, C. L., Hansen, D. J., \& Garbin, C. P. (2003). Adult survivors of childhood abuse: an analysis of coping mechanisms used for stressful childhood memories and current stressors. Journal of Family Violence, 18, 227-239.

Gazzard, B. G., Price, H. L., Libby, G. W., \& Dawson, A. M. (1978). The social toll of Crohn's disease. British Medical Journal, 2, 1117-1119.

Gilovich, T., \& Medvec, V. H. (1995). The experience of regret: what, when, and why. Psychological Bulletin, 102, 379-395. 
Glinder, J., \& Compas, B. (1999). Self-blame attributions in women with newly diagnosed breast cancer: a prospective study of psychological adjustment. Health Psychology, 18, 475-481.

Glyshaw, K., Cohen, L. H., \& Towbes, L. C. (1989). Coping strategies and psychological distress: prospective analyses of early and middle adolescents. American Journal of Community Psychology, 17, 607-623.

Gordon, G. D. (2008). Structural equation modeling. Retrieved from North Carolina State University, Public Administration Program Web site: http://faculty.chass.ncsu.edu/garson/PA765/structur.htm\#report.

Greenberg, M. A. (1995). Cognitive processing of traumas: the role of intrusive thoughts and reappraisals. Journal of Applied Social Psychology, 25, 1262-1296. Halstead, M. T., \& Fernsler, J. I. (1994). Coping strategies of long-term cancer survivors. Cancer Nursing, 17(2), 94-100.

Grossman, F. K., Sorsoli, L., \& Kia-Keating, M. (2006). A gale force wind: meaning making by male survivors of childhood sexual abuse. American Journal of Orthopsychiatry, 76, 434-444.

Hall, N. J., Rubin, G. P., Dougall, A., Hungin, A. P. S., Neely, J. (2005). The fight for 'health-related normality': a qualitative study of the experiences of individuals living with established inflammatory bowel disease (IBD). Journal of Health Psychology, 10(3), 443-455.

Halstead, M. T., \& Fernsler, J. I. (1994). Coping strategies of long-term cancer survivors. Cancer Nursing, 17, 94-100. 
Harland, N. J., \& Georgieff, K. (2003). Development of the coping strategies questionnaire 24 , a clinically utilitarian version of the Coping Strategies Questionnaire. Rehabilitation Psychology, 48(4), 296-300.

Harper, F. W. K., Schmidt, J. E., Beacham, A. O., Salsman, J. M., Averill, A. A., Graves, K. D. et al. (2007). The role of social cognitive processing theory and optimism in positive psychosocial and physical behavior change after cancer diagnosis and treatment. Psycho-Oncology, 16, 79-91.

Harvey, J. H., Orbuch, T. L., \& Fink, K. (1990). The social psychology of accountmaking: meaning, hope, and generativity. New Zealand Journal of Psychology, 19, 46-57.

Harvey, R. F., \& Bradshaw, J. M. (1980). A simple index of Crohn's-disease activity. Lancet, 1, 514.

Helgeson, V. S., Reynolds, K. A., \& Tomich, P. L. (2006). A meta-analytic review of benefit-finding and growth. Journal of Consulting and Clinical Psychology, 74, 797-816.

Holm, J. E., Holroyd, K. A., Hursey, K. G., Penzien, D. B. (1986). The role of stress in recurrent tension headache. Headache, 26, 160-167.

Horowitz, M. J. (1991). Person schemas. In M. Horowitz (Ed.), Person schemas and maladaptive interpersonal patterns (pp. 13-31). Chicago: University of Chicago Press.

Horowitz, M. J. (1997). Stress response syndromes: PTSD, grief, and adjustment disorders. Northvale, NJ: Aronson. 
Horowitz, M. J., Wilner, M., \& Alvarez, W. (1979). Impact of Event Scale: A measure of subjective stress. Psychosomatic Medicine, 41, 209-218.

Hu, L.T. \& Bentler, P.M. (1999). Cutoff criteria for fit indexes in covariance structure analysis: Conventional criteria versus new alternatives. Structural Equation Modeling: A Multidisciplinary Journal, 6, 1-55.

Hurd, L. B. (1999). Crohn's disease: Pathogenesis and the role of genetics, environment, and cytokenesis. Nurse-Patient Link, 1(1), 1-5.

Irvine, E. J. (2004). Review article: patients' fears and unmet needs in inflammatory bowel disease. Alimentary Pharmacology \& Therapeutics, 20(4), 54-59.

Janoff-Bulman, R. (1989). Assumptive worlds and the stress of traumatic events: applications of the schema construct. Social Cognition, 7, 113-136.

Janoff-Bulman, R. (1991). Understanding people in terms of their assumptive worlds. In D. Ozer, J. M. Healy, Jr., \& A. J. Stewart (Eds.), Perspectives in personality: a research manual (pp.99-116). London: Jessica Kingsley.

Janoff-Bulman, R. (1992). Shattered assumptions: towards a new psychology of trauma. New York: Free Press.

Janoff-Bulman, R., \& Frantz, C. M. (1997). The impact of trauma on meaning: from meaningless world to meaningful life. In M. Power \& C. Brewin (Eds.), The transformation of meaning in psychological therapies: integrating theory and practice. Sussex, England: Wiley \& Sons.

Janoff-Bulman, R., \& Lang-Gunn, L. (1988). Coping with disease and accidents: the role of self-blame attributions. In L. Y. Abramson (Ed.), Social-personal inference in clinical psychology (pp. 116-147). New York: Guilford. 
Janoff-Bulman, R., \& Schwartzberg, S. S. (1991). Toward a general model of personal change: applications to victimization and psychotherapy. In C. R. Snyder \& D. R. Forsyth (Eds.), Handbook of social and clinical psychology: a health perspective (pp. 488-508). New York: Pergamon.

Jalowiec, A. (1991). Psychometric results on the 1987 Jalowiec coping scale. School of Nursing. Chicago: Loyola University of Chicago.

Jim, H. S., Richardson, S. A., Golden-Kreutz, D. M., \& Anderson, B. L. (2006). Strategies used in coping with a cancer diagnosis predict meaning in life for survivors. Health Psychology, 25, 753-761.

Joachim, G., \& Milne, B. (1985). The effects of inflammatory bowel disease on lifestyle. The Canadian Nurse, 81, 38-40.

Jones, S., \& Fox, S. (2009). Generations online in 2009. Pew Internet \& American Life Project. Retrieved May 2, 2009 from http://www.pewinternet.org/Reports/2009/ Generations-Online-in-2009.aspx

Jones, M. P., Bratten, J., \& Keefer, L. (2007). Quality of life in patients with inflammatory bowel disease and irritable bowel syndrome differs between subjects recruited from the clinic or Internet. American Journal of Gastroenterology, 102, 2232-2237.

Joseph, S., \& Linley, P. A. (2005). Positive adjustment to threatening events: an organismic valuing theory of growth through adversity. Review of General Psychology, 9, 262-280.

Kaptein, A. A., Helder, D. I., Scharloo, M., Van Kempen, G. M. J., Weinman, J., Van Houwelingen, H. J. C., \& Roos, R. A. C. (2006). Illness perceptions and coping 
explain well-being in patients with Huntington's Disease. Psychology and Health, 21(4), 431-446.

Keith, T. Z. (2005). Multiple regression and beyond. Boston: Pearson Education.

Kesimci, A., Göral, F. S., \& Gençöz, T. (2005). Determinants of stress-related growth: gender, stressfulness of the event, and coping strategies. Current Psychology: Developmental, Learning, Personality, Social, 24, 68-75.

Kinash, R. G., Fischer, D. G., Lukie, B. E., \& Carr, T. L. (1993). Coping patterns and related characteristics in patients with IBD. Rehabilitation Nursing, 18, 12-19.

King, G. A. (2004). The meaning of life experiences: application of a meta-model to rehabilitation sciences and services. American Journal of Orthopsychiatry, 74, 7288.

Kline, R. B. (2005). Principles and practice of structural equation modeling $\left(2^{\text {nd }}\right.$ ed.). New York: Guilford.

Klinger, E. (1977). Meaning and void: Inner experience and the incentive in people's lives. Minneapolis, MN: University of Minnesota Press.

Kommalage, M. (2009). Use of the Internet by patients attending specialist clinics in Sri Lanka: a cross-sectional study. BMC Medical Informatics and Decision Making, 9. Retrieved from http://www.biomedcentral.com/content/pdf/1472-6947-912.pdf

Kraaij, V., Garnefski, N., \& Vlietstra, A. (2007). Cognitive coping and depressive symptoms in definitive infertility: a prospective study. Journal of Psychosomatic Obstetrics \& Gynecology, 29, 9-16. 
Kraaij, V., Van der Veek, S. M. C., Garnefski, N., Schroevers, M., Witlox, R., \& Maes, S. (2008). Coping, goal adjustment, and psychological well-being in HIV-infected men who have sex with men. AIDS Patient Care and STDs, 22, 395-402.

Kurina, L. M., Goldacre, M. J., Yeates, D., \& Gill, L. E. (2001). Depression and anxiety in people with inflammatory bowel disease. Journal of Beside \& Community Health, 55, 716-720.

Kushner, H. S. (1981). When bad things happen to good people. New York: Schocken.

Larsson, K., Lööf, L., Rönnblom, A., \& Nordin, K. (2008). Quality of life for patients with exacerbations in inflammatory bowel disease and how they cope with disease activity. Journal of Psychosomatic Research, 64, 139-148.

Lazarus, R. S. (1974). Psychological stress and coping in adaptation and illness. International Journal of Psychiatry in Medicine, 5(4), 321-333.

Lazarus, R. (1983). The costs and benefits of denial. In S. Breznitz (Ed.), The denial of stress (pp. 1-30). New York: International Universities Press.

Lazarus, R. S. (1992).Coping with the stress of illness. World Health Organization Regional Publications-European Series, 44, 11-31.

Lazarus, R. S. (1993). Coping theory and research: past, present, and future. Psychosomatic Medicine, 55, 234-247.

Lazarus, R. S. (2001). Relational meaning and discrete emotions. In (Scherer, K. R., \& Schorr, A. Eds.), Appraisal processes in emotion: theory, methods, research (pp. 37-67). New York: Oxford University Press.

Lazarus, R. S., \& Folkman, S. (1984). Stress, appraisal, and coping. New York: Springer Publishing Co. 
Lazarus, R. S., \& Folkman, S. (1987). Transactional theory and research on emotions and coping. European Journal of Personality, 1, 141-169.

Lazarus, R. S., \& Launier, R. (1978). Stress-related transactions between person and environment. In L. A. Pervin \& M. Lewis (Eds.), Perspectives in interactional psychology (pp. 287-327). New York: Plenum.

Lee, V., Cohen, S. R., Edgar, L., Laizner, A. M., \& Gagnon, A. J. (2004). Clarifying "meaning" in the context of cancer research: a systematic literature review. Palliative and Supportive Care, 2, 291-303.

Lee, V., Cohen, S. R., Edgar, L., Laizner, A. M., \& Gagnon, A. J. (2006a). Meaning making and psychological adjustment to cancer: Development of an intervention and pilot results. Oncology Nursing Forum, 33, 291-302.

Lee, V., Cohen, S. R., Edgar, L., Laizner, A. M., \& Gagnon, A. J. (2006b). Meaning making intervention during breast and colorectal cancer treatment improves selfesteem, optimism and self-efficacy. Social Science \& Medicine, 62, 3133-31345.

Lehman, D., Davis, C., DeLongis, A., Wortman, C., Bluck, S., Mandel, D., \& Ellard, J. (1993). Positive and negative life changes following bereavement and their relations to adjustment. Journal of Social and Clinical Psychology, 12, 90-112.

Lengua, L. J., \& Stormshak, E. A. (2000). Gender, gender roles, and personality: gender differences in the prediction of coping and psychological symptoms. Sex Roles: A Journal of Research. Retrieved from http://findarticles.com/p/articles/mi_m2294/ is_2000_Dec/ai_75959828/pg_2/

Lerner, M. J., \& Gignac, M. A. M. (1992). Is it coping or is it growth? A cognitiveaffective model of contentment in the elderly. In L. Montada, S. Filipp, \& M. J. 
Lerner (Eds.), Life crises and experiences of loss in adulthood (pp. 321-337). Hillsdale, NJ: Lawrence Erlbaum Associates.

Levenstein, S. (2004). Embracing complexity: what determines quality of life in inflammatory bowel disease? European Journal of Gastroenterology \& Hepatology, 16, 1253-1255.

Levenstein, S., Li, Z., \& Drossman, D. A. (1998). Cross-cultural variation in diseaserelated concerns among patients with inflammatory bowel disease. Gastroenterology, 114, 1021.

Lewis, F. M. (1989). Attributions of control, experienced meaning, and psychosocial well-being in patients with advanced cancer. Journal of Psychosocial Oncology, 7, 105-119.

Lewis, S. E. (1995). A search for meaning: making sense of depression. Journal of Mental Health, 4(4), 369-381.

Li, J., \& Lambert, V. (2007). Coping strategies and predictors of general well-being in women with breast cancer in the People's Republic of China. Nursing and Health Sciences, 9, 199-204.

Linley, P. A., \& Joseph, S. (2004). Positive change following trauma and adversity: a review. Journal of Traumatic Stress, 17, 11-21.

Lipowski, Z. J. (1983). Psychosocial reactions to physical illness. Canadian Medical Association Journal, 128, 1069-1072.

Littlewood, J. L., Cramer, D., Hoekstra, J., \& Humphrey, G. B. (1991). Gender differences in parental coping following their child's death. British Journal of Guidance and Counseling, 19, 139-148. 
Livneh, H. (2000). Psychosocial adaptation to cancer: the role of coping strategies. Journal of Rehabilitation, 66(2), 40-49.

Longobardi, T., \& Bernstein, C. N. (2007). Utilization of health-care resources by patients With IBD in Manitoba: a profile of time since diagnosis. American Journal of Gastroenterology, 102, 1683-1691.

Loonen, H. J., Grootenhuis, M. A., Last, B. F., Haan, R. J. De, Bouquet, J., Derkx, H. H. J. (2002). Measuring quality of life in children with inflammatory bowel disease: The Impact-II (NL). Quality of Life Research, 11(1), 47-56.

Madden, S., \& Sim, J. (2006). Creating meaning in fibromyalgia syndrome. Social Science \& Medicine, 63, 2962-2973.

Malcarne, V. L., \& Greenbergs, H. L. (1996). Psychological adjustment to systemic sclerosis. American College of Rheumatology, 9(1), 51-59.

Mallett, S. J., Lennard-Jones, J. E., Bingley, J., \& Gilon, E. (1978). Colitis. Lancet, Sept. $16,2,619-621$.

Marris, P. (1986). Loss and change. London: Routledge \& Kegan Paul.

Martin, L. L., \& Tesser, A. (1989). Toward a motivational and structural theory of ruminative thought. In J. S. Uleman \& J. A. Bargh (Eds.), Unintended thought (pp. 306-325). New York: Guilford.

Martin, L. L., Tesser, A., \& McIntosh, W. D. (1993). Wanting but not having: the effects of unattained goals on thoughts and feelings. In D. M. Wegner \& J. W. Pennebaker (Eds.), Handbook of mental control (pp. 552-572). Englewood Cliffs, NJ: Prentice Hall. 
Mattlin, J. A., Wethington, E., \& Kessler, R. (1990). Situational determinants of coping and coping effectiveness. Journal of Health and Social Behavior, 31, 103-122.

Maunder, R., \& Esplen, M. J. (1999). Facilitating adjustment to inflammatory bowel disease: a model of psychosocial intervention in non-psychiatric patients. Psychotherapy and psychosomatics, 68, 230-240.

Mayberry, M. K., Probert, C., Srivastava, E., Rhodes, J., \& Mayberry, J. F. (1992). Perceived discrimination in education and employment by people with Crohn's disease: a case-control study of educational achievement and employment. Gut, $312-314$

McCracken, L. M., \& Eccleston, C. A. (2005). A prospective study of acceptance of pain and patient functioning with chronic pain. Pain, 8, 164-169.

McCrae, R. R. (1982). Age differences in the use of coping mechanisms. Journal of Gerontology, 37, 454-460.

McDonald, R. P., \& Ho, M. R. (2002). Principle and practice in reporting structural equation analyses. Psychological Methods, 7, 64-82.

McHugh, J. P. (1998). Body image and ostomy surgery. Ostomy Quarterly, 35, 30-31.

McIntosh, D. N., Silver, R. C., \& Wortman, C. B. (1993). Religion's role in adjustment to a negative life event: coping with the loss of a child. Journal of Personality and Social Psychology, 65, 812-821.

McMillen, J. C., \& Fisher, R. H. (1998). The perceived benefit scales: measuring perceived positive life changes after negative events. Social Work Research, 22, 173-187. 
McMillen, J. C., Smith, E., \& Fisher, R. (1997). Perceived benefit and mental health after three types of disaster. Journal of Consultation and Clinical Psychology, 65, 733739.

McMillen, J. C., Zuravin, S., \& Rideout, G. (1995). Perceived benefit from child sexual abuse. Journal of Consulting and Clinical Psychology, 65, 1037-1043.

Mendola, R., Tennen, H., Affleck, G., McCann, L., \& Fitzgerald, T. (1990). Appraisal and adaptation among women with impaired infertility. Cognitive Therapy and Research, 14, 79-93.

Mikulincer, M., \& Florian, V. (1996). Coping and adaptation to trauma and loss. In M. Zeidner \& N. S. Endler (Eds.), Handbook of coping: theory, research, applications (pp. 554-572). New York: Wiley.

Milam, J. E. (2004). Posttraumatic growth among HIV/AIDS patients. Journal of Applied Social Psychology, 34, 2353-2376.

Milam, J. E., Ritt-Olson, A., \& Unger, J. B. (2004). Posttraumatic growth among adolescents. Journal of Adolescent Research, 19, 192-204.

Miles, M. B., \& Huberman, A. M. (1994). An expanded sourcebook: qualitative data analysis $\left(2^{\text {nd }}\right.$ ed.). Thousand Oaks: Sage Publications.

Millar, K. U., Tesser, A., \& Millar, M. G. (1988). The effects of a threatening life event on behavior sequences and intrusive thought: a self-disruption explanation. Cognitive Therapy and Research, 12, 441-457.

Miller, J. F. (1983). Coping with chronic illness: overcoming powerlessness. Philadelphia: Davis Company. 
Miller, S., M., \& Kirsch, N. (1987). Sex differences in cognitive coping with stress. In R. C. Barnett, L. Biener, \& G. K. Baruch (Eds.), Gender and stress (pp. 278-307). New York: The Free Press.

Millon, T., Green, C. J., \& Meagher, R. (1982). The Millon Behavioral Health Inventory manual ( $3^{\text {rd }}$ edition). Minneapolis: National Computer Systems.

Mishel, M. H. (1988). Uncertainty in illness. Image Journal of Nursing Scholarship, 20, $225-232$.

Mitchell, A., Guyatt, G., Singer, J., \& Irvine, E. J. (1988). Quality of life in patients with inflammatory bowel disease. Journal of Clinical Gastroenterology, 10, 306-310.

Mohr, D. C., Dick, L. P., Russo, D., Pinn, J., Boudewyn, A. C., Likosky, W. et al., (1999). The psychosocial impact of multiple sclerosis: exploring the patient's perspective. Health Psychology, 18, 376-382.

Moody, G. A., \& Mayberry, J. F. (1993). Perceived sexual dysfunction amongst patients with inflammatory bowel disease. Digestion, 54, 256-260.

Moody, G. A., Probert, C. S., Jayanthi, V., \& Mayberry, J. F. (1992). The attitude of employers to people with inflammatory bowel disease. Gut, 29, 1229-1235.

Moos, R. H., \& Schaefer, J. A. (1986). Coping resources and processes: current concepts and measures. In L. Goldberger \& S. Breznitz (Eds.), Handbook of stress $\left(2^{\text {nd }}\right.$ ed.; pp. 234-257). New York: Free Press.

Moos, R. H., \& Tsu, D. V. (1977). Coping with physical illness. New York: Plenum Medical Company.

Monat, A., \& Lazarus, R. S. (1991). Stress and coping: An anthology. New York: Columbia University Press. 
Moreno-Jiménez, B., López Blanco, B., Rodríguez-Muñoz, A., \& Garrosa Hernández, E. (2007). The influence of personality factors on health-related quality of life of patients with inflammatory bowel disease. Journal of Psychosomatic Research, $62,39-46$.

Moyer, P. (2006). Women with IBD have more severe quality of life issues than men [Abstract]. Abstract 35 from the American College of Gastroenterology 2006 Annual Meeting. Retrieved from http://www.medscape.com/viewarticle/546827

Murray, J. B. (1984). Psychological factors in ulcerative colitis. Journal of General Psychology, 110, 201-221.

Musil, C. M., Jones, S. L., \& Warner, C. D. (1998). Structural equation modeling and its relationship to multiple regression and factor analysis. Research in Nursing and Health, 21, 271-281.

Neimeyer, R. A. (2006). Re-storying loss: fostering growth in the posttraumatic narrative. In L. Calhoun \& R. Tedeschi (Eds.), Handbook of posttraumatic growth: Research and practice (pp. 68-80). Mahwah, NJ: Erlbaum.

Nightingale, A. (2006). Treatment and management of inflammatory bowel disease. Primary Health Care, 16, 27-32.

Ninot, G., Fortes, M., Poulain, M., Brun, A., Desplan, J., Préfaut, C., \& Varray, A. (2006). Gender difference in coping strategies among patients enrolled in an inpatient program. Heart and Lung: The Journal of Acute and Clinical Care, 35, 130-136.

Nolen-Hoeksema, S. (1987). Sex differences in unipolar depression: evidence and theory. Psychological Bulletin, 101, 259-282. 
North, C. S., Clouse, R. E., Sptznagel, E. L., \& Alperes, D. H. (1990). The relationship of ulcerative colitis to psychiatric factors: a review of findings and methods. American Journal of Psychiatry, 147, 974-981.

O'Connor, A. P., Wicker, C. A., \& Germino, B. B. (1990). Understanding the cancer patient's search for meaning. Cancer Nursing, 13, 167-175.

O’Dougherty Wright, M., Crawford, E., \& Sebastian, K (2007). Positive reframing of childhood sexual abuse experiences: the role of coping, benefit-finding and meaning making. Journal of Family Violence, 22, 597-608.

Pakenham, K. I. (2005). Benefit finding in multiple sclerosis and associations with positive and negative outcomes. Health Psychology, 24, 123-132.

Paloutzian, R. F., Richardson, J. T., \& Rambo, L. R. (1999). Religious conversion and personality change. Journal of Personality, 67, 1047-1079.

Pargament, K. I. (1997). The psychology of religion and coping. New York: Guilford. Pargament, K. I., Koenig, H. G., \& Perez, L. M. (2000). The many methods of religious coping: development and initial validation of the RCOPE. Journal of Clinical Psychology, 56, 519-543.

Pargament, K. I., Koenig, H. G., Tarakeshwar, N., \& Hahn, J. (2001). Religious struggle as a predictor of mortality among medically ill elderly patients: A two-year longitudinal study. Archives of Internal Medicine, 161, 1881-1885.

Pargament, K. I., Smith, B., \& Koenig, H. (1996). Religious coping with the Oklahoma City Bombing: the Brief RCOPE. Paper presented at the Annual Convention of the American Psychological Association, Toronto, ON. 
Park, C. L. (1998). Implications of posttraumatic growth for individuals. In R. G. Tedeschi, C. L. Park, \& L. G. Calhoun (Eds.), Posttraumatic growth: positive changes in the aftermath of crisis (pp. 153-177). Mahweh, New Jersey: Lawrence Erlbaum.

Park, C. L. (2004). The notion of growth following stressful life experiences: Problems and prospects. Psychological Inquiry, 15, 69-76.

Park, C. L., (2005). Religion as a meaning making framework in coping with life stress. Journal of Social Issues, 61, 707-729.

Park, C. L. (2006). Exploring relations among religiousness, meaning, and adjustment to lifetime and current stressful encounters. Anxiety, Stress, and Coping, 19, 33-45.

Park, C. L. (2008). Testing the meaning making model of coping with loss. Journal of Social and Clinical Psychology, 27, 970-994.

Park, C. L., \& Ai, A. L. (2006). Meaning making and growth: new directions for research on survivors of trauma. Journal of Loss and Trauma, 11, 389-407.

Park, C. L. \& Blumberg, C. J. (2002). Disclosing trauma through writing: testing the meaning making hypothesis. Cognitive Therapy and Research, 26, 597-616.

Park, C. L., \& Cohen, L. H. (1993). Religious and nonreligious coping with the death of a friend. Cognitive Therapy and Research, 17, 561-577.

Park, C. L., Cohen, L. H., \& Murch, R. (1996). Assessment and prediction of stressrelated growth. Journal of Personality, 64, 71-105.

Park, C. L., Edmondson, D., Fenster, J. R., \& Blank, T. O. (2008). Meaning making and psychological adjustment following cancer: the mediating roles of growth, life 
meaning, and restored just-world beliefs. Journal of Consulting and Clinical Psychology, 76, 863-875.

Park, C. L., \& Fenster, J. A. (2004). Stress-related growth: predictors and processes. Journal of Social and Clinical Psychology, 23, 195-215.

Park, C. L., \& Folkman, S. (1997). Meaning in the context of stress and coping. Review of General Psychology, 1(2), 115-144.

Park, C., \& Folkman, S. (2005). Religion as a meaning making framework in coping with life stress. Journal of Social Issues, 61, 707-729.

Payne, A. J., Joseph, S., \& Tudway, J. (2007). Assimilation and accommodation processes following traumatic experiences. Journal of Loss and Trauma, 12, $73-$ 89.

Pearlin, L. I. (1991). The study of coping: An overview of problems and directions. In J. Eckenrode (Ed.), The social context of coping (pp. 261-276). New York: Plenum. Pearlin, L. I., \& Schooler, C. (1978). The structure of coping. Journal of Health and Social Behavior, 9, 3-21.

Perloff, L. S. (1983). Perceptions of vulnerability to victimization. Journal of Social Issues, 2, 41-61.

Petrie, K. J., Buick, D. L., Weinman, J., \& Booth, R. J. (1999). Positive effects of illness reported by myocardial infarction and breast cancer patients. Journal of Psychosomatic Research, 47, 537-543.

Pew Internet \& American Life Project (2008). Demographics of Internet Users. December 2008 Survey. Retrieved May 2, 2009 from http://www.pewinternet.org/Data-Tools/Download-Data/ /media/Infographics/ 
Trend\%20Data/January\%202009\%20updates/Demographics\%20of\%20Internet\% 20Users\%201\%206\%2009.jpg

Phillips, L. J., \& Stuifbergen, A. K. (2009). Structural equation modeling of disability in women with fibromyalgia or multiple sclerosis. Western Journal of Nursing Research, 31, 89-109.

Plante, T. G., \& Sherman, A. C. (Eds.). (2001). Faith and Health: Psychological Perspectives. New York: Guilford Press.

Plattner, I. E., \& Meiring, N. (2006). Living with HIV: the psychological relevance of meaning making. AIDS Care, 18, 241-245.

Polatinsky, S., \& Esprey, Y. (2000). An assessment of gender differences in the perception of benefit resulting from the loss of a child. Journal of Traumatic Stress, $13,709-718$.

Pollin, I. (1995). Medical crisis counseling: short-term therapy for long-term illness. New York: Norton \& Company.

Porter, L. S., \& Stone, A. A. (1995). Are there really gender differences in coping? A reconsideration of previous data and results from a daily study. Journal of Social and Clinical Psychology, 14, 184-202.

Ptacek, J. T., Smith, R. E., \& Zanas, J. (1992). Gender, appraisal, and coping: A longitudinal analysis. Journal of Personality, 60, 747-770.

Rachman, S. (1980). Emotional processing, Behaviour Research and Therapy, 18, 51-60. Ramirez-Maestre, C., \& Valdiva, Y. (2003). Evaluación del functionamiento diario en pacientes con dolor crónico. Psicología Conductual, 11, 283-291. 
Rao, S. S., Holdsworth, C. D., \& Read, N. W. (1988). Symptoms and stool patterns in patients with ulcerative colitis. Gut, 29, 342-345.

Reker, G. T., \& Wong, P. T. P. (1988). Aging as an individual process: toward a theory of personal meaning. In J. E. Birren \& V. L. Bengston (Eds.), Emergent theories of aging (pp. 214-246). New York: Springer.

Reker, G. T., Peacock, E. J., \& Wong, P. T. P. (1987). Meaning and purpose in life and well-being: a life-span perspective. Journal of Gerontology, 42, 44-49.

Reuter, K., Classen, C. C., Roscoe, J. A., Morrow, G. R., Kirshner, J. J., Rosenbluth, R. et al. (2006). Association of coping style, pain, age, and depression with fatigue in women with primary breast cancer. Psycho-Oncology, 15, 772-779.

Rhodes, A. R. (2006). Quality of life issues for people with IBD: an exploratory study to investigate the relationship of coping skills, social support and negative social interactions to anxiety and depression for people with IBD. Unpublished doctoral dissertation, The Ohio State University, Columbus.

Richaud de Minzi, M. C., \& Sacchi, C. (2005). Stressful situations and coping strategies in relation to age. Psychological Reports, 97, 405-418.

Richer, M. C., \& Ezer, H. (2000). Understanding beliefs and meanings in the experience of cancer: a concept analysis. Journal of Advanced Nursing, 32, 1108-1115.

Roberts, S. A., Kiselica, M. S., \& Fredrickson, S. A. (2002). Quality of life of persons with medical illnesses: counseling's holistic contribution. Journal of Counseling \& Development, 80, 422-432. 
Rosario, M., Shinn, M., Morch, H., \& Huckabee, C. B. (1988). Gender differences in coping and social supports. Journal of Social and Clinical Psychology, 23(2), $195-215$.

Rosenstiel, A. K., \& Keefe, F. J. (1983). The use of coping strategies in chronic low back pain patients: relationship to patient characteristics and current adjustment. Pain, $17,33-44$.

Rowe, M. M., \& Allen, R. G. (2004). Spirituality as a means of coping with chronic illness. American Journal of Health Studies, 19, 62-67.

Rowland, J. H. (1989). Interpersonal resources: Coping. In J. C. Holland \& J. H. Rowland (Eds.), Handbook of psycho-oncology: Psychological care of the patient with cancer (pp. 44-57). New York: Oxford University Press.

Samson, A., \& Siam, H. (2008). Adapting to a major chronic illness: a proposal for a comprehensive task-model approach. Patient Education and Counseling, 70, 426429.

Schaefer, J., \& Moos, R. (1992). Life crises and personal growth. In B. Carpenter (Ed.), Personal coping: theory, research, and application (pp.149-170). Westport, CT: Praeger.

Schaefer, J., \& Moos, R. (1998). The context for posttraumatic growth: life crises, individual and social resources, and coping. In R. G. Tedeschi, C. L. Park, \& L. G. Calhoun (Eds.), Posttraumatic growth: positive changes in the aftermath of crisis (pp. 99-125). Mahweh, New Jersey: Lawrence Erlbaum. 
Schnoll, R. A., Harlow, L. L., Stolbach, L. L., \& Brandt, U. (1998). A structural model of the relationships among stage of disease, age, coping, and psychological adjustment in women with breast cancer. Psycho-oncology, 7, 69-77.

Schumacker, R.E. \& Lomax, R.G. (2004). A beginner's guide to structural equation modeling. New Jersey: Lawrence Erlbaum Associates.

Schwarz, S. P., \& Blanchard, E. B. (1991). Evaluation of a psychological treatment for inflammatory bowel disease. Behavior Research and Therapy, 29, 167-177.

Schwarzer, R. \& Knoll, N. (2003). Positive coping: mastering demands and searching for meaning. In S. J. Lopez \& C. R. Snyder (Eds.), Positive psychological assessment: A handbook of models and measures (pp. 393-409). Washington, DC: American Psychological Association.

Scioli, A., McClelland, D. C., Weaver, S. L., \& Madden, E. M. (2000). Coping strategies and integrative meaning as moderators of chronic illness. International Journal of Aging and Human Development, 51(2), 115-136.

Sears, S. R., Stanton, A. L., \& Danoff-Burg, S. (2003). The yellow brick road and the Emerald City: benefit finding, positive reappraisal coping, and posttraumatic growth in women with early-stage breast cancer. Health Psychology, 22, 487-497.

Sewitch, M. J., Abrahamowicz, M., Bitton, A., Daly, D., Wild, G. E., Cohen, A., et al. (2001). Psychological distress, social support, and disease activity in patients with inflammatory bowel disease. American Journal of Gastroenterology, 96, 14701479.

Sharpe, L., \& Curran, L. (2006). Understanding the process of adjustment to illness. Social Sciences \& Medicine, 62, 1153-1166. 
Shumaker, S. A., \& Hill, D. R. (1991). Gender differences in social support and physical health. Health Psychology, 10, 102-111.

Shuman, R. (1996). The psychology of chronic illness. New York: Basic Books.

Siegel, K., \& Schrimshaw, E. W. (2000). Perceiving benefits in adversity: stress-related growth in women living with HIV/AIDS. Social Science and Medicine, 51, 15431554.

Siegel, K., Schrimshaw, E. W., \& Pretter, S. (2005). Stress-related growth among women living with HIV/AIDS: examination of an explanatory model. Journal of Behavioral Medicine, 28, 403-414.

Silberman, I. (2005). Religion as a meaning system: implications for the new millennium. Journal of Social Issues, 6l(4), 641-663.

Silberman, S. (n.d.). The intimate relationship of sex and IBD. Retrieved April 14, 2009, from http://www.ccfa.org/frameviewer/?url=/media/pdf/ibdsexuality.pdf

Silver, R. L., Boon, C., \& Stones, M. H. (1983). Searching for meaning in misfortune: making sense of incest. Journal of Social Issues, 39, 81-102.

Skaggs, B. G., \& Barron, C. R. (2006). Searching for meaning in negative events: concept analysis. Journal of Advanced Nursing, 53, 559-570.

Smith, C. A., Haynes, K. N., Lazarus, R. S., \& Pope, L. K. (1993). In search of the "hot" cognitions: attributions, appraisals, and their relation to emotion. Journal of Personality and Social Psychology, 65, 916-929.

Smolen, D. M., \& Topp, R. (1998). Coping methods of patients with inflammatory bowel disease and prediction of perceived health, functional status, and well-being. Gastroenterology Nursing, 21, 112-118. 
Snow-Turek, A. L., Norris, M. P., \& Tan, G. (1996). Active and passive coping strategies in chronic pain patients. Pain, 64, 455-462.

Soetikno, R. M., Mrad, R., Pao, V., \& Lenert, L. A. (1997). Quality-of-life research on the Internet: feasibility and potential biases in patients with ulcerative colitis. American Medical Information Association, 4, 426-435.

Sorenson, D. L. S. (1995). Life event timing synchrony. Image: Journal of Nursing Scholarship, 27, 297-300.

Sperling, M. (1960). Symposium of disturbances of the digestive tract II: unconscious fantasy life and object-relationships in ulcerative colitis. International Journal of Psychoanalysis, 41, 450-455.

SPSS for Windows, Rel. 17.0. 2008. Chicago: SPSS Inc.

Stanton, A. L., Bower, J. E., \& Low, C. A. (2006). Posttraumatic growth after cancer. In L. G. Calhoun \& R. G. Tedeschi (Eds.). Handbook of posttraumatic growth: research and practice (pp.138-175). Mahwah, NJ: Erlbaum.

Stanton, A. L., Danoff-Berg, S., Cameron, C. L., and Ellis, A. P. (1994). Coping through emotional approach: problems of conceptualization and confounding. Journal of Personality and Social Psychology, 66, 350-362.

Stanton, A.L., Danoff-Burg, S., Cameron, C.I., Bishop, M., Collins, C.A., Kirk, S.B., \& Sworowski, L.A. (2000a). Emotionally expressive coping predicts psychological and physical adjustment to breast cancer. Journal of Consulting and Clinical Psychology, 68, 875-882. 
Stanton, A. L., Kirk, S. B., Cameron, C. L., \& Danoff-Burg, S. (2000b). Coping through emotional approach: scale construction and validation. Journal of Personality and Social Psychology, 78, 1150-1169.

Stanton, A., Tennen, H., Affleck, G., \& Mendola, R. (1992). Coping and adjustment to infertility. Journal of Social and Clinical Psychology, 11, 1-13.

Steeves, R. (1992). Patients who have undergone bone marrow transplantation: their quest for meaning. Oncology Nursing Forum, 19, 899-905.

Steiger, J. H, \& Lind, J. C. (1980, June). Statistically based tests for the number of common factors. Paper presented at the Psychometric Society Annual Meeting, Iowa City, IA.

Steiner-Grossman, P., Banks, P. A., \& Present, D. H. (1992). The new people not patients: a source book for living with inflammatory bowel disease. Dubuque: Kendall/Hunt.

Stone, A. A., \& Neale, J. M. (1984). New measure of daily coping: Development and preliminary results. Journal of Personality and Social Psychology, 46, 892-906.

Tait, R., \& Silver, R. C. (1989). Coming to terms with major negative life events. In J. S. Uleman \& J. A. Bargh (Eds.), Unintended thought (pp. 351-382). New York: Guilford.

Tashakkori, A., \& Teddlie, C. (1998). Mixed methodology: Combining qualitative and quantitative approaches. Sage: Thousand Oaks.

Taylor, S. E. (1983). Adjusting to threatening events: a theory of cognitive adaptation. American Psychologist, 38, 1161-1173. 
Taylor, S. E., \& Brown, J. D. (1988). Illusion and well-being: a social psychological perspective on mental health. Psychological Bulletin, 103, 193-210.

Taylor, S. E., \& Brown, J. D. (1994). Positive illusion and well-being revisited: separating fiction from fact. Psychological Bulletin, 116, 21-27.

Tedeschi, R. G., \& Calhoun, L. G. (1995). Trauma and transformation: growing in the aftermath of suffering. Thousand Oaks, CA: Sage.

Tedeschi, R. G., \& Calhoun, L. G. (1996). The post-traumatic growth inventory: Measuring the positive legacy of trauma. Journal of Trauma and Stress, 9, 45571.

Tedeschi, R. G., \& Calhoun, L. G. (2004). Posttraumatic growth: conceptual foundations and empirical evidence. Psychological Inquiry, 15, 1-15.

Tedeschi, R. G., Park, C. L., \& Calhoun, L. G. (1998). Posttraumatic growth: conceptual issues. In R. G. Tedeschi, C. L. Park, \& L. G. Calhoun (Eds.), Posttraumatic growth: positive changes in the aftermath of crisis (pp. 1-22). Mahwah, New Jersey: Lawrence Erlbaum Associates.

Tennen, H., \& Affleck, G. (2002). Benefit finding and benefit reminding. In S. J. Lopez \& C. R. Snyder (Eds.), Handbook of positive psychology (pp. 584-599). New York: Oxford.

Tennen, H., Affleck, G., Urrows, S., Higgins, P., \& Mendola, R. (1992). Perceiving control, construing benefits, and daily processes in rheumatoid arthritis. Canadian Journal of Behavioral Science, 24, 186-203.

Testa, M. A., \& Simonson, D. C. (1996). Assessment of quality-of-life outcomes. New England Journal of Medicine, 334(13), 835-840. 
Thompson, S. C. (1985). Finding positive meaning in a stressful event and coping. Basic and Applied Psychology, 6, 279-295.

Thompson, S. C. (1991). The search for meaning following a stroke. Basic and Applied Social Psychology, 12(1), 81-96.

Thompson, S. C., \& Janigian, A. (1988). Life schemes: a framework for understanding the search for meaning. Journal of Social and Clinical Psychology, 7, 260-280.

Thompson, S. C., \& Pitts, J. (1993). Factors relating to a person's ability to find meaning after a diagnosis of cancer. Journal of Psychosocial Oncology, 11, 1-21.

Thompson, W. G. (1993). The angry gut: coping with colitis and Crohn's disease. New York: Plenum Press.

Thornton, A. A., \& Perez, M. A. (2006). Posttraumatic growth in prostate cancer survivors and their partners. Psychooncology, 15, 285-296.

Timmer, A., Bauer, A., Dignass, A., \& Rogler, G. (2007). Sexual function in persons with inflammatory bowel disease: a survey with matched controls. Clinical Gastroenterology and Hepatology, 5, 87-94.

Tomich, P. L., \& Helgeson, V. S. (2002). Five years later: a cross-sectional comparison of breast cancer survivors with healthy women. Psycho-Oncology, 11, 154-169.

Tomich, P. L., \& Helgeson, V. S. (2004). Is finding something good in the bad always good? Benefit finding among women with breast cancer. Health Psychology, 23, $16-23$.

Treadwell, J. R., Soetikno, R. M., \& Lenert, L. A. (1999). Feasibility of quality-of-life research on the Internet: a follow-up study. Quality of Life Research, 8, 743-747. 
Treharne, G. J., Lyons, A. C., Booth, D. A., \& Kitas, G. D. (2007). Psychological wellbeing across 1 year with rheumatoid arthritis: coping resources as buffers of perceived stress. British Journal of Health Psychology, 12, 323-345.

Trochim, W. M. K. (2006). Research Methods Knowledge Base. Nonprobability Sampling. Retrieved June 17, 2009 from http://www.socialresearchmethods.net/ $\mathrm{kb} /$ sampnon.php

Turner, J. A., Clancy, S., \& Vitaliano, P. P. (1987). Relationships of stress, appraisal and coping to chronic low back pain. Behavior Research and Therapy, 25, 281-288.

Turnquist, D., Harvey, J., \& Anderson, B. (1988). Attributions and adjustment to lifethreatening illness. British Journal of Personality and Social Psychology, 46, 489502.

United States Census Bureau (2000). Census 2000 Summary File 3. Retrieved May 2, 2009 from http://factfinder.census.gov/servlet/QTTable?_bm=y\&geo_id $=01000$ US\&-qr_name=DEC_2000_SF3_U_QTP20\&ds_name $=$ DEC_2000_SF3_U

Updegraff, J. A., Taylor, S. E., Kemeny, M. E., \& Wyatt, G. E. (2002). Positive and negative effects of HIV infection in women with low socioeconomic resources. Personality and Social Psychology Bulletin, 28, 382-394.

Urcuyo, K. R., Boyers, A. E., Carver, C. S., \& Antoni, M. H. (2005). Finding benefit in breast cancer: relations with personality, coping, and concurrent well-being. Psychology and Health, 20, 175-192. 
van den Bout, J., van Son-schoones, N., Schipper, J., \& Groffen, C. (1988). Attributional cognitions, coping behavior, and self-esteem in inpatients with severe spinal cord injuries. Journal of Clinical Psychology, 44, 17-22.

van der Zaag-Loonen, H. J., Grootenhuise, M. A., Last, B. F., \& Derkx, H. H. (2004).

Coping strategies and quality of life of adolescents with inflammatory bowel disease. Quality of Life Research, 13, 1011-1019.

van Uden-Kraan, C., Drossaert, C. H. C., Taal, E., Smit, W. M., Moens, H. B., Siesling, S. et al. (2009). Health-related Internet use by patients with somatic diseases: frequency of use and characteristics of users. Informatics for Health \& Social Care, 34, 18-29.

Vickberg, S. M. J. (2003). The Concerns About Recurrence Scale (CARS): a systematic measure of women's fears about the possibility of breast cancer recurrence. Annals of Behavioral Medicine, 25, 16-24.

Vickberg, S. M. J., DuHamel, K. N., Smith, M. Y., Manne, S. L., Winkel, G., Papadopoulos, E. B. et al., (2001). Global meaning and psychological adjustment among survivors of bone marrow transplant. Psycho-Oncology, 10, 29-39.

Walker, J. R., Ediger, J. P., Graff, L. A., Greenfield, J. M., Clara, I., Lix, L. et al., (2008). The Manitoba IBD cohort study: a population-based study of the prevalence of lifetime and 12-month anxiety and mood disorders. American Journal of Gastroenterology, 103, 1989-1997.

Warrington, K., \& Gottlieb, L. (1987). Uncertainty and anxiety of hysterectomy patients during hospitalization. Nursing Papers, 19(1), 59-73. 
Weinstein, N. D. (1987). Unrealistic optimism about susceptibility to health problems: conclusions from a community sample. Journal of Behavioral Medicine, 10, 481500.

Weiss, T. (2002). Posttraumatic growth in women with breast cancer and their husbands: an intersubjective validation study. Journal of Psychosocial Oncology, 20, 65-80.

Weiss, T. (2004). Correlates of posttraumatic growth in married breast cancer survivors. Journal of Social and Clinical Psychology, 23(5), 733-746.

Wineman, N. M. (1990). Adaptation to multiple sclerosis: the role of social support, functional disability, and perceived uncertainty. Nursing Research, 39(5), 294299.

Wineman, N. M., O'Brien, R. A., Nealon, N. R., \& Kaskel, B. (1993). Congruence in uncertainty between individuals with multiple sclerosis and their spouses. Journal of Neuroscience Nursing, 25, 356-361.

Yalom, I. D. (1998). The Yalom Reader. New York: Basic Books.

Ziebland, S., Chapple, A, Dumelow, C., Evans, J., Prinjha, S., \& Rozmovits, L. (2004). How the Internet affects patients' experience of cancer: a qualitative study. British Medical Journal, 328, 564-570. Retrieved from http://www.bmj.com/cgi/reprint/ $328 / 7439 / 564$

Zigmond, A. S., \& Snaith, R. P. (1983). The Hospital Anxiety and Depression Scale. Acta Psychiatrica Scandinavica, 67, 361-370. 


\section{APPENDIX A}

\section{(CONSENT PREAMBLE)}

\section{COPING WITH INFLAMMATORY BOWEL DISEASE}

\section{Dear Prospective Participant:}

You have been invited to participate in a research study by answering the attached survey about how people cope with Inflammatory Bowel Disease, which includes questions about your thoughts, feelings and experiences with the either Crohn's Disease or Ulcerative Colitis. Anyone diagnosed with these forms of IBD is invited to participate as this is an opportunity to share your experience and help make a difference in the profession's understanding and treatment of this complex illness.

The survey will take approximately $20-40$ minutes to complete. There are no known risks for your participation in this research study; however, some people might consider questions about their coping strategies or stressful life events to be sensitive or personal. An example of such a question is, "How much did your IBD interfere with your ability to establish intimacy?" If you feel that any item is too sensitive or personal, you may skip it. You do not have to answer any questions that make you uncomfortable. If you should become upset or distressed, you may call 1-800-784-2433, a 24-hour crisis line.

Taking part in this study is voluntary. By completing this survey you agree to take part in this research study. If you decide to be in this study, you may still withdraw at any time. If you decide not to be in this study or if you stop taking part at any time, you will not lose any benefits for which you may qualify. The information collected may not benefit you directly; however, what is learned in this study may be helpful to others. The information you provide will be used to refine our understanding of how people experience, and adapt to, IBD and stressful life events in general.

Although your participation is completely voluntary, upon completion of this online survey you will have the option of providing your contact information (name, phone \#, and/or email address) so that you may be entered into a drawing for a chance to win one of two $\$ 50.00$ prizes. In the event that you win, you will be contacted by the Co-Investigator of the study.

Your completed survey will be stored at the University of Louisville. Individuals from the Department of Educational and Counseling Psychology, the Institutional Review Board (IRB), the Human Subjects Protection Program Office (HSPPO), and other regulatory agencies may inspect these records. In all other respects, however, the data will be held in confidence to the extent permitted by law. Should the data be published, your identity will not be disclosed. 
If you have any questions about your rights as a research subject, you may call the Human Subjects Protection Program Office at (502) 852-5188. You can discuss any questions about your rights as a research subject, in private, with a member of the Institutional Review Board (IRB). You may also call this number if you have other questions about the research, and you cannot reach the research staff, or want to talk to someone else. The IRB is an independent committee made up of people from the University community, staff of the institutions, as well as people from the community not connected with these institutions. The IRB has reviewed this research study.

If you have any questions, concerns, or complaints about the research study, please contact Erica Adams at: (502) 852-3118 or the study's Principal Investigator, Dr. Sam Stringfield at (502) 852-0615.

Sincerely,

Erica Adams, M.S.

Doctoral Candidate

Dept. of Educational and Counseling Psychology

University of Louisville 


\section{APPENDIX B}

\section{QUESTIONNAIRE}

\subsection{Sociodemographic Information}

1.1 What is your age?

1.2 What is your gender?

Female

Male

1.3 Highest level of education completed? (Please check one)

Some High School

_ Technical or Associate's Degree

__ Master's Degree

- High School Degree

4-year College Degree

_ Doctorate (e.g., Ph.D)

Some College

Some Graduate School

MD

1.4 What is your Race/Ethnicity? (Please check one)

Caucasian/White/European-American

European

African-American

African

Asian-American

East Asian

South Asian

Middle Eastern

Pacific Islander

Hispanic-American/Latino

Central/South American/Mexican

Native American/First Nations/Native Alaskan

Multiracial/Other (Please Specify:

1.5 What is your employment status? (Please check one)

Full-time

Part-time

Unemployed

Disabled 
1.6 Are you on any disability program (Medicaid, SSI, or SSDI) due to your IBD? Yes

No

\subsection{Stressful Event (IBD) Information}

2.1 Which form of Inflammatory Bowel Disease (IBD) do you have? (Please check one) Crohn's Disease Ulcerative Colitis

2.2 How long ago where you diagnosed?

years months

2.3 How many times have you been hospitalized due to complications related to IBD?

2.4 How many IBD-related surgeries have you had?

2.5 Is your IBD currently "active"?

$$
\text { Yes }
$$

No

2.6 In the past week, how many loose or very soft stools have you had per day?

2.7 In the past week, how many times did you experience incontinence of the bowel?

2.8 Over the past week, how would you rate your abdominal pain? (Please circle one.)

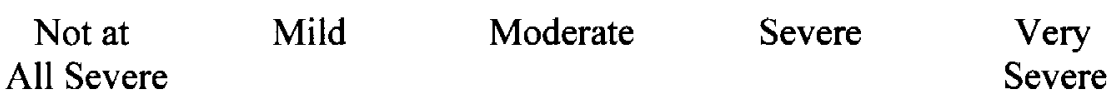

2.9 Over the past week, how would you rate your appetite? (Please circle one.)

$$
\text { Healthy Fair Poor Very Poor }
$$

2.10 Over the past week, how would you rate your general well-being? (Please circle one.)

Very Good Good Average Poor Very Poor




\subsection{Stressful Event Appraisal Scale}

(modified from Park \& Folkman, 2005)

Please respond to the following statements based on your current views of your IBD. If an item does not apply to you for any reason, please skip it.

\begin{tabular}{|c|c|c|c|c|}
\hline $\begin{array}{l}\text { Beliefs Tiolation: } \\
\text { To what exteft does hax ing IBD conflet with your: }\end{array}$ & at at & & & $\because$ ith \\
\hline 3.11 sense of the world being fair or just? & 1 & 2 & 3 & 4 \\
\hline 3.12 feelings of being in control of your life? & 1 & 2 & 3 & 4 \\
\hline 3.13 sense that the people who are supposed to be in charge" have control? & 1 & $\frac{5}{2}$ & 3 & 4 \\
\hline 3.14 sense that God or a higher power is in control? & 1 & 2 & 3 & 4 \\
\hline 3.15 views of there being a purposeful God or higher power? & 1 & 2 & 3 & 4 \\
\hline 3.16 views of there being 2 loving and merciful God or higher power? & 1 & 2 & 3 & 4 \\
\hline 3.17 views of there being an angry and $w$ enge ful God? & 1 & 2 & 3 & 4 \\
\hline 3.18 belief that things happen for a reason? & 1 & 2 & 3 & 4 \\
\hline 3.19 understanding of what life is all about? & 1 & 2 & 3 & 4 \\
\hline 3.20 beliefs of hife being basically good? & 1 & 2 & 3 & 4 \\
\hline $\begin{array}{l}\text { Goal hiolation: } \\
\text { How mach does your IBD interfere with your ahilin to acconplish ea th of thes } \\
\text { goals or desired states? }\end{array}$ & $\begin{array}{l}\text { Sot } \\
\text { at } 3 \mathrm{l}\end{array}$ & & & $\begin{array}{l}\because r \\
y+h\end{array}$ \\
\hline 3.21 Companionship (being with others) & 1 & 2 & 3 & 4 \\
\hline 3.22 Social support and commumity & 1 & 2 & 3 & 4 \\
\hline 3.23 Spinituality & 1 & 2 & 3 & 4 \\
\hline 3.24 Self-acceptance & 1 & 2 & 3 & 4 \\
\hline 3.25 Physical health & 1 & 2 & 3 & 4 \\
\hline 3.26 Inner Peace & 1 & 2 & 3 & 4 \\
\hline 3.27 Fmancial security & 1 & 2 & 3 & 4 \\
\hline 3.28 Achievement in my career & 1 & 2 & 3 & 4 \\
\hline 3.29 Creative or Artistic Accomplishment & 1 & 2 & 3 & 4 \\
\hline 3.30 Athletic accomplishment Exercise \& Fitness & 1 & 2 & 3 & 4 \\
\hline 3.31 Intima cy (Emotional closeness) & 1 & 2 & 3 & 4 \\
\hline
\end{tabular}




\subsection{Brief COPE scale}

This questionnaire concerns how you cope with IBD IN GENERAL. Try to rate each item separately in your mind from the others. Make your answers as true for you as you can. Use the following choices:

$$
1=\text { Not at all } \quad 2=\text { A little bit } \quad 3=\text { A medium amount } \quad 4=\mathrm{A} \text { lot }
$$

4.1. Turn to work or other activities to take my mind off things.

4.2 Concentrate my efforts on doing something about the situation I'm in.

4.3 Say to myself "this isn't real."

4.4 Use alcohol or other drugs to make myself feel better.

4.5 Get emotional support from others.

4.6 Give up trying to deal with it.

4.7 Take time to figure out what I'm really feeling.

4.8 Take action to try to make the situation better.

4.9 Refuse to believe that it is happening.

4.10 Say things to let my unpleasant feelings escape.

4.11 Get help and advice from other people.

4.12 Use alcohol or other drugs to help me get through it.

4.13 Try to see it in a different light, to make it seem more positive.

4.14 Criticize myself.

4.15 Realize that my feelings are valid and important.

4.16 Try to come up with a strategy about what to do.

4.17 Get comfort and understanding from someone.

4.18 Give up the attempt to cope.

4.19 Look for something good in what was happening.

4.20 Make jokes about it.

4.21 Do something to think about it less, like going to movies or shopping.

4.22 Accept the reality of the fact that it has happened.

4.23 Allow myself to express my emotions.

4.24 Express my negative feelings.

4. 25 Try to find comfort in my religion or spiritual beliefs.

4.26 Try to get advice or help from other people about what to do.

4.27 Learn to live with it.

4.28 Think hard about what steps to take.

4.29 Blame myself for things that happened.

4.30 Pray or meditate.

4.31 Let my feelings come out freely.

4.32 Make fun of the situation.

$\begin{array}{llll}1 & 2 & 3 & 4 \\ 1 & 2 & 3 & 4 \\ 1 & 2 & 3 & 4 \\ 1 & 2 & 3 & 4 \\ 1 & 2 & 3 & 4 \\ 1 & 2 & 3 & 4 \\ 1 & 2 & 3 & 4 \\ 1 & 2 & 3 & 4 \\ 1 & 2 & 3 & 4 \\ 1 & 2 & 3 & 4 \\ 1 & 2 & 3 & 4 \\ 1 & 2 & 3 & 4 \\ 1 & 2 & 3 & 4 \\ 1 & 2 & 3 & 4 \\ 1 & 2 & 3 & 4 \\ 1 & 2 & 3 & 4 \\ 1 & 2 & 3 & 4 \\ 1 & 2 & 3 & 4 \\ 1 & 2 & 3 & 4 \\ 1 & 2 & 3 & 4 \\ 1 & 2 & 3 & 4 \\ 1 & 2 & 3 & 4 \\ 1 & 2 & 3 & 4 \\ 1 & 2 & 3 & 4 \\ 1 & 2 & 3 & 4 \\ 1 & 2 & 3 & 4 \\ 1 & 2 & 3 & 4 \\ 1 & 2 & 3 & 4 \\ 1 & 2 & 3 & 4 \\ 1 & 2 & 3 & 4 \\ 1 & 2 & 3 & 4 \\ 1 & 2 & 3 & 4\end{array}$




\subsection{Impact of Events on Self}

The following is a list of comments made by people regarding their experience with a stressful life event. Please read each item and indicate how true each has been for you IN GENERAL with respect to your experience with IBD.

\begin{tabular}{|c|c|c|c|c|c|}
\hline & $\begin{array}{l}\text { Sot at } \\
\text { all }\end{array}$ & A little bixt & Moderately & $\begin{array}{c}\text { Quite } \\
\text { bit }\end{array}$ & Extremely \\
\hline 6.1 Any reminder brings back feelings about it. & 0 & 1 & 2 & 3 & 4 \\
\hline $\begin{array}{l}\text { 6.2 I have trouble staying a sleep or falling asleep because } \\
\text { of pictures or thoughts about it that come into my mind. }\end{array}$ & 0 & 1 & 2 & 3 & 4 \\
\hline 6.3 Other things keep making me think about it. & 0 & 1 & 2 & 3 & 4 \\
\hline 6.4 I think a bout it when I don't mean to. & 0 & 1 & 2 & 3 & 4 \\
\hline 6.5 Pictures about it pop into my mind. & 0 & 1 & 2 & 3 & 4 \\
\hline $\begin{array}{l}6.6 \text { I avoid letting myself get upset when I think about it } \\
\text { or amreminded of it }\end{array}$ & 0 & 1 & 2 & 3 & 4 \\
\hline 6. Thave waves of strong feelings a bout it. & 0 & 1 & 2 & 3 & 4 \\
\hline 6.8 Ihave dreams about it. & 0 & $i$ & 2 & 3 & 4 \\
\hline $6.9 \mathrm{My}$ feelings about it are kind of numb. & 0 & i & 2 & $\overline{3}$ & 4 \\
\hline $6.10 \mathrm{Itry}$ to remove it frommemory. & 0 & 1 & 2 & 3 & 4 \\
\hline 6.11 I stay away from remin ders of it. & 0 & 1 & 2 & 3 & 4 \\
\hline 6.12 I feel as if it hasn thappened or im t real. & 0 & 1 & 2 & 3 & 4 \\
\hline 6.13 I tris not to talk about it. & 0 & 1 & 2 & 3 & 4 \\
\hline $\begin{array}{l}6.14 \text { I am a ware that I still have a lot of feelings about it, } \\
\text { but I don t deal with them. }\end{array}$ & 0 & 1 & 2 & 3 & 4 \\
\hline 6.15 I thr not to think about it. & 0 & 1 & 2 & 3 & 4 \\
\hline
\end{tabular}




\subsection{Stress-Related Growth Scale}

For this questionnaire, please keep in mind your experience with IBD. Read the following statements and respond to each item as it is true for you using the scale below:

$$
0=\text { Not at all } \quad 1=\text { Somewhat } \quad 2=\text { A great deal }
$$

Because of my experience with IBD:

8.1 I have learned to be nicer to others.

8.2 I feel freer to make my own decisions.

8.3 I have learned that I have something of value to teach others about life.

$\begin{array}{lllll}8.4 & \text { I have learned to be myself and not try to be what } & 0 & 1 & 2\end{array}$ others want me to be.

8.5 I have learned to work through problems and not just give up.

8.6 I have learned to find more meaning in life.

8.7 I have learned to how to reach out and help others.

8.8 I have learned to be a more confident person.

8.9 I have learned to listen more carefully when others talk to me.

8.10 I have learned to be open to new information and ideas.

8.11 I have learned to communicate more honestly with others.

8.12 I have learned that I want to have some impact on the world.

8.13 I have learned that it's OK to ask others for help.

8.14 I have learned to stand up for my personal rights.

1

$8.15 \mathrm{I}$ have learned that there are more people who care about me than I thought.

$\begin{array}{lll}0 & 1 & 2 \\ 0 & 1 & 2 \\ 0 & 1 & 2 \\ 0 & 1 & 2\end{array}$

\subsection{Thinking about your IBD}

A stressful life event, such as the experience of IBD, can sometimes conflict with your beliefs about the world and/or goals you have. Take a minute to reflect on any conflicts or contradictions you might have noticed between what your IBD has meant to you and your beliefs about the world, as well as any goals you had. In what ways, if any, have you changed how you see your IBD? Have you changed your goals? Have you changed how you see the world? 


\title{
CURRICULUM VITAE
}

\author{
Erica Adams \\ 1936 South Sunny Ridge Rd. \\ Dayton, OH 45414 \\ (859) 893-0640 \\ ericaadams77@gmail.com
}

\section{EDUCATION}

8/2005-Present Doctoral Candidate in Counseling Psychology (GPA: 4.0) Dept. of Educational and Counseling Psychology, University of Louisville, Louisville, KY Advisors: Patrick Pössel, Ph.D. and Samuel Stringfield, Ph.D. Degree Conferment Expected: August 2009 Dissertation Title: Living with Inflammatory Bowel Disease: A test of the meaning-making model of coping

$5 / 2004$

Master of Science in Clinical Psychology (GPA: 4.0)

Dept. of Psychology, Eastern Kentucky University, Richmond, KY Advisors: Robert Brubaker, Ph.D. and Don Beal, Ph.D.

$5 / 1999$

Bachelor of Arts in Psychology (GPA: 3.94)

Dept. of Psychology, University of Kentucky, Lexington, KY Advisors: Ramesh Bhatt, Ph.D. and Rick Hoyle, Ph.D.

Honors Thesis Title: The effects of academic performance on global and domain-specific self-esteem

\section{CERTIFICATES/LICENSES}

1/2006 -- Passed EPPP, Licensed Psychological Associate (2006-2009), State of Kentucky (\#0785)

\section{SUPERVISED CLINICAL EXPERIENCE}

8/2008 - Present $\quad$ Dayton Veteran's Affairs Medical Center, Dayton, OH APA Accredited Pre-doctoral Psychology Internship 
Completion Date: August 18, 2009

Major Rotation: Primary Care/Health Psychology

Primary Supervisor: Amy Burleson Sullivan, Psy.D.

Responsibilities: Conduct diagnostic evaluations, comprehensive pain evaluations, and pre-transplant psychological evaluations; provide focused interventions addressing psychological factors affecting medical conditions, provide short-term psychotherapy for a range of problems, including depression, anxiety, stressmanagement, lifestyle/behavior changes, compliance, and grief/loss; provide consultation-liaison services to primary care providers; facilitate a Chronic Pain Family Education group (4 sessions-1 month); facilitate the MOVE! Program (a behavioral treatment program for overweight veterans); receive 2 hours of individual supervision/week

Minor Rotation: Mental Health Clinic Supervisor: Rebecca Graham, Ph.D. Responsibilities: Conduct psychological/diagnostic evaluations; prepare integrated reports; provide individual psychotherapy, facilitate Dialectical Behavior Therapy (DBT) group; provide umbrella supervision to practicum students

Minor Rotation: Geropsychology Supervisor: Patricia Perry, Psy.D. and Nicole Best, Psy.D. Responsibilities: Provide individual and family psychotherapy to elderly adults; facilitate a 'Growing through Grief' group; address end-of-life issues in Hospice/Palliative care patients; observe decisional capacity and neuropsychological evaluations

Minor Rotation: Substance Abuse Treatment Supervisor: Peter Herr, Ph.D.

Responsibilities: Provide individual psychotherapy to inpatient adults, addressing substance abuse issues; facilitate a daily process-oriented group; lead a series of didactics/education classes; conduct biopsychosocial, personality, and chemical dependency assessements; present cases to the multidisciplinary treatment team

5/2007 - 8/2007 VA Healthcare Center at Dupont, Louisville, KY Supervisor: Jeanne Bennett, Psy.D.

Responsibilities: Perform neuropsychological assessments with adult outpatients; administer, score and interpret a variety of intelligence, personality and neuropsychological tests (i.e., WAISIII, MMPI-2, MCMI-2, RBANS, WMS-II, TAT, Incomplete Sentences, Rey Osterrieth); integrate data into full neuropsychological reports 

Supervisors: Steve Simon, Ph.D. and Russ Williams, Psy.D. Responsibilities: Perform psychological and forensic assessments with male and female psychiatric patients not yet convicted of crimes; administer personality and intelligence tests, competency evaluations, neuropsychological screenings; interpret and integrate data into full psychological reports Supervisors: Gina Owens, Ph.D. and Dugan Mershone, MSW, CADC

Responsibilities: Provide group and family therapy with residents (aged 18+) on an acute chemical dependency unit; completing psychosocial and chemical dependency assessments; maintain medical chart and progress notes

\section{Seven Counties Services, Family Preservation Program, Louisville, KY} Supervisor: Pat Aulbach, Psy.D.

Responsibilities: Provide intensive home-based services for families with severely emotionally disturbed children at risk of removal from the home; provide family therapy, parent training, group therapy, and individual therapy with children and adults; provide concrete services as needed, (i.e., helping families clean their homes); assist families in the location of community resources; collaborate with other mental health professionals and other involved agencies

$6 / 2002-8 / 2005$

Bluegrass Regional MH-MR Board, Children's Wraparound Services, Richmond, KY

Supervisors: Tripp Griesinger, Ph.D.

Responsibilities: Provide intensive individual and group therapy to severely emotionally disturbed children (aged 4-16) in an outpatient setting; provide home-based parent support/training and family/marital therapy, as well as in-school support for children; conduct intake interviews, including psychosocial/health histories; create treatment plans, home/school behavioral plans; collaborate with involved agencies (i.e., outpatient therapists, psychiatrists, DCBS, DJJ); assist in the implementation and success of a pilot model of an Intensive Outpatient Program in Madison County

\section{1/2003 - 12/2003 Psychology Clinic, Eastern Kentucky University, Richmond,} KY

Supervisors: Robert Brubaker, Ph.D., Myra-Beth Bundy, Ph.D., Donald Beal, Ph.D., and Jim Batts, Ph.D. 
$8 / 2003-12 / 2003$

$1 / 2003-5 / 2003$

$2 / 2001-6 / 2002$

$10 / 1999-2 / 2001$
Responsibilities: Provide group and individual therapy with children and adults; administer intellectual, achievement and psychological instruments, including the WAIS-III, WJ-III, WPPSI-R, WISC, KAIT, MMPI-2, BDI, and WIAT-II; complete comprehensive evaluations for learning disabilities, ADHD, etc.; create treatment plans and integrated psychological reports

\section{Cornerstone Counseling, Somerset, KY \& Berea, KY}

Supervisor: Mitch Holbrook, M. Div.

Responsibilities: Provide individual therapy with children, adolescents and adults; conduct family and marital therapy sessions; maintained client files, including the creation and review of treatment plans; conduct comprehensive assessments

\section{Richmond Family Resource Center, Mayfield Elementary School, Richmond, KY \\ Supervisors: Rochelle Garrett, LCSW and Robert Brubaker, Ph.D. Responsibilities: Provide individual therapy to children aged 5 to 12; create and implement four separate therapeutic groups for children covering issues of social skills, impulse control, divorce, anger management, and grief; produce a video modeling project for the anger management group}

\section{Bluegrass Regional MH-MR Board, Children's Treatment Program, Richmond, KY}

Supervisor: Mary Ann Long, MA

Responsibilities: Facilitate intensive group therapy 3 hours per day, 4 days per week for severely emotionally disturbed children aged 5 to 13 in an outpatient setting; provide individual counseling in/out of the office and in school; provide weekly individual and group parent support/training in addition to a bi-weekly parent meeting; lead 3 ADHD parent groups and create a behavioral monitoring instrument for use with these groups; conduct intake interviews; create treatment plans, and home/school behavioral plans

\section{Bluegrass Regional MH-MR Board, Bluegrass Personal Care Home, Lexington, $\mathrm{KY}$}

Supervisor: Laura Palmer, LCSW

Responsibilities: Provide direct care to severely and persistently mentally ill adults in a residential setting; facilitate and cofacilitate group therapy covering such issues as social skills, daily living skills, stress management, and physical health; maintain medical records, including psychosocial histories and treatment plans. 


\section{RESEARCH EXPERIENCE}

$7 / 2006-7 / 2008$

Department of Educational and Counseling Psychology University of Louisville, Louisville, KY Graduate Research Assistant Supervisors: Patrick Possel, Ph.D. and Michael F. Steger, Ph.D. Responsibilities: Proofread/edit manuscripts; develop IRBs; conduct literature searches and reviews; produce article summaries; create recruitment letters and flyers; code qualitative data; analyze qualitative and quantitative data; co-author journal manuscripts

8/2005-5/2008 Department of Educational and Counseling Psychology University of Louisville, Louisville, KY Research Team Member Research Mentors: Nancy Cunningham, Ph.D. and Michael F. Steger, Ph.D.

Responsibilities: Serve as leader of research projects; recruit research participants; run subjects; deliver conference presentations; conduct literature reviews; produce article summaries; co-author conference proposals and journal manuscripts; analyze quantitative and qualitative data

\section{MANUSCRIPTS IN PROGRESS}

Adams, E., \& Poessel, P. (under review). The Link Between Major Depression and Types of Cancer: A Review of Relevant Literature.

\section{CONFERENCE PRESENTATIONS}

Beauchamp, B., Smith, F., Gilles, J., \& Adams, E. (2008, November). Successfully navigating the internship application process. Panel presentation at the 2008 Kentucky Psychological Association's Annual Convention.

Adams, E. (2008, March). Determinants of stress-related growth in individuals with inflammatory bowel disease. Paper presentation at the 2008 Kentucky Psychological Association Student Academic Conference.

Schuster, S. \& Adams, E. (2007, November). Protecting and Promoting the Profession: KPA's 2008 Legislative Agenda. Workshop presentation at the 2007 Kentucky Psychological Association's Annual Convention. 
Adams, E., \& Steger, M. F. (2007, August). Seeking and finding meaning in the context of the sacred. Poster accepted by the $115^{\text {th }}$ Annual Convention of the American Psychological Association, San Francisco, CA.

Adams, E. (2007, March). Professional development from three perspectives. Panel presentation at the Kentucky Psychological Association Spring Academic Conference, Lexington, KY.

Adams, E., Steger, M. F., \& Banister, A. (2007, March) Seeking and finding meaning in the context of the sacred. Poster presentation at the Kentucky Psychological Association Spring Academic Conference, Lexington, KY.

Cunningham, N., Whitten, M., \& Adams, E. (2006, November). Bully victimization in middle school: Approaches in intervention. Workshop presentation at the $8^{\text {th }}$ Annual Ending Sexual Assault and Domestic Violence Conference, Lexington, KY.

Cunningham, N., Adams, E., Paul, L., \& Nordloh, G. (2006, August). The relationship between different types of bullying behaviors and students' commitment, attachment, and attitudes toward bullying. Poster presentation the $114^{\text {th }}$ Annual Convention of the American Psychological Association, New Orleans, LA.

\section{TEACHING EXPERIENCE}

$2006-2008$

Intellectual Assessment

Department of Educational and Counseling Psychology, University of Louisville, Louisville, KY

Lecture Topics: WAIS-III and WISC-IV

$11 / 2005$

Youth Forum for Peace

Sponsors: University of Louisville, Muhammad Ali Institute for Peace and Justice

\section{PROFESSIONAL MEMBERSHIP \& SERVICE}

9/2005 - Present Kentucky Psychological Association

Student Affiliate

9/2005 - Present American Psychological Association

Student Affiliate

6/2006 - 7/2008 Kentucky Psychological Association of Graduate Students (KPAGS)

President

Responsibilities/Activities: Maintain student website; recruit student members via professional outreach (i.e., oral presentations, 
etc.); attend quarterly board meetings; assist in organization of annual academic conference; write articles for quarterly newsletter and annual report; assist in preparation for annual convention (workshop evaluations, recruitment of volunteers, etc.); assist in creation of a student track of workshops for KPA's $75^{\text {th }}$ Annual Convention

5/2007-7/2008 Kentucky Psychological Association Task Force on Sequence of Training Student Representative Activities: Attend task force meeting; assist in formulating recommendations to KPA Board of Directors; present Task Force recommendations to Kentucky Board of Examiners

$1 / 2007-11 / 2007$

Department of Educational and Counseling Psychology University of Louisville, Louisville, KY

Student-Faculty Liaison

Responsibilities: Attend monthly faculty meetings; assist department in search for and screening of faculty candidates; attend weekly APA Re-accreditation meetings; assist in revisions of ECPY Doctoral Student Handbook

8/2006-11/2007 Doctoral Student Organization

Department of Educational and Counseling Psychology University of Louisville, Louisville, KY

Program Chair

Responsibilities/Activities: Attend monthly meetings; organize social events; provide ECPY students with opportunities for professional development (i.e., trainings, workshops, volunteering); disseminate information among ECPY doctoral students

\section{PROFESSIONAL REFERENCES}

Available upon request 